\title{
2007
}

\section{Y-12 National Security Complex Annual Illness and Injury Surveillance Report}

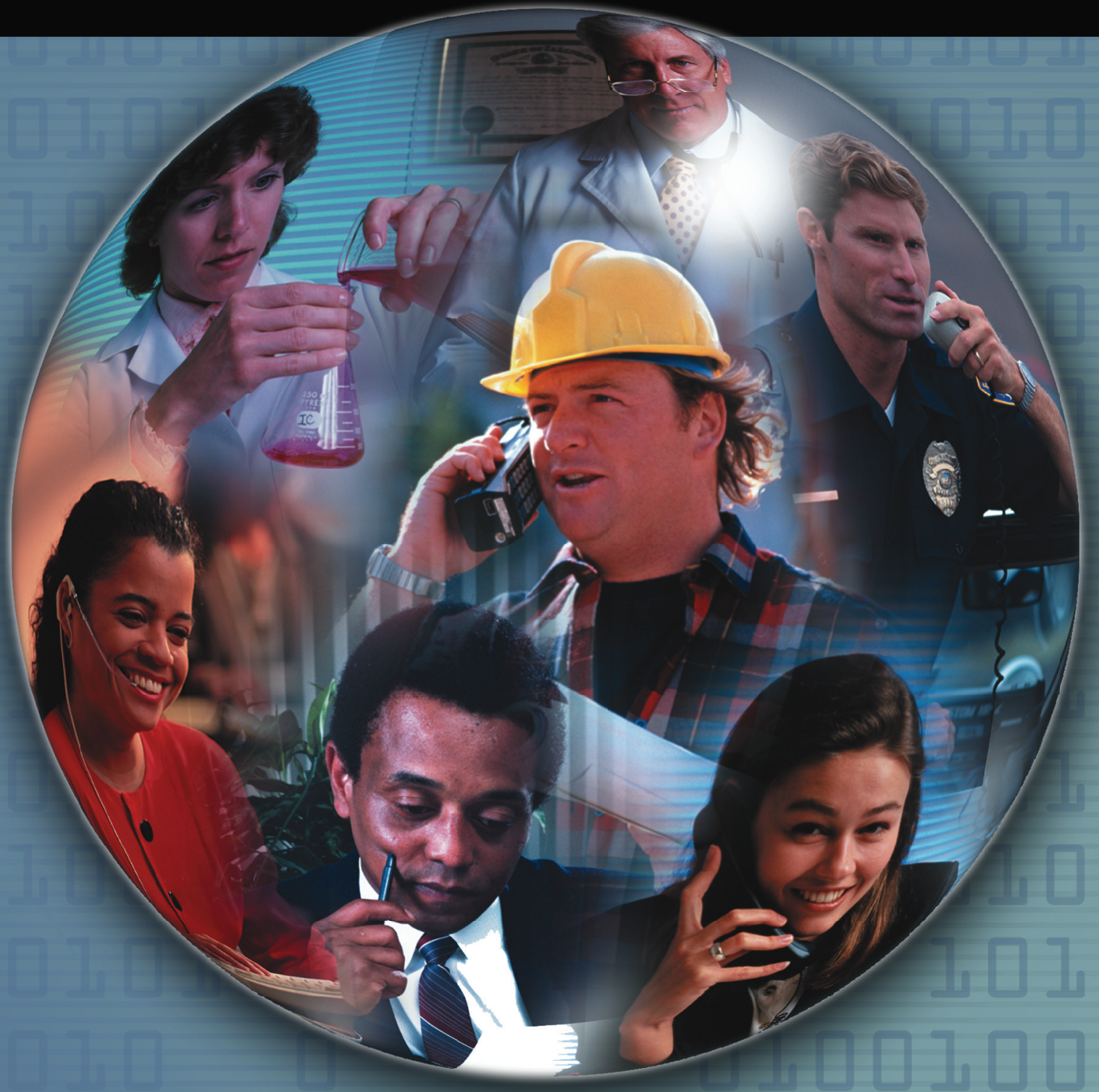




\section{Y-12 National Security Complex 2007 Illness and Injury Surveillance Report}

Questions or comments about this report or the Illness and Injury Surveillance Program (IISP) may be directed to:

E-mail:

Dr. Cliff Strader at cliff.strader@hq.doe.gov

or Dr. Bonnie Richter at bonnie.richter@hq.doe.gov

or direct letters to:

Mail Stop HS-13 / 270CC

U.S. Department of Energy

1000 Independence Avenue, S.W.

Washington, DC 20585-0270

Additional information about the Department of Energy's Office of Illness and Injury Prevention Programs, the IISP, and annual reports for DOE sites participating in this program can be found at:

http://www.hss.energy.gov/healthsafety/WSHP/epi/surv/

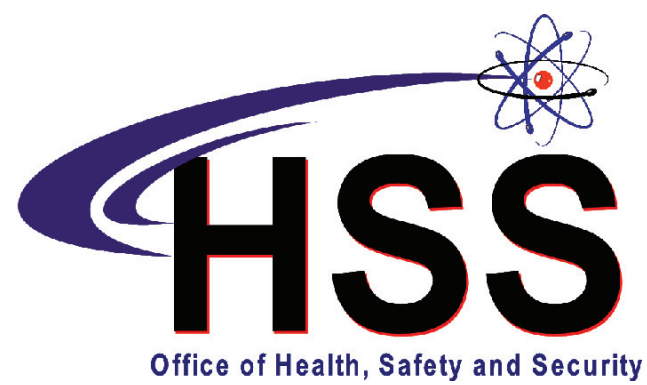

ACKNOWLEDGEMENT

LifeART images copyright 2000 Lippincott Williams \& Wilkins. All rights reserved.

This document was produced under contract number DE-AC05-06OR23100 between the U.S. Department of Energy and Oak Ridge Associated Universities. 


\section{Y-12 National Security Complex \\ 2007 Illness and Injury Surveillance Report}

At A Glance

The Y-12 work force consisted of 4,959 employees in 2007. The size of the work force has been about 5,000 since 2003. Women made up about 26 percent of all workers, which is consistent with other DOE sites participating in the Illness and Injury Surveillance Program (IISP).

\section{Illness and Injury}

There were 905 absences reported in 2007, an increase of 86 absences from 2006 but a reduction from the high of 1,043 absences reported in 2003.

Line Operators had the highest absence rates for both men and women in 2007. Technical Support workers had the lowest absence rate for men and Security and Fire workers had the lowest absence rate for women.

Among both men and women, disorders of the musculoskeletal system and respiratory conditions have been among the 3 most common diagnoses since 2000. These 2 diagnostic categories are typically among the 3 most commonly reported at DOE sites participating in the IISP.

Women lost 10,916 calendar days due to injury and illness with an average length of 35 days. Men lost 25,345 calendar days due to injury and illness with an average of 43 days. The average length of absences has remained stable since 2003 for both men and women.

Age-adjusted rates for all illness and injury diagnoses combined decreased from 2003 to 2004 among men but have been increasing slowly since 2004. Among women, the rate has been fairly constant over the same period.

Twelve diagnoses for sentinel health events were reported in 2007. Seven diagnoses involved carpal tunnel syndrome, 4 of which were reported by female Administrative Support workers. 


\section{OSHA}

There were 20 OSHA-recordable events among women and 56 events among men. The rate of OSHA events among the Y-12 work force in 2007 was 2 per 100 workers. OSHA event rates have declined at Y-12 since 2003, similar to the decline that has been observed nationally and within DOE.

Injuries accounted for 39 percent of the diagnoses reported by men; the most common type of injury was sprains and strains. Four diagnoses were reported for exposure to gases, fumes, and vapors. For women, musculoskeletal conditions (joint disorders and rheumatism) accounted for 44 percent of the diagnoses reported.

Among women, Line Operators had the highest rates of OSHA events ( 3 per 100 workers); Crafts workers had the highest rate of OSHA events among men (5 per 100 workers). Professional workers had the lowest rate of OSHA events among men. Female Technical Support, Security and Fire, and Crafts workers reported no OSHA events in 2007.

Men reported a total of 1,192 lost and restricted workdays in 2007 compared with 1,048 lost and restricted workdays in 2006 , a 14 percent increase. However, the number of OSHA events increased by 40 percent, so the average number of days lost and restricted per event declined from 26 days in 2006 to 21 days for men in 2007. Among women, lost and restricted workdays increased more than 4 times from 76 workdays in 2006 to 359 in 2007. Since the number of events only increased by about half, the average number of lost and restricted workdays increased for women from 6 days in 2006 to 18 days in 2007. 


\section{The Y-12 National Security Complex \\ Work Force - 2007}

The Work Force by Gender and Age ............ 1

The Work Force by Gender and Job

Category $\ldots 1$

Number and Length of Absences

Absence Rate by Gender and Age .2

Number of Days Absent by

Gender and Age

Absence Rate by Job Category

and Gender.

Average Duration of Absence by

Job Category and Gender.

\section{Diagnostic Categories}

Number of Diagnoses and Lost Calendar

Days by Diagnostic Category

(Categorized by ICD-9-CM) and Gender....... 4

Common Diagnoses Among Female

Workers in 2007

Common Diagnoses Among Male

Workers in 2007 ...6

Number of Most Frequently Reported

Diagnoses by Job Category and Gender ......7

\section{Rates of Disease Occurrence}

Rates for All Illnesses and Injuries Combined by Job Category, Gender, and Age

Rates for Selected Diagnostic Categories by Job Category, Gender, and Age. . .8

\section{Time Trends}

Age-Adjusted Rates for All Diagnoses Combined Among Women and Men from 2003 to 2007 . 10
Age-Adjusted Rates for Selected Diagnostic Categories Among Women and Men from 2003 to 2007

Age-Adjusted Rates for All Diagnoses Combined Among Women and Men by Job Category from 2003 to 2007 ..... 12

\section{Sentinel Health Events for Occupations (SHEOs)}

Characteristics of SHEOs by Gender. 13

SHEO Diagnoses by Gender 13

Occupational Safety and Health Administration (OSHA)-Recordable Events

OSHA-Recordable Events by Gender and Age 14

OSHA-Recordable Events by Job

Category and Gender 14

Diagnostic and Accident Categories for OSHA-Recordable Events

OSHA-Recordable Diagnoses by Diagnostic Category and Gender..... 15

OSHA-Recordable Accidents by Type and Gender.... 16

\section{Rates of OSHA-Recordable Events}

OSHA-Recordable Rates by Age and Job Categories Among Women, All

Diagnoses Combined 17

OSHA-Recordable Rates by Age and Job Categories Among Men, All Diagnoses Combined 17

Time Trends for OSHA-Recordable Events

Age-Adjusted Rates for All OSHA-Recordable Diagnoses Combined Among Women and Men by Job Category from 2003 to $2007 \ldots 18$

\section{Appendices}

Appendices A-W. 20 
The Y-12 National Security Complex Work Force - 2007

Figure 1. The Work Force by Gender and Age

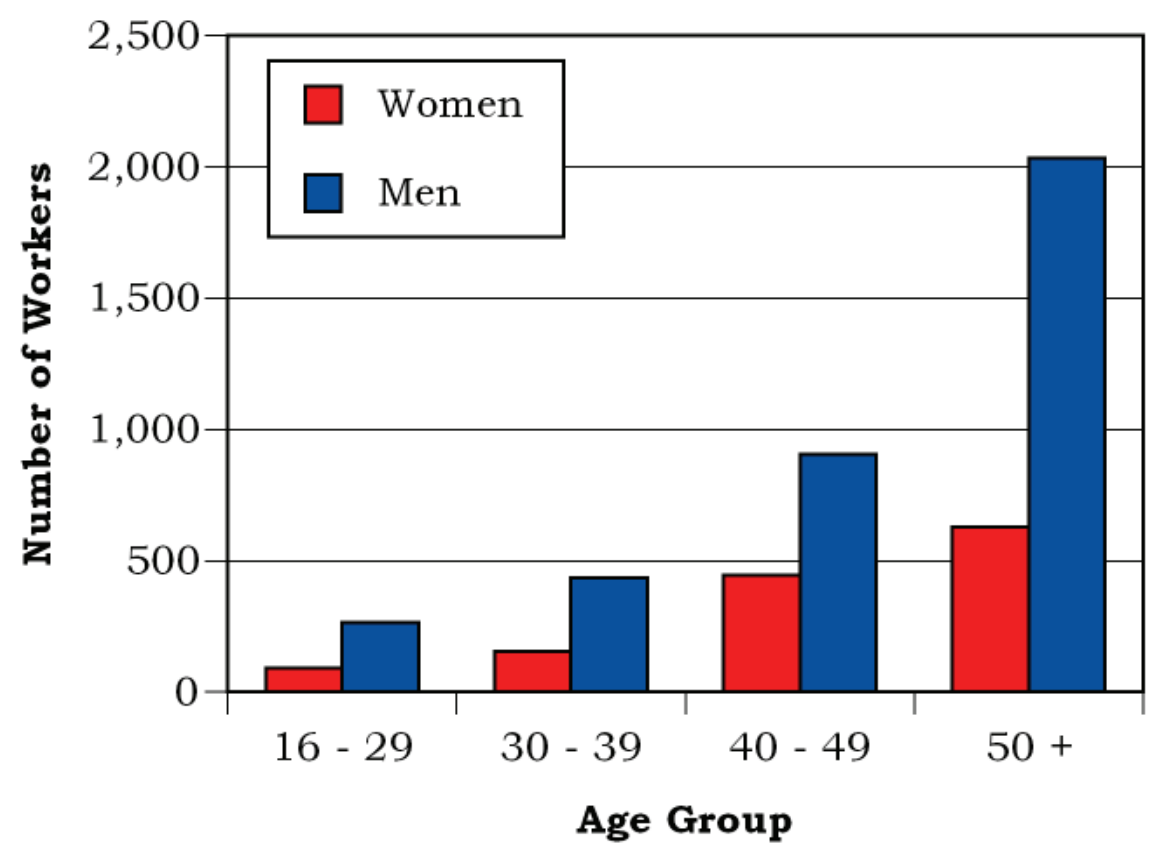

Figure 2. The Work Force by Gender and Job Category

\begin{tabular}{|c|c|c|}
\hline Job Category & Women & Men \\
\hline \multirow{2}{*}{ Professional } & 457 & 1,694 \\
\hline & $35 \%$ & $46 \%$ \\
\hline \multirow{2}{*}{ Administrative Support } & 544 & 348 \\
\hline & $41 \%$ & $10 \%$ \\
\hline \multirow{2}{*}{ Technical Support } & 90 & 139 \\
\hline & $7 \%$ & $4 \%$ \\
\hline \multirow{2}{*}{ Service } & 99 & 331 \\
\hline & $7 \%$ & $\mathbf{9} \%$ \\
\hline \multirow{2}{*}{ Security and Fire } & 37 & 128 \\
\hline & $3 \%$ & $3 \%$ \\
\hline \multirow{2}{*}{ Crafts } & 32 & 789 \\
\hline & $2 \%$ & $22 \%$ \\
\hline \multirow{2}{*}{ Line Operators } & 62 & 209 \\
\hline & $5 \%$ & $6 \%$ \\
\hline Total & $\begin{array}{l}1,321 \\
100 \%\end{array}$ & $\begin{array}{l}3,638 \\
100 \%\end{array}$ \\
\hline
\end{tabular}


Number and Length of Absences

Figure 3. Absence Rate by Gender and Age

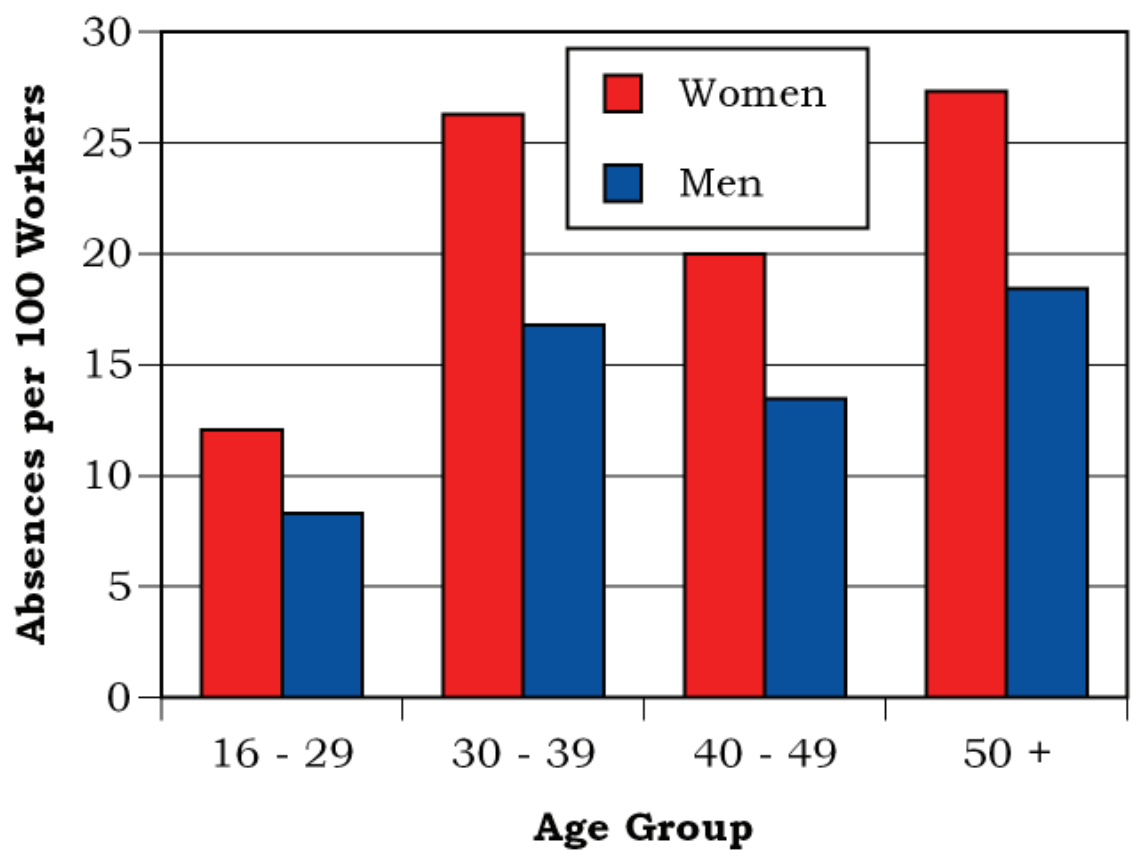

Figure 4. Number of Days Absent by Gender and Age

\begin{tabular}{|c|c|c|c|c|}
\hline \multirow{3}{*}{ Gender } & \multirow{2}{*}{ Age } & Number of & \multicolumn{2}{|c|}{ Number of Days Absent } \\
\cline { 3 - 5 } & & Absences & Total & Average \\
\hline \multirow{4}{*}{ Women } & $16-29$ & 11 & 318 & 29 \\
\cline { 2 - 5 } & $30-39$ & 41 & 1,155 & 28 \\
\cline { 2 - 5 } & $40-49$ & 89 & 2,887 & 32 \\
\cline { 2 - 5 } & $50+$ & 172 & 6,556 & 38 \\
\cline { 2 - 5 } & Total & 313 & 10,916 & 35 \\
\hline \multirow{4}{*}{ Men } & $16-29$ & 22 & 941 & 43 \\
\cline { 2 - 5 } & $30-39$ & 73 & 2,614 & 36 \\
\cline { 2 - 5 } & $40-49$ & 122 & 4,766 & 39 \\
\cline { 2 - 5 } & $50+$ & 375 & 17,024 & 45 \\
\cline { 2 - 5 } & Total & 592 & 25,345 & 43 \\
\hline
\end{tabular}


Figure 5. Absence Rate by Job Category and Gender

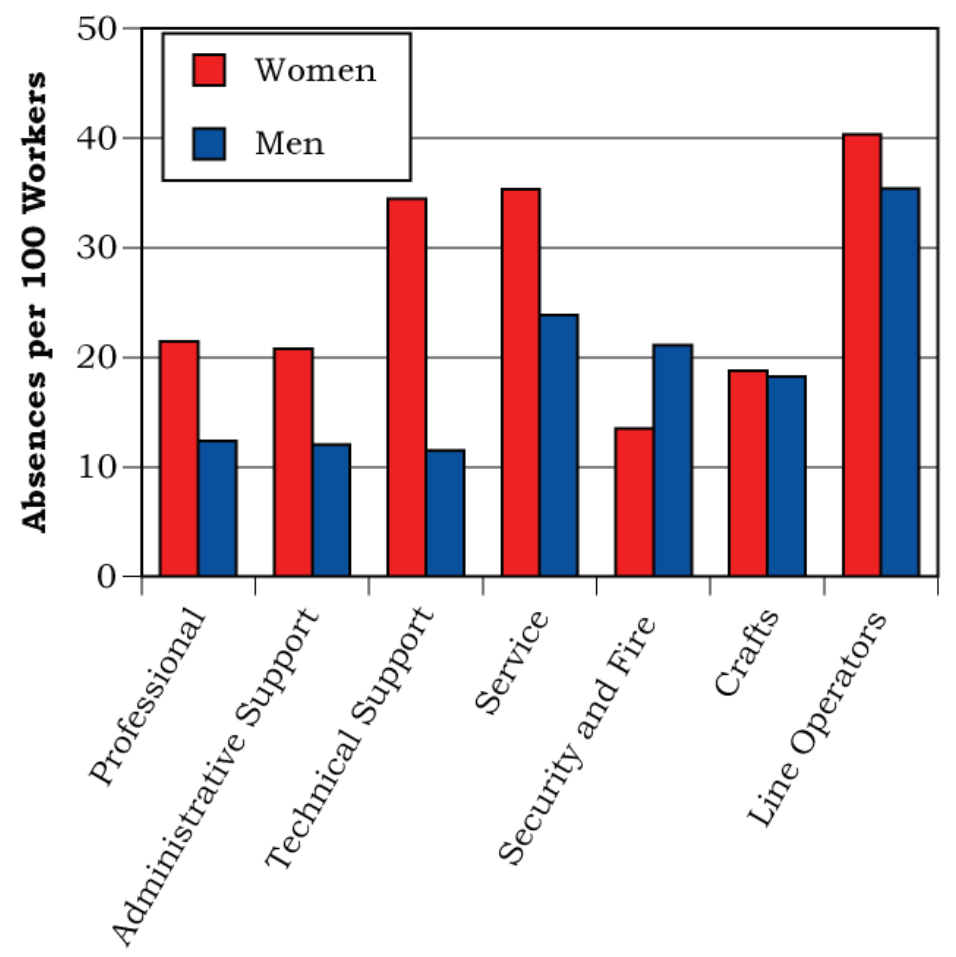

Job Category

Figure 6. Average Duration of Absence by Job Category and Gender

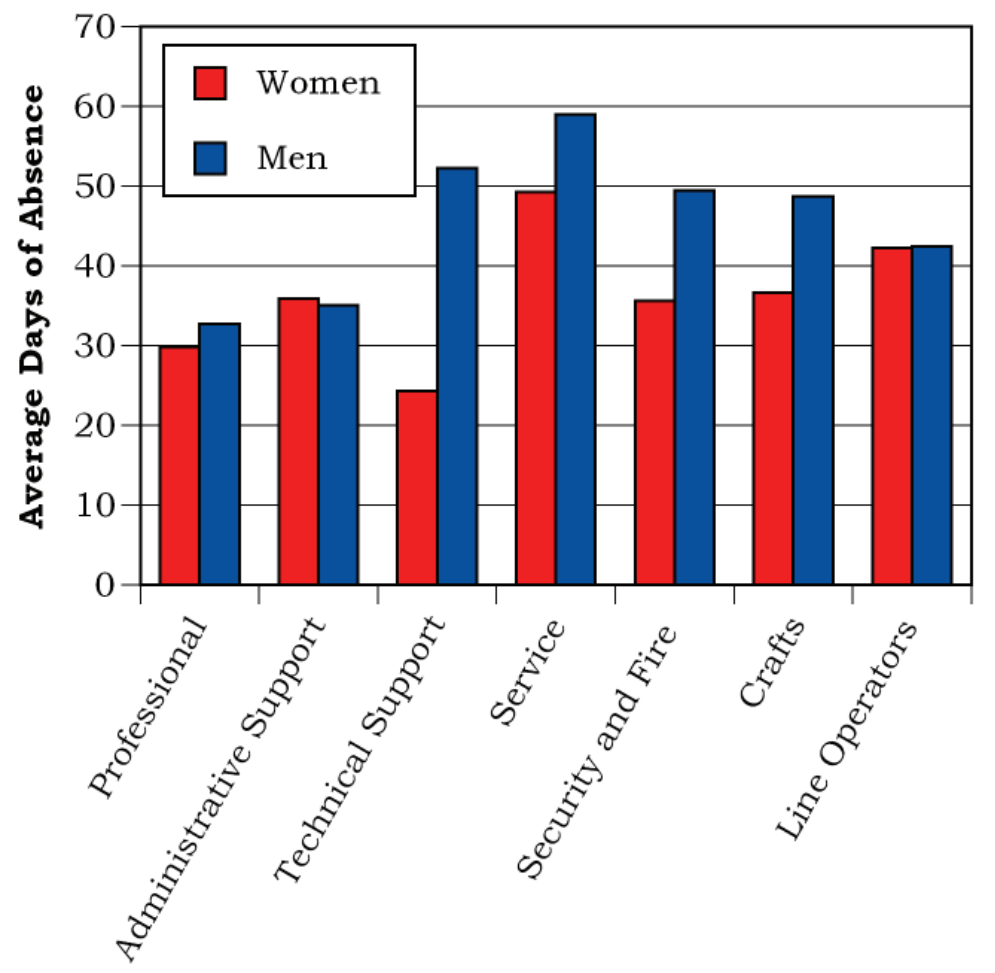

Job Category 


\section{Diagnostic Categories}

\section{Figure 7. Number of Diagnoses and Lost Calendar Days by Diagnostic Category (Categorized by ICD-9-CM) and Gender}

\begin{tabular}{|c|c|c|c|c|}
\hline \multirow[b]{2}{*}{ Diagnostic Category } & \multicolumn{2}{|c|}{ Women } & \multicolumn{2}{|c|}{ Men } \\
\hline & $\begin{array}{l}\text { Number of } \\
\text { Diagnoses }\end{array}$ & $\begin{array}{c}\text { Number } \\
\text { of Lost } \\
\text { Calendar } \\
\text { Days }\end{array}$ & $\begin{array}{l}\text { Number of } \\
\text { Diagnoses }\end{array}$ & $\begin{array}{c}\text { Number } \\
\text { of Lost } \\
\text { Calendar } \\
\text { Days }\end{array}$ \\
\hline Benign Growths & 10 & 380 & 5 & 152 \\
\hline Blood & 0 & 0 & 3 & 76 \\
\hline Cancer & 16 & 626 & 26 & 1,566 \\
\hline Digestive & 33 & 604 & 96 & 2,319 \\
\hline Endocrine/Metabolic & 12 & 589 & 12 & 604 \\
\hline Existing Birth Condition & 2 & 147 & 1 & 7 \\
\hline Genitourinary & 42 & 968 & 43 & 1,003 \\
\hline Heart/Circulatory & 15 & 811 & 59 & 2,706 \\
\hline Infections/Parasites & 13 & 378 & 20 & 538 \\
\hline Injury & 40 & 1,591 & 99 & 5,417 \\
\hline Miscarriage & 0 & 0 & NA & NA \\
\hline Musculoskeletal & 79 & 3,502 & 165 & 8,516 \\
\hline Nervous System & 20 & 536 & 25 & 782 \\
\hline Psychological & 11 & 652 & 24 & 1,410 \\
\hline Respiratory & 65 & 603 & 116 & 1,570 \\
\hline Skin & 3 & 60 & 8 & 294 \\
\hline Unspecified Symptoms & 29 & 643 & 29 & 1,033 \\
\hline
\end{tabular}

Note: Lost calendar days for each absence are counted more than once when multiple diagnoses occur in different diagnostic categories for the same absence. 
Figure 8. Common Diagnoses Among Female Workers in 2007

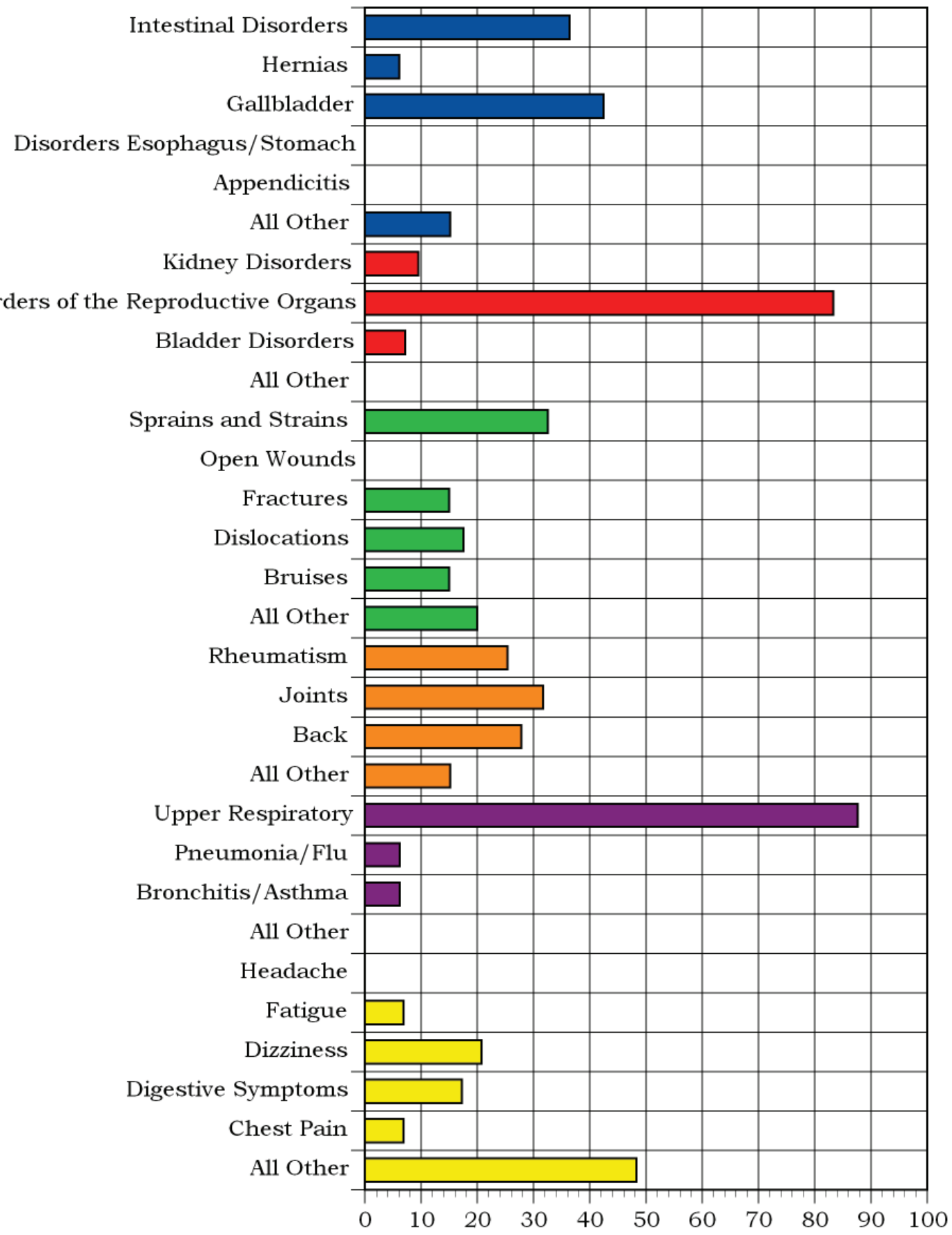

Percent Distribution of Diagnoses Within Diagnostic Category

Digestive, 33 Diagnoses

Genitourinary, 42 Diagnoses

Injury, 40 Diagnoses
Musculoskeletal, 79 Diagnoses

Respiratory, 65 Diagnoses

Unspecified Symptoms, 29 Diagnoses 
Figure 9. Common Diagnoses Among Male Workers in 2007

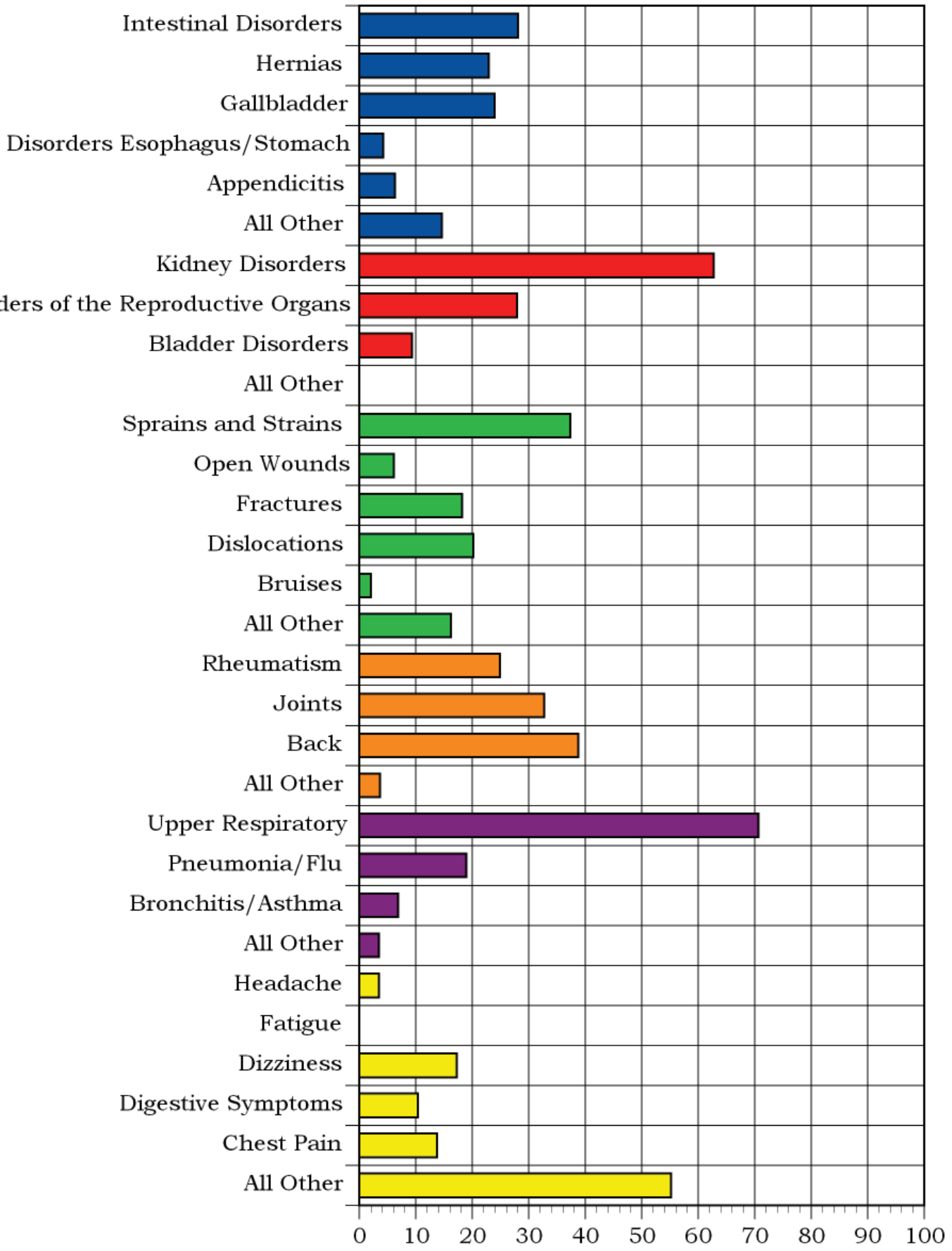

Percent Distribution of Diagnoses Within Diagnostic Category

Digestive, 96 Diagnoses

Genitourinary, 43 Diagnoses

Injury, 99 Diagnoses
Musculoskeletal, 165 Diagnoses

Respiratory, 116 Diagnoses

Unspecified Symptoms, 29 Diagnoses 


\section{Figure 10. Number of Most Frequently Reported Diagnoses by Job Category and Gender}

\begin{tabular}{|c|c|c|c|c|}
\hline Job Category & Men & & Women & \\
\hline \multirow{3}{*}{ Professional } & Respiratory & 53 & Musculoskeletal & 21 \\
\hline & Musculoskeletal & 51 & Genitourinary & 19 \\
\hline & Injury & 43 & Respiratory & 18 \\
\hline \multirow{4}{*}{ Administrative Support } & Musculoskeletal & 8 & Musculoskeletal & 27 \\
\hline & Respiratory & 8 & Respiratory & 17 \\
\hline & Heart/Circulatory & 6 & Genitourinary & 15 \\
\hline & Injury & 6 & Injury & 15 \\
\hline \multirow{4}{*}{ Technical Support } & Injury & 5 & Respiratory & 13 \\
\hline & Respiratory & 3 & Musculoskeletal & 10 \\
\hline & Digestive & 2 & Injury & 5 \\
\hline & Musculoskeletal & 2 & & \\
\hline \multirow{4}{*}{ Service } & Musculoskeletal & 30 & Musculoskeletal & 9 \\
\hline & Digestive & 10 & Respiratory & 9 \\
\hline & Injury & 10 & Genitourinary & 5 \\
\hline & & & Injury & 5 \\
\hline \multirow{3}{*}{ Security and Fire } & Musculoskeletal & 12 & Musculoskeletal & 2 \\
\hline & Digestive & 5 & Respiratory & 2 \\
\hline & Injury & 5 & Heart/Circulatory & 1 \\
\hline \multirow{4}{*}{ Crafts } & Musculoskeletal & 34 & Digestive & 4 \\
\hline & Digestive & 32 & Unspecified Symptoms & 2 \\
\hline & Respiratory & 23 & Injury & 1 \\
\hline & & & Musculoskeletal & 1 \\
\hline \multirow{3}{*}{ Line Operators } & Musculoskeletal & 28 & Musculoskeletal & 9 \\
\hline & Respiratory & 16 & Respiratory & 6 \\
\hline & Digestive & 12 & Injury & 3 \\
\hline
\end{tabular}




\section{Rates of Disease Occurrence}

Figure 11. Rates for All Illnesses and Injuries Combined by Job Category, Gender, and Age

\begin{tabular}{|c|c|c|c|c|}
\hline \multirow{2}{*}{$\begin{array}{c}\text { All Illnesses \& } \\
\text { Injuries Combined }\end{array}$} & \multicolumn{4}{|c|}{ Rate per 1,000} \\
\hline & Job Category & Age & Men & Women \\
\hline & \multirow{2}{*}{ Professional } & $<50$ & 129 & 226 \\
\hline & & $50+$ & 179 & 326 \\
\hline & \multirow{2}{*}{ Administrative Support } & $<50$ & 86 & 190 \\
\hline & & $50+$ & 163 & 332 \\
\hline & \multirow{2}{*}{ Technical Support } & $<50$ & 120 & 533 \\
\hline & & $50+$ & 125 & 467 \\
\hline & \multirow{2}{*}{ Service } & $<50$ & 228 & 475 \\
\hline & & $50+$ & 366 & 390 \\
\hline & \multirow{2}{*}{ Security and Fire } & $<50$ & 227 & 143 \\
\hline & & $50+$ & 377 & 125 \\
\hline & \multirow{2}{*}{ Crafts } & $<50$ & 148 & 263 \\
\hline & & $50+$ & 262 & 231 \\
\hline & \multirow{2}{*}{ Line Operators } & $<50$ & 451 & 375 \\
\hline & & $50+$ & 425 & 447 \\
\hline
\end{tabular}

Figure 12. Rates for Selected Diagnostic Categories by Job Category, Gender, and Age

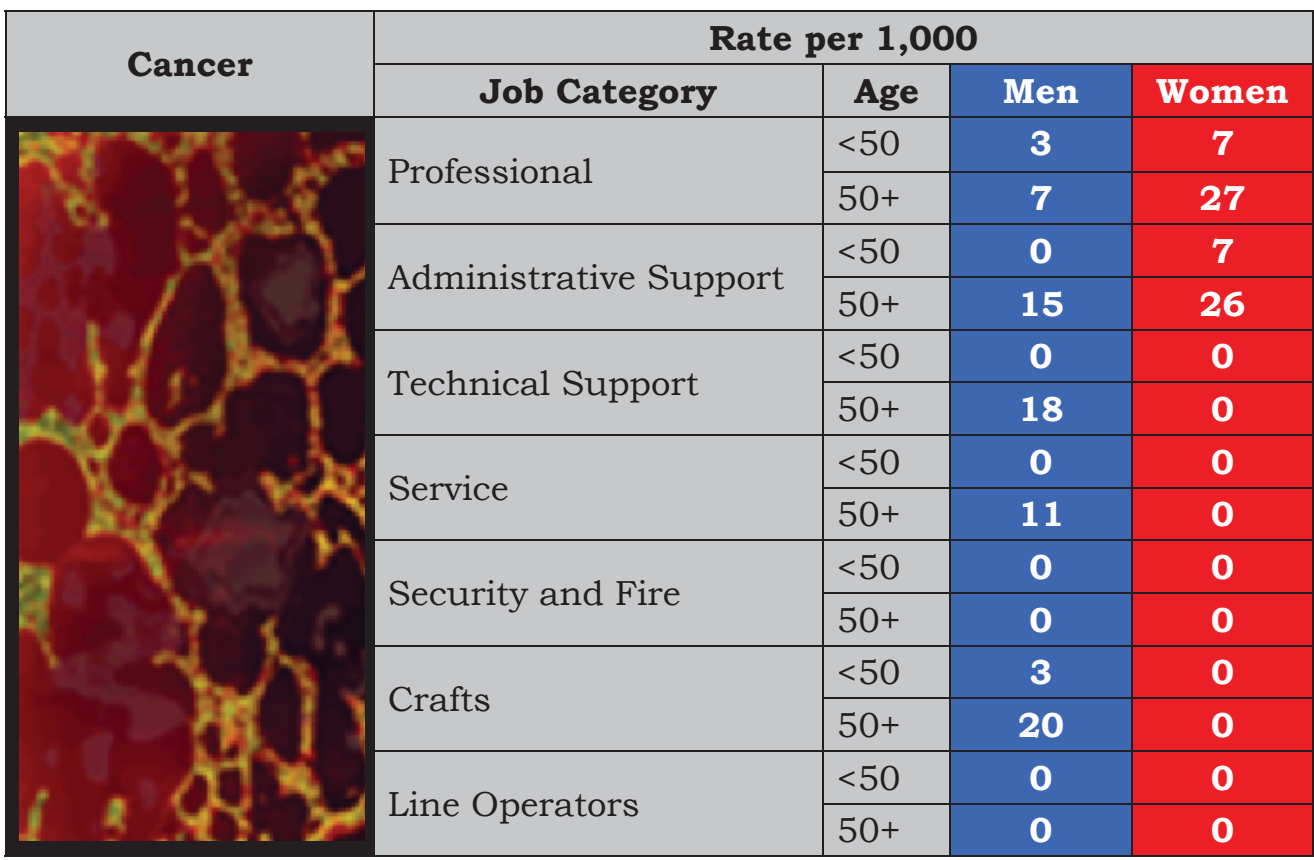




\section{Figure 12. Rates for Selected Diagnostic Categories by Job Category, Gender, and Age (Continued)}

\begin{tabular}{|c|c|c|c|c|}
\hline \multirow{2}{*}{ Heart/Circulatory } & \multicolumn{4}{|c|}{ Rate per 1,000} \\
\hline & Job Category & Age & Men & Women \\
\hline & \multirow{2}{*}{ Professional } & $<50$ & 5 & 0 \\
\hline & & $50+$ & 11 & 27 \\
\hline & \multirow{2}{*}{ Administrative Support } & $<50$ & 0 & 0 \\
\hline & & $50+$ & 31 & 26 \\
\hline & \multirow{2}{*}{ Technical Support } & $<50$ & 0 & 0 \\
\hline & & $50+$ & 0 & 0 \\
\hline & \multirow{2}{*}{ Service } & $<50$ & 7 & 0 \\
\hline & & $50+$ & 38 & 17 \\
\hline & \multirow{2}{*}{ Security and Fire } & $<50$ & 13 & 48 \\
\hline & & $50+$ & 19 & 0 \\
\hline & \multirow{2}{*}{ Crafts } & $<50$ & 0 & 0 \\
\hline & & $50+$ & 41 & 0 \\
\hline & \multirow{2}{*}{ Line Operators } & $<50$ & 25 & 0 \\
\hline & & $50+$ & 57 & 26 \\
\hline
\end{tabular}

\begin{tabular}{|c|c|c|c|c|}
\hline \multirow{2}{*}{ Respiratory } & \multicolumn{4}{|c|}{ Rate per 1,000} \\
\hline & Job Category & Age & Men & Women \\
\hline & \multirow{2}{*}{ Professional } & $<50$ & 30 & 30 \\
\hline & & $50+$ & 32 & 53 \\
\hline & \multirow{2}{*}{ Administrative Support } & $<50$ & 26 & 29 \\
\hline & & $50+$ & 20 & 33 \\
\hline & \multirow{2}{*}{ Technical Support } & $<50$ & 24 & 156 \\
\hline & & $50+$ & 18 & 133 \\
\hline & \multirow{2}{*}{ Service } & $<50$ & 7 & 75 \\
\hline & & $50+$ & 43 & 102 \\
\hline & \multirow{2}{*}{ Security and Fire } & $<50$ & 13 & 48 \\
\hline & & $50+$ & 57 & 63 \\
\hline & \multirow{2}{*}{ Crafts } & $<50$ & 27 & 0 \\
\hline & & $50+$ & 30 & 0 \\
\hline & \multirow{2}{*}{ Line Operators } & $<50$ & 115 & 0 \\
\hline & & $50+$ & 23 & 158 \\
\hline
\end{tabular}


Figure 12. Rates for Selected Diagnostic Categories by Job Category, Gender, and Age (Continued)

\begin{tabular}{|c|c|c|c|c|}
\hline \multirow{2}{*}{ Injury } & \multicolumn{4}{|c|}{ Rate per 1,000} \\
\hline & Job Category & Age & Men & Women \\
\hline & \multirow{2}{*}{ Professional } & $<50$ & 21 & 19 \\
\hline & & $50+$ & 29 & 32 \\
\hline & \multirow{2}{*}{ Administrative Support } & $<50$ & 26 & 18 \\
\hline & & $50+$ & 10 & 37 \\
\hline & \multirow{2}{*}{ Technical Support } & $<50$ & 48 & 67 \\
\hline & & $50+$ & 18 & 44 \\
\hline & \multirow{2}{*}{ Service } & $<50$ & 14 & 75 \\
\hline & & $50+$ & 43 & 34 \\
\hline & \multirow{2}{*}{ Security and Fire } & $<50$ & 27 & 0 \\
\hline & & $50+$ & 57 & 0 \\
\hline & \multirow{2}{*}{ Crafts } & $<50$ & 20 & 53 \\
\hline & & $50+$ & 30 & 0 \\
\hline & \multirow{2}{*}{ Line Operators } & $<50$ & 57 & 83 \\
\hline & & $50+$ & 23 & 26 \\
\hline
\end{tabular}

\section{Time Trends}

Figure 13. Age-Adjusted Rates for All Diagnoses Combined Among Women and Men from 2003 to 2007*

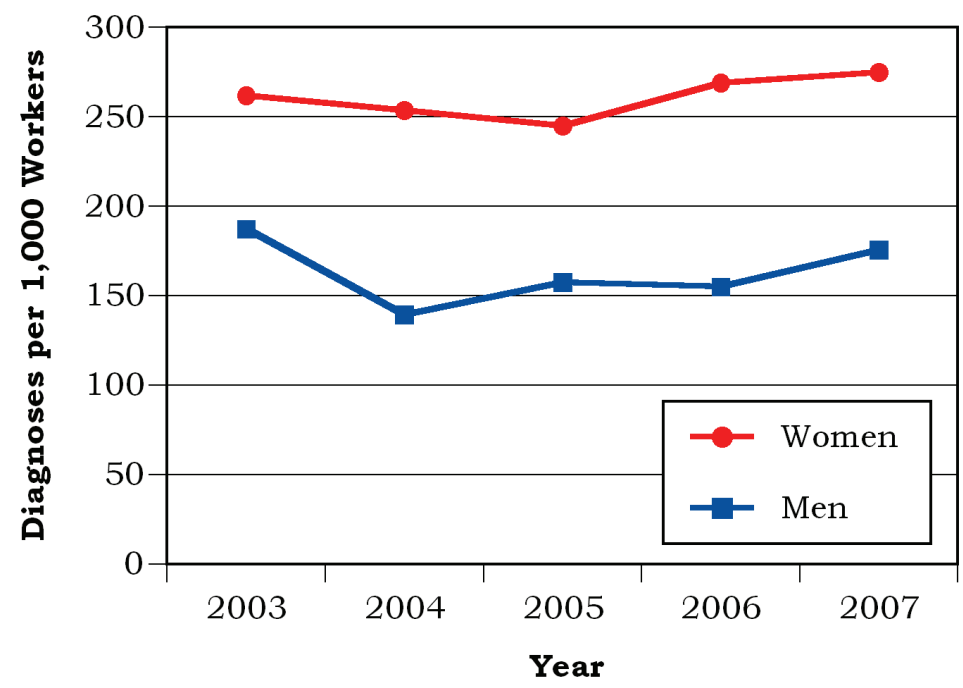

* Standardized to age distribution of 2000 U.S. population. 
Figure 14. Age-Adjusted Rates for Selected Diagnostic Categories Among Women and Men from 2003 to 2007*

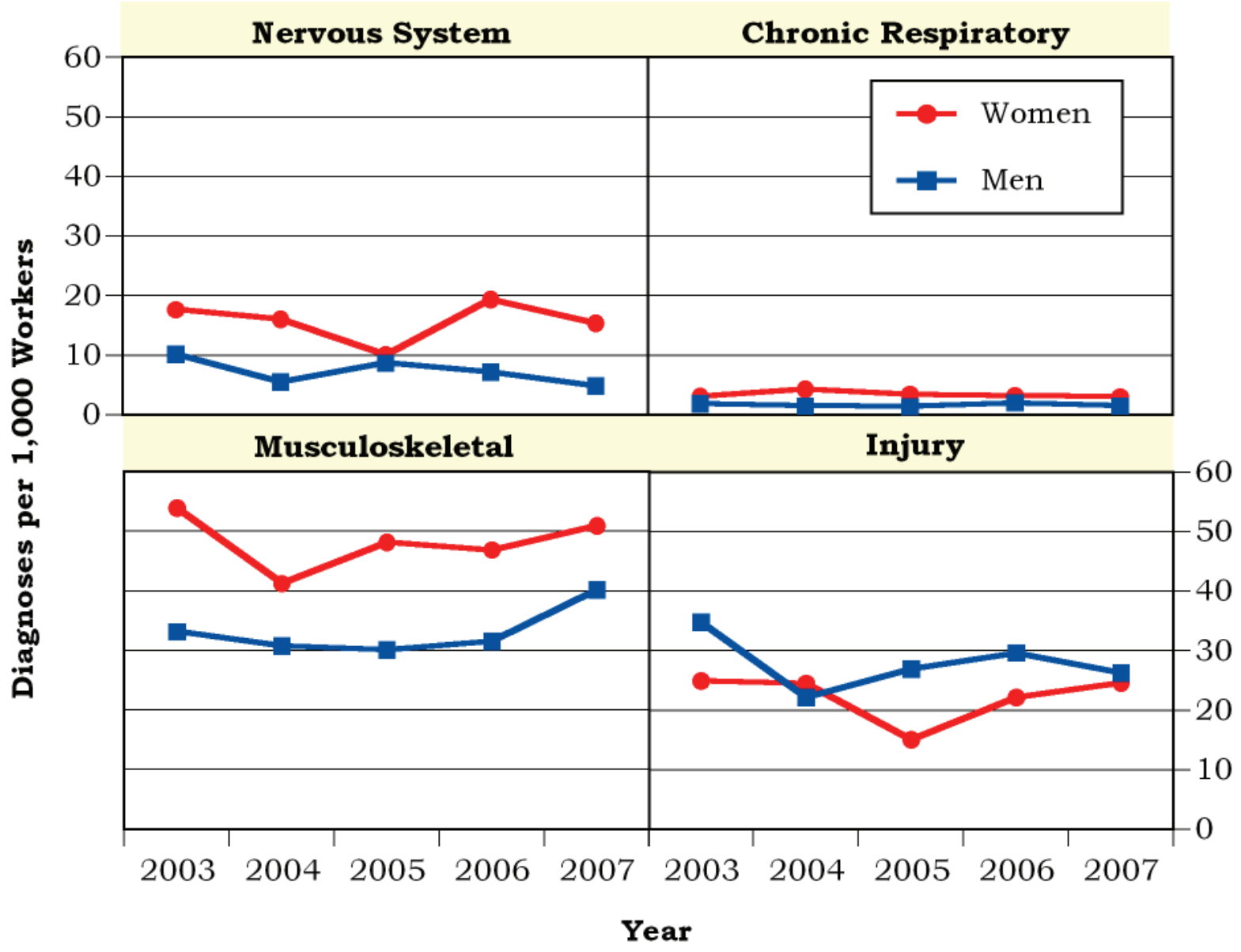

* Standardized to age distribution of 2000 U.S. population. 
Figure 15. Age-Adjusted Rates for All Diagnoses Combined Among Women and Men by Job Category from 2003 to 2007*

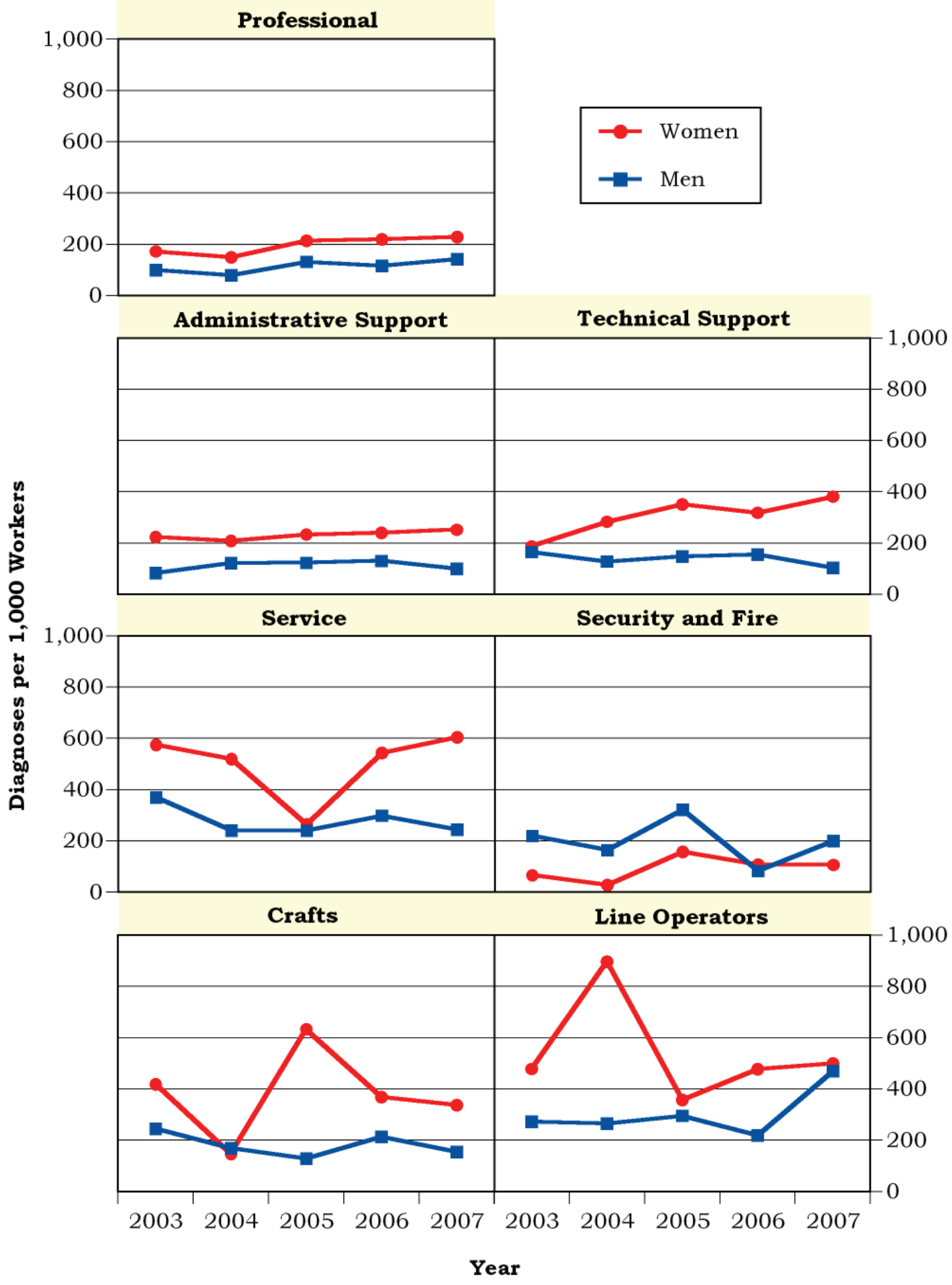

* Standardized to age distribution of 2000 U.S. population. 


\section{Sentinel Health Events for Occupations (SHEOs)}

An occupational sentinel health event (SHEO) is a disease, disability, or death that is likely to be occupationally related. Although sentinel health events may indicate an occupational exposure, many may result from nonoccupational exposures. Sentinel health events are therefore assessed in two categories:

Definite Sentinel Health Events: Diseases that are unlikely to occur in the absence of an occupational exposure (e.g., asbestosis).

Possible Sentinel Health Events: Diseases that may be occupational but can also occur in the absence of an occupational exposure (e.g., lung cancer or carpal tunnel syndrome).

Figure 16. Characteristics of SHEOs by Gender

\begin{tabular}{|l|c|c|c|c|}
\hline \multirow{2}{*}{} & \multicolumn{2}{|c|}{$\begin{array}{c}\text { Total Number of } \\
\text { SHEO Diagnoses }\end{array}$} & \multicolumn{2}{c|}{$\begin{array}{c}\text { Total Number of } \\
\text { Days Absent }\end{array}$} \\
\cline { 2 - 5 } & Men & Women & Men & Women \\
\hline Definite & 1 & 0 & 7 & 0 \\
\hline Possible & 7 & 4 & 509 & 54 \\
\hline Total & 8 & 4 & 516 & 54 \\
\hline
\end{tabular}

Figure 17. SHEO Diagnoses by Gender

\begin{tabular}{|l|c|c|}
\hline \multirow{2}{*}{\multicolumn{1}{|c|}{ Diagnoses }} & \multicolumn{2}{c|}{ Gender } \\
\cline { 2 - 3 } & Women & Men \\
\hline Carpal Tunnel Syndrome & 4 & 3 \\
\hline Pneumonconiosis (Berylliosis) & 0 & 0 \\
\hline Musculoskeletal Conditions & 0 & 0 \\
\hline Injuries & 0 & 0 \\
\hline Other Conditions & $\mathbf{0}$ & $\mathbf{5}$ \\
\hline
\end{tabular}


Occupational Safety and Health Administration (OSHA)-Recordable Events

Figure 18. OSHA-Recordable Events by Gender and Age

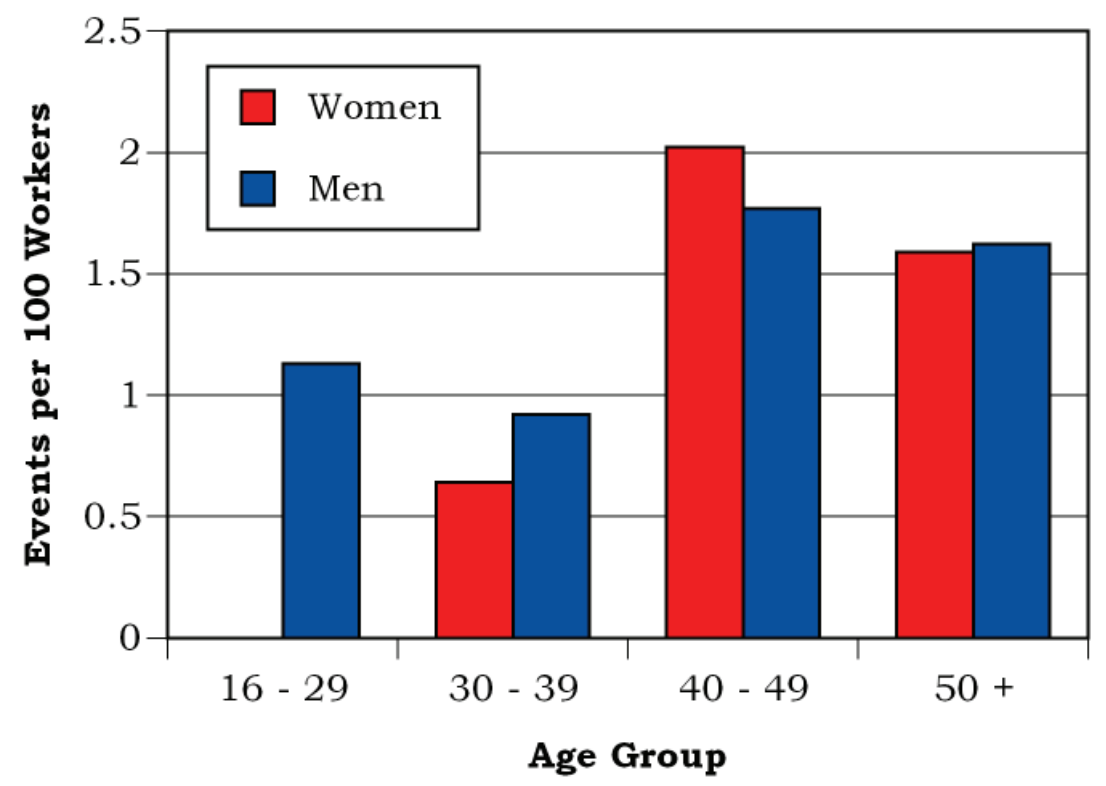

Figure 19. OSHA-Recordable Events by Job Category and Gender

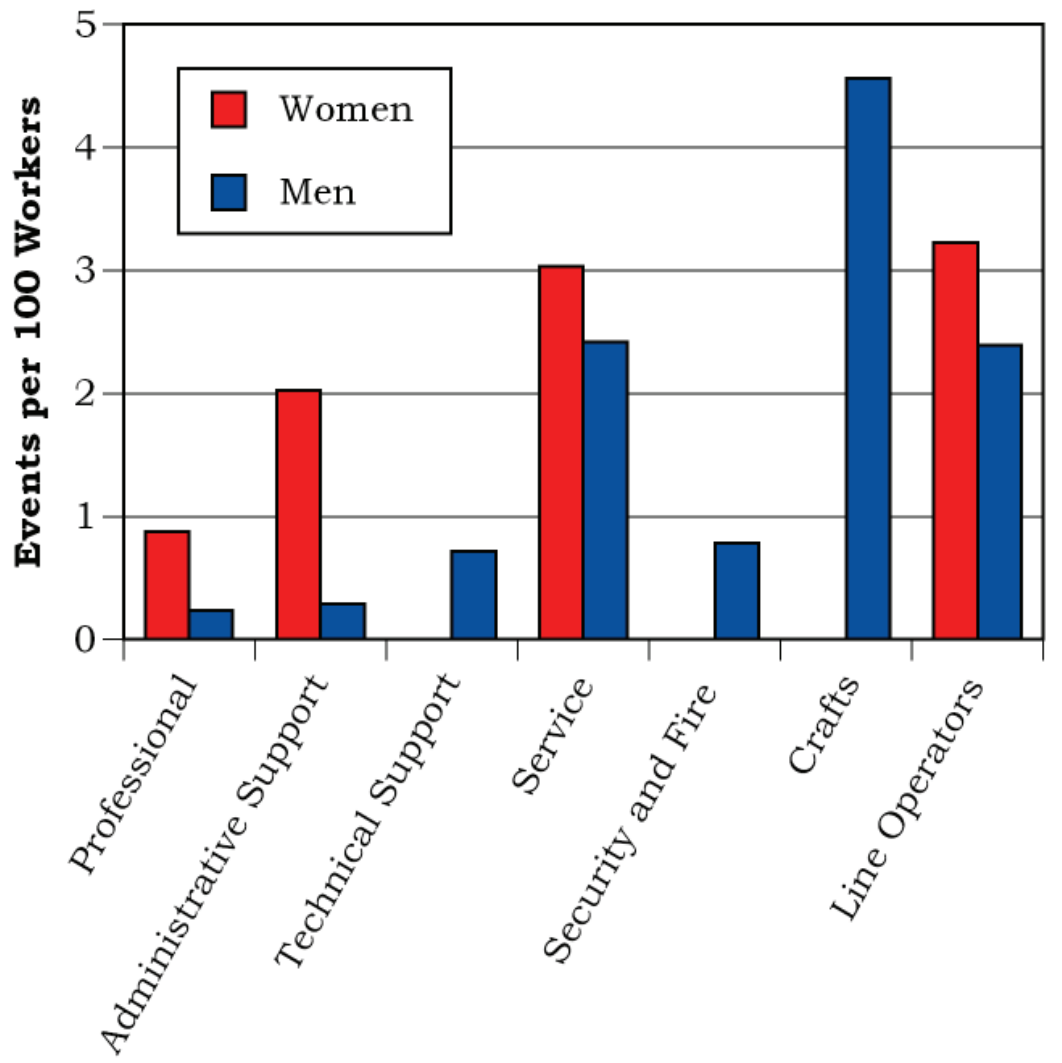

Job Category 


\section{Diagnostic and Accident Categories for OSHA-Recordable Events}

Figure 20. OSHA-Recordable Diagnoses by Diagnostic Category and Gender

\begin{tabular}{|l|c|c|}
\hline \multirow{2}{*}{ Diagnostic Category } & \multicolumn{2}{|c|}{ Gender } \\
\cline { 2 - 3 } & Women & Men \\
\hline Musculoskeletal & $\mathbf{2 5}$ & 29 \\
\hline Nervous System & $\mathbf{5}$ & $\mathbf{1 4}$ \\
\hline Respiratory & $\mathbf{1}$ & $\mathbf{1 0}$ \\
\hline Skin & $\mathbf{0}$ & $\mathbf{1}$ \\
\hline Unspecified Symptoms & $\mathbf{1 1}$ & $\mathbf{1 5}$ \\
\hline Injury & $\mathbf{1 5}$ & $\mathbf{4 4}$ \\
\hline Fractures - Upper Limb & $\mathbf{1}$ & $\mathbf{1}$ \\
\hline Back Sprains \& Strains & $\mathbf{1}$ & $\mathbf{6}$ \\
\hline Other Sprains \& Strains & $\mathbf{3}$ & $\mathbf{1 0}$ \\
\hline Open Wounds - Head, Neck, Trunk & $\mathbf{1}$ & $\mathbf{3}$ \\
\hline Open Wounds - Upper Limb & $\mathbf{0}$ & $\mathbf{3}$ \\
\hline Open Wounds - Lower Limb & $\mathbf{0}$ & $\mathbf{1}$ \\
\hline Superficial Injuries & $\mathbf{0}$ & $\mathbf{1}$ \\
\hline Bruises & $\mathbf{5}$ & $\mathbf{8}$ \\
\hline Crushing Injuries & $\mathbf{0}$ & $\mathbf{1}$ \\
\hline Foreign Bodies Entering Orifice & $\mathbf{0}$ & $\mathbf{3}$ \\
\hline Burns & $\mathbf{0}$ & $\mathbf{1}$ \\
\hline Unspecified Injuries & $\mathbf{3}$ & $\mathbf{2}$ \\
\hline Adverse Reactions to Non-Medical & $\mathbf{1}$ & $\mathbf{4}$ \\
\hline Substances & & \\
\hline
\end{tabular}


Figure 21. OSHA-Recordable Accidents by Type and Gender

\begin{tabular}{|l|c|c|}
\hline \multirow{2}{*}{\multicolumn{2}{|c|}{ Accident Category }} & \multicolumn{2}{|c|}{ Gender } \\
\cline { 2 - 3 } & Women & Men \\
\cline { 2 - 3 } & $\begin{array}{c}\text { Number of } \\
\text { Accidents }\end{array}$ & $\begin{array}{c}\text { Number of } \\
\text { Accidents }\end{array}$ \\
\hline Poisoning - Non-Medicinal & $\mathbf{1}$ & $\mathbf{5}$ \\
\hline Falls & $\mathbf{4}$ & $\mathbf{5}$ \\
\hline Natural/Environmental Factors & $\mathbf{0}$ & $\mathbf{1}$ \\
\hline Submersion/Suffocation/Foreign Bodies & $\mathbf{0}$ & $\mathbf{3}$ \\
\hline Other Accidents & $\mathbf{1 5}$ & $\mathbf{4 0}$ \\
\hline Struck by an Object & $\mathbf{1}$ & $\mathbf{8}$ \\
\hline Machinery & $\mathbf{0}$ & $\mathbf{1}$ \\
\hline Cutting/Piercing Instrument/Object & $\mathbf{0}$ & $\mathbf{3}$ \\
\hline Hot, Corrosive, or Caustic Material/ & $\mathbf{0}$ & $\mathbf{1}$ \\
\hline Steam & & $\mathbf{1 8}$ \\
\hline Overexertion/Strenuous Movements & $\mathbf{5}$ & $\mathbf{6}$ \\
\hline Noise & $\mathbf{0}$ & $\mathbf{3}$ \\
\hline Repetitive Trauma & $\mathbf{9}$ & $\mathbf{5 4}$ \\
\hline Total & $\mathbf{2 0}$ & \\
\hline
\end{tabular}




\section{Rates of OSHA-Recordable Events}

Figure 22. OSHA-Recordable Rates by Age and Job Categories Among Women, All Diagnoses Combined

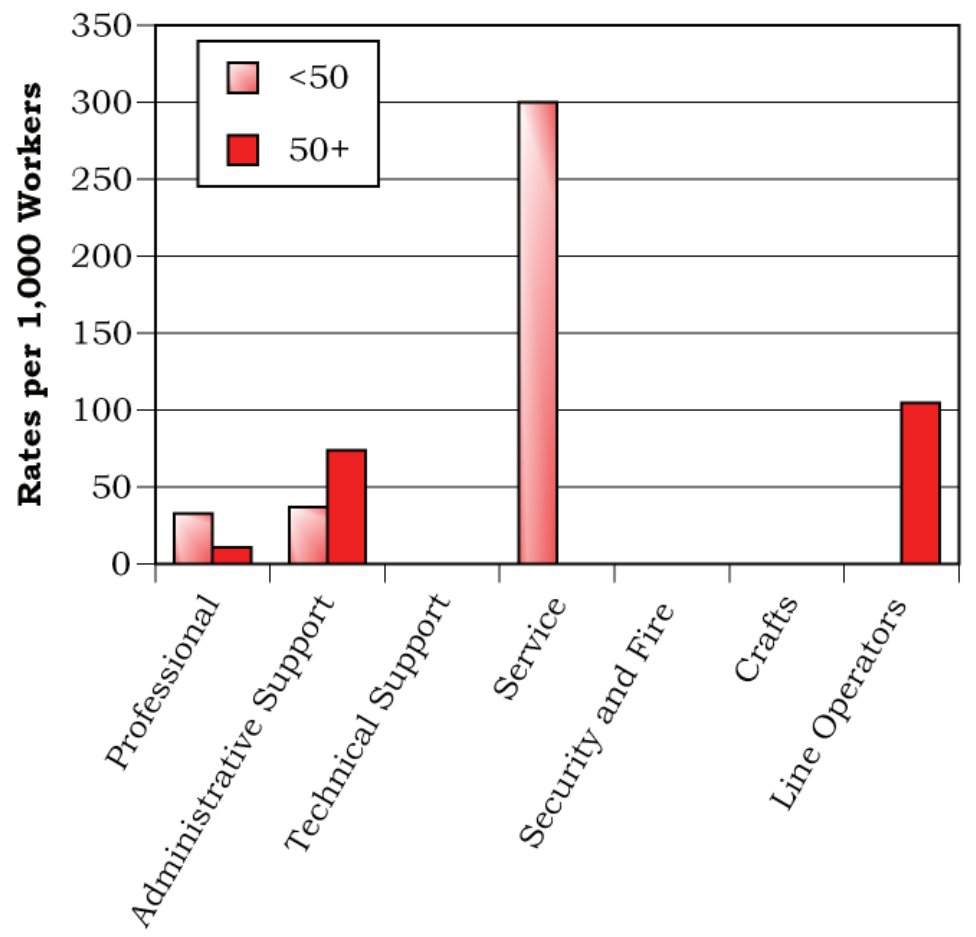

Job Category

Figure 23. OSHA-Recordable Rates by Age and Job Categories Among Men, All Diagnoses Combined

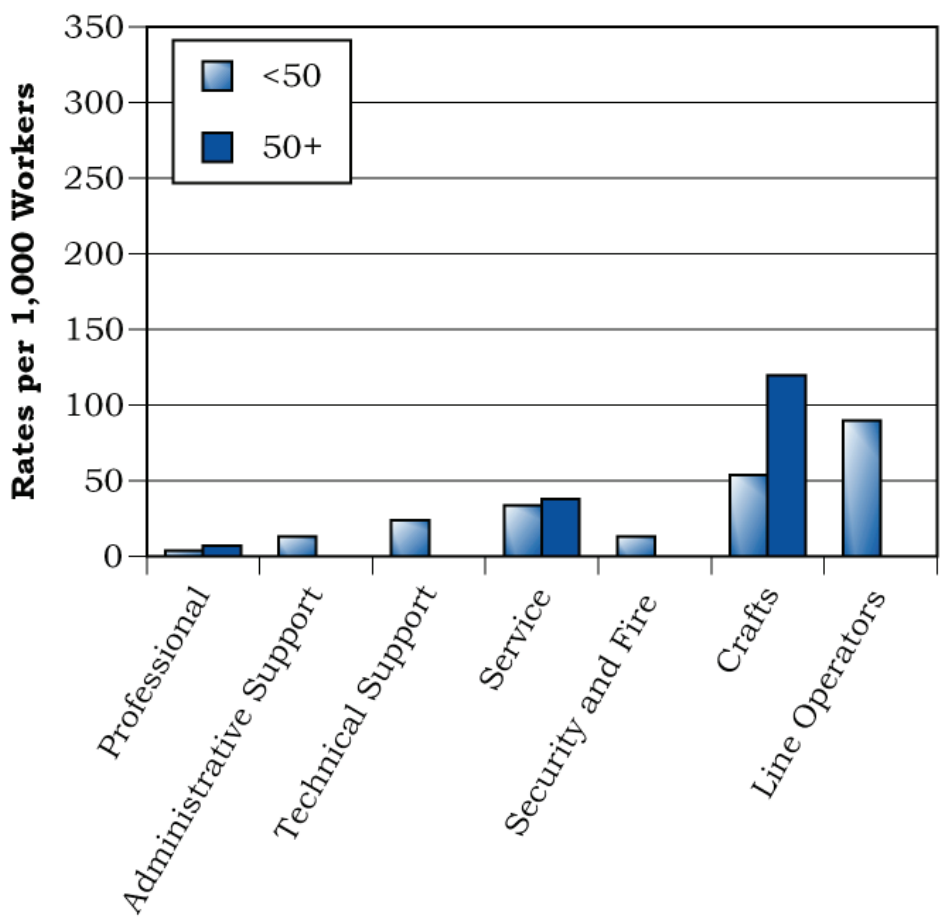

Job Category 


\section{Time Trends for OSHA-Recordable Events}

Figure 24. Age-Adjusted Rates for All OSHA-Recordable Diagnoses Combined Among Women and Men by Job Category from 2003 to 2007*

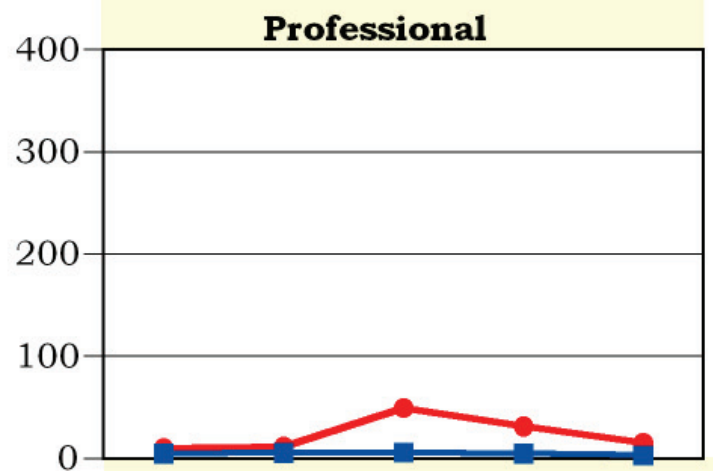

$$
\begin{aligned}
& - \text { Women } \\
& -\leftarrow \text { Men }
\end{aligned}
$$

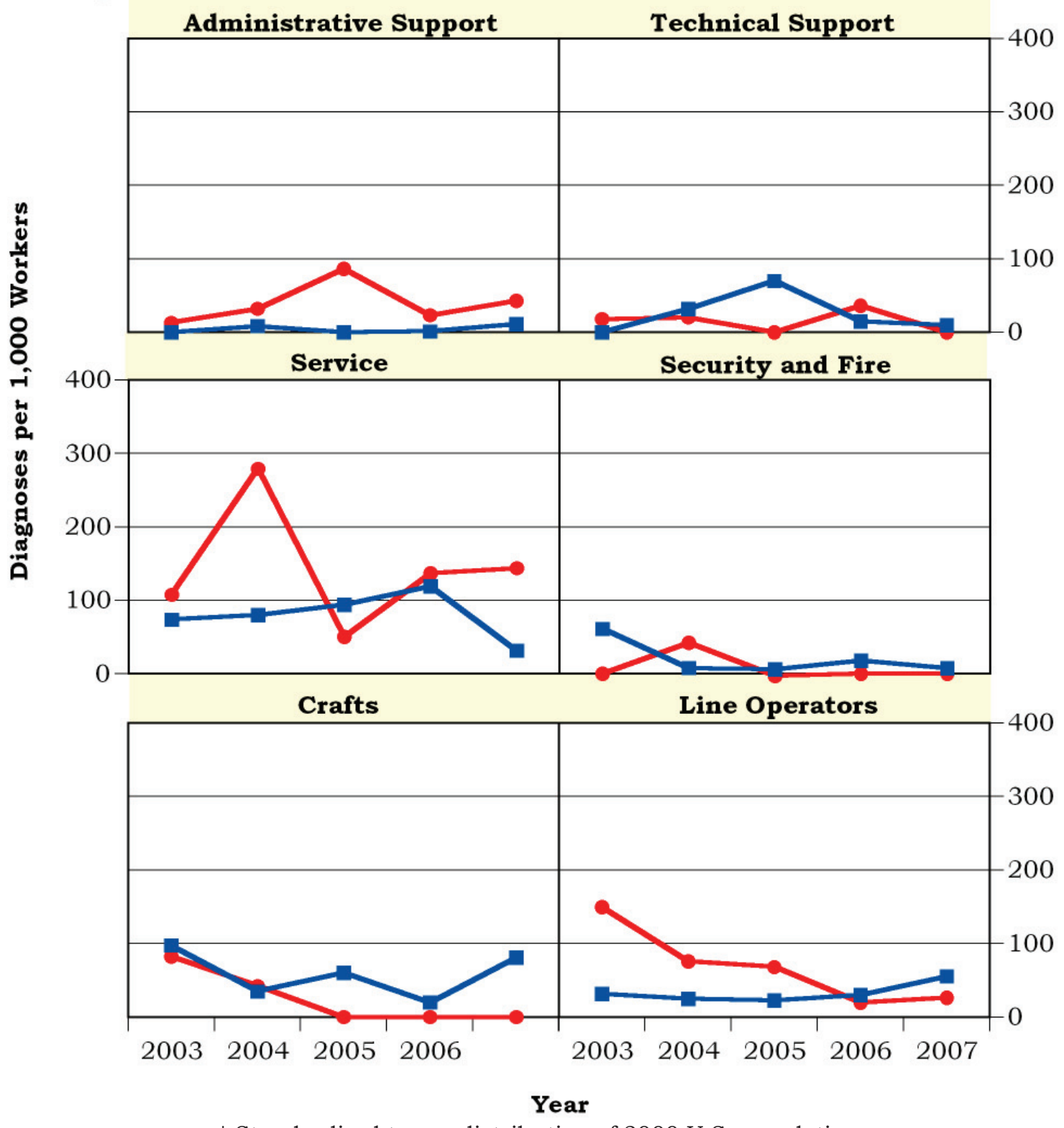

* Standardized to age distribution of 2000 U.S. population. 


\section{Appendices}


Y-12 National Security Complex 2007

Absence Data

Appendix A. Work Force by Gender, Age, and Job Category

\begin{tabular}{|c|c|c|c|c|c|c|c|c|c|c|c|}
\hline \multirow{3}{*}{ Job Category } & \multicolumn{5}{|c|}{ Women } & \multicolumn{5}{|c|}{ Men } & \multirow[b]{3}{*}{ TOTAL } \\
\hline & \multicolumn{4}{|c|}{ Age Group } & \multirow[b]{2}{*}{ TOTAL } & \multicolumn{4}{|c|}{ Age Group } & \multirow[b]{2}{*}{ TOTAL } & \\
\hline & $16-29$ & 30 - 39 & $40-49$ & $50+$ & & $16-29$ & $30-39$ & $40-49$ & $\mathbf{5 0}+$ & & \\
\hline Professional & 56 & 53 & 161 & 187 & 457 & 149 & 159 & 423 & 963 & 1,694 & 2,151 \\
\hline Administrative Support & 23 & 61 & 189 & 271 & 544 & 16 & 42 & 94 & 196 & 348 & 892 \\
\hline Technical Support & 4 & 18 & 23 & 45 & 90 & 10 & 25 & 48 & 56 & 139 & 229 \\
\hline Service & 3 & 11 & 26 & 59 & 99 & 26 & 38 & 81 & 186 & 331 & 430 \\
\hline Security and Fire & 0 & 4 & 17 & 16 & 37 & 11 & 33 & 31 & 53 & 128 & 165 \\
\hline Crafts & 4 & 2 & 13 & 13 & 32 & 33 & 92 & 172 & 492 & 789 & 821 \\
\hline Line Operators & 1 & 7 & 16 & 38 & 62 & 20 & 46 & 56 & 87 & 209 & 271 \\
\hline TOTAL & 91 & 156 & 445 & 629 & 1,321 & 265 & 435 & 905 & 2,033 & 3,638 & 4,959 \\
\hline
\end{tabular}

Appendix B. Age Distribution of the Work Force by Gender

\begin{tabular}{|l|r|r|r|r|r|r|r|r|}
\hline \multirow{3}{*}{ Year } & \multicolumn{4}{|c|}{ Women } & \multicolumn{4}{c|}{ Men } \\
\cline { 2 - 9 } & \multicolumn{1}{|c|}{ Percent Distribution by Age Group } & \multicolumn{1}{c|}{ Percent Distribution by Age Group } \\
\cline { 2 - 9 } & $\mathbf{1 6}-\mathbf{2 9}$ & $\mathbf{3 0}-\mathbf{3 9}$ & $\mathbf{4 0 - 4 9}$ & $\mathbf{5 0}+$ & $\mathbf{1 6}-\mathbf{2 9}$ & $\mathbf{3 0}-\mathbf{3 9}$ & $\mathbf{4 0}-\mathbf{4 9}$ & $\mathbf{5 0}+$ \\
\hline $\mathbf{1 9 9 8}$ & 3.53 & 25.56 & 44.17 & 26.74 & 1.38 & 14.26 & 39.96 & 44.40 \\
\hline $\mathbf{1 9 9 9}$ & 3.21 & 23.11 & 45.31 & 28.37 & 1.30 & 14.80 & 38.78 & 45.12 \\
\hline $\mathbf{2 0 0 0}$ & 2.93 & 21.13 & 45.34 & 30.61 & 1.63 & 13.25 & 38.59 & 46.54 \\
\hline $\mathbf{2 0 0 1}$ & 2.02 & 19.48 & 45.70 & 32.80 & 2.09 & 11.10 & 36.21 & 50.60 \\
\hline $\mathbf{2 0 0 2}$ & 4.95 & 18.75 & 42.91 & 33.38 & 5.79 & 12.13 & 32.42 & 49.66 \\
\hline $\mathbf{2 0 0 3}$ & 6.36 & 16.02 & 42.99 & 34.64 & 5.91 & 11.74 & 30.31 & 52.04 \\
\hline $\mathbf{2 0 0 4}$ & 6.77 & 14.59 & 40.00 & 38.65 & 6.57 & 11.68 & 27.69 & 54.06 \\
\hline $\mathbf{2 0 0 5}$ & 6.92 & 12.84 & 37.82 & 42.43 & 7.90 & 11.24 & 26.06 & 54.81 \\
\hline $\mathbf{2 0 0 6}$ & 7.44 & 13.01 & 35.04 & 44.51 & 7.83 & 11.37 & 25.43 & 55.37 \\
\hline $\mathbf{2 0 0 7}$ & 6.89 & 11.81 & 33.69 & 47.62 & 7.28 & 11.96 & 24.88 & 55.88 \\
\hline
\end{tabular}


Y-12 National Security Complex 2007

Absence Data

Appendix C. Total Number of Workers Who Reported at Least One Absence by Gender, Age, and Job Category*

\begin{tabular}{|c|c|c|c|c|c|c|c|c|c|c|c|}
\hline \multirow{3}{*}{ Job Category } & \multicolumn{5}{|c|}{ Women } & \multicolumn{5}{|c|}{ Men } & \multirow[b]{3}{*}{ TOTAL } \\
\hline & \multicolumn{4}{|c|}{ Age Group } & \multirow[b]{2}{*}{ TOTAL } & \multicolumn{4}{|c|}{ Age Group } & \multirow[b]{2}{*}{ TOTAL } & \\
\hline & $16-29$ & 30 - 39 & $40-49$ & $50+$ & & $16-29$ & 30 - 39 & $40-49$ & $50+$ & & \\
\hline Professional & 1 & 10 & 35 & 37 & 83 & 7 & 21 & 34 & 117 & 179 & 262 \\
\hline Administrative Support & 4 & 11 & 24 & 58 & 97 & 0 & 3 & 7 & 24 & 34 & 131 \\
\hline Technical Support & 0 & 4 & 6 & 9 & 19 & 0 & 4 & 5 & 6 & 15 & 34 \\
\hline Service & 1 & 4 & 5 & 17 & 27 & 2 & 4 & 14 & 43 & 63 & 90 \\
\hline Security and Fire & 0 & 1 & 2 & 2 & 5 & 0 & 5 & 4 & 10 & 19 & 24 \\
\hline Crafts & 2 & 0 & 1 & 3 & 6 & 0 & 8 & 20 & 89 & 117 & 123 \\
\hline Line Operators & 1 & 1 & 7 & 9 & 18 & 8 & 13 & 18 & 20 & 59 & 77 \\
\hline TOTAL & 9 & 31 & 80 & 135 & 255 & 17 & 58 & 102 & 309 & 486 & 741 \\
\hline
\end{tabular}

*Only those job categories and gender/age combinations with at least one absence appear in this table.

Appendix D. Total Number of Absences by Gender, Age, and Job Category*

\begin{tabular}{|c|c|c|c|c|c|c|c|c|c|c|c|}
\hline \multirow{3}{*}{ Job Category } & \multicolumn{5}{|c|}{ Women } & \multicolumn{5}{|c|}{ Men } & \multirow[b]{3}{*}{ TOTAL } \\
\hline & \multicolumn{4}{|c|}{ Age Group } & \multirow[b]{2}{*}{ TOTAL } & \multicolumn{4}{|c|}{ Age Group } & \multirow[b]{2}{*}{ TOTAL } & \\
\hline & $16-29$ & 30 - 39 & $40-49$ & $50+$ & & $16-29$ & 30 - 39 & $40-49$ & $50+$ & & \\
\hline Professional & 2 & 12 & 38 & 46 & 98 & 7 & 25 & 42 & 136 & 210 & 308 \\
\hline Administrative Support & 4 & 13 & 25 & 71 & 113 & 0 & 4 & 8 & 30 & 42 & 155 \\
\hline Technical Support & 0 & 8 & 9 & 14 & 31 & 0 & 4 & 5 & 7 & 16 & 47 \\
\hline Service & 2 & 6 & 7 & 20 & 35 & 4 & 6 & 17 & 52 & 79 & 114 \\
\hline Security and Fire & 0 & 1 & 2 & 2 & 5 & 0 & 6 & 7 & 14 & 27 & 32 \\
\hline Crafts & 2 & 0 & 1 & 3 & 6 & 0 & 13 & 23 & 108 & 144 & 150 \\
\hline Line Operators & 1 & 1 & 7 & 16 & 25 & 11 & 15 & 20 & 28 & 74 & 99 \\
\hline TOTAL & 11 & 41 & 89 & 172 & 313 & 22 & 73 & 122 & 375 & 592 & 905 \\
\hline
\end{tabular}

*Only those job categories and gender/age combinations with at least one absence appear in this table. 
Y-12 National Security Complex 2007

Absence Data

Appendix E. Distribution of the Number of Calendar Days Missed per Absence by Gender and Age*

\begin{tabular}{|c|c|c|c|c|c|c|c|c|c|c|c|}
\hline \multirow{3}{*}{$\begin{array}{c}\text { Number of } \\
\text { Calendar Days }\end{array}$} & \multicolumn{5}{|c|}{ Women } & \multicolumn{5}{|c|}{ Men } & \multirow[b]{3}{*}{ TOTAL } \\
\hline & \multicolumn{4}{|c|}{ Age Group } & \multirow[b]{2}{*}{ TOTAL } & \multicolumn{4}{|c|}{ Age Group } & \multirow[b]{2}{*}{ TOTAL } & \\
\hline & $16-29$ & $30-39$ & $40-49$ & $50+$ & & $16-29$ & $30-39$ & $40-49$ & $50+$ & & \\
\hline$<15$ & 4 & 15 & 42 & 76 & 137 & 3 & 21 & 50 & 138 & 212 & 349 \\
\hline $15-28$ & 5 & 13 & 17 & 33 & 68 & 8 & 25 & 30 & 69 & 132 & 200 \\
\hline $29-42$ & 0 & 3 & 6 & 15 & 24 & 3 & 9 & 11 & 37 & 60 & 84 \\
\hline $43-56$ & 0 & 5 & 9 & 14 & 28 & 2 & 3 & 8 & 40 & 53 & 81 \\
\hline $57-91$ & 1 & 4 & 7 & 15 & 27 & 5 & 9 & 7 & 38 & 59 & 86 \\
\hline $92-182$ & 1 & 1 & 6 & 15 & 23 & 1 & 5 & 13 & 43 & 62 & 85 \\
\hline $183+$ & 0 & 0 & 2 & 4 & 6 & 0 & 1 & 3 & 10 & 14 & 20 \\
\hline TOTAL & 11 & 41 & 89 & 172 & 313 & 22 & 73 & 122 & 375 & 592 & 905 \\
\hline
\end{tabular}

*Only those gender/age combinations with at least one absence appear in this table. 
Y-12 National Security Complex 2007

Absence Data

Appendix F. Distribution of the Number of Calendar Days Missed per Absence by Gender and Job Category*

Women

\begin{tabular}{|c|c|c|c|c|c|c|c|c|}
\hline \multirow{2}{*}{$\begin{array}{c}\text { Number of } \\
\text { Calendar Days }\end{array}$} & \multicolumn{7}{|c|}{ Job Category } & \multirow[b]{2}{*}{ TOTAL } \\
\hline & Professional & $\begin{array}{c}\text { Administrative } \\
\text { Support }\end{array}$ & Technical Support & Service & Security and Fire & Crafts & Line Operators & \\
\hline$<15$ & 46 & 52 & 19 & 9 & 2 & 2 & 7 & 137 \\
\hline $15-28$ & 20 & 21 & 5 & 12 & 1 & 2 & 7 & 68 \\
\hline $57-91$ & 7 & 11 & 1 & 4 & 0 & 0 & 4 & 27 \\
\hline $92-182$ & 2 & 9 & 2 & 5 & 1 & 1 & 3 & 23 \\
\hline $183+$ & 2 & 2 & 0 & 2 & 0 & 0 & 0 & 6 \\
\hline TOTAL & 98 & 113 & 31 & 35 & 5 & 6 & 25 & 313 \\
\hline
\end{tabular}

Men

\begin{tabular}{|c|c|c|c|c|c|c|c|c|}
\hline \multirow{2}{*}{$\begin{array}{l}\text { Number of } \\
\text { Calendar Days }\end{array}$} & \multicolumn{7}{|c|}{ Job Category } & \multirow[b]{2}{*}{ TOTAL } \\
\hline & Professional & $\begin{array}{l}\text { Administrative } \\
\text { Support }\end{array}$ & Technical Support & Service & Security and Fire & Crafts & Line Operators & \\
\hline$<15$ & 100 & 21 & 9 & 20 & 8 & 38 & 16 & 212 \\
\hline $15-28$ & 43 & 7 & 0 & 18 & 4 & 37 & 23 & 132 \\
\hline $57-91$ & 10 & 4 & 2 & 14 & 3 & 11 & 15 & 59 \\
\hline $92-182$ & 13 & 3 & 3 & 9 & 5 & 24 & 5 & 62 \\
\hline $183+$ & 4 & 1 & 0 & 7 & 0 & 1 & 1 & 14 \\
\hline TOTAL & 210 & 42 & 16 & 79 & 27 & 144 & 74 & 592 \\
\hline
\end{tabular}

*Only those gender/job category combinations with at least one absence appear in this table. 


\section{Y-12 National Security Complex 2007}

\section{Absence Data}

Appendix G. Number of Diagnoses in Each Diagnostic Category by Gender and Age*

\begin{tabular}{|c|c|c|c|c|c|c|}
\hline & & \multicolumn{5}{|c|}{ Women } \\
\hline & & \multicolumn{4}{|c|}{ Age Group } & \multirow[b]{2}{*}{ TOTAL } \\
\hline & & $16-29$ & 30 - 39 & $40-49$ & $50+$ & \\
\hline Diagnostic Category & ICD-9-CM Code & \multirow[b]{2}{*}{0} & \multirow[b]{2}{*}{2} & \multirow[b]{2}{*}{4} & \multirow[b]{2}{*}{7} & \multirow[b]{2}{*}{13} \\
\hline INFECTIOUS \& PARASITIC DISEASES (DIS) & 001-139 & & & & & \\
\hline -Intestinal Infectious Dis & 001-009 & 0 & 1 & 0 & 1 & 2 \\
\hline -Other Bacterial Dis & $030-041$ & 0 & 0 & 1 & 4 & 5 \\
\hline -Polio \& Other Viral CNS Dis & 045-049 & 0 & 0 & 1 & 0 & 1 \\
\hline -Viral Dis with Exanthem & $050-057$ & 0 & 0 & 0 & 1 & 1 \\
\hline -Other Viral Dis \& Chlamydiae & 070-079 & 0 & 1 & 2 & 1 & 4 \\
\hline MALIGNANT NEOPLASMS & $140-208,230-234$ & 0 & 2 & 2 & 12 & 16 \\
\hline -Lip, Oral Cavity, Pharynx & $140-149$ & 0 & 0 & 0 & 0 & 0 \\
\hline -Digestive \& Peritoneal & 150-159 & 0 & 0 & 0 & 0 & 0 \\
\hline -Respiratory \& Intrathoracic & $160-165$ & 0 & 0 & 0 & 1 & 1 \\
\hline -Bone, Connective Tissue, Skin & $170-173,176$ & 0 & 0 & 1 & 0 & 1 \\
\hline -Breast & 174-175 & 0 & 1 & 1 & 5 & 7 \\
\hline -Genitourinary & 179-189 & 0 & 0 & 0 & 0 & 0 \\
\hline -Other \& Unspecified Sites & 190, 193-199 & 0 & 1 & 0 & 4 & 5 \\
\hline -Lymphatic \& Hematopoietic & $200-208$ & 0 & 0 & 0 & 1 & 1 \\
\hline -Carcinoma in situ & $230-234$ & 0 & 0 & 0 & 1 & 1 \\
\hline BENIGN \& UNCERTAIN NEOPLASMS & 210-229, 235-239 & 0 & 1 & 4 & 5 & 10 \\
\hline ENDOCRINE/METABOLIC/IMMUNITY & $240-279$ & 1 & 3 & 2 & 6 & 12 \\
\hline -Thyroid Gland Disorders & $240-246$ & 0 & 2 & 1 & 1 & 4 \\
\hline -Other Endocrine Gland Dis & $250-259$ & 0 & 1 & 1 & 4 & $\overline{6}$ \\
\hline -Other Metabolic \& Immunity Disorders & $270-279$ & 1 & 0 & 0 & 1 & 2 \\
\hline BLOOD \& BLOOD-FORMING ORGANS & $280-289$ & 0 & 0 & 0 & 0 & 0 \\
\hline MENTAL DISORDERS & $290-319$ & 0 & 1 & 5 & 5 & 11 \\
\hline -Psychoses & 290-299 & 0 & 1 & 3 & 1 & 5 \\
\hline -Non-Psychotic Disorders & $300-302,306-316$ & 0 & 0 & 2 & 4 & 6 \\
\hline -Alcohol Dependence & 303 & 0 & 0 & 0 & 0 & 0 \\
\hline NERVOUS SYSTEM (NS) \& SENSE ORGANS & $320-389$ & 0 & 3 & 8 & 9 & 20 \\
\hline -Other Disorders of Central NS & $340-349$ & 0 & 1 & 1 & 0 & 2 \\
\hline -Disorders of Peripheral NS & $350-359$ & 0 & 0 & 5 & 3 & 8 \\
\hline -Disorders of Eye & $360-379$ & 0 & 0 & 0 & 3 & 3 \\
\hline -Dis of Ear \& Mastoid & $380-389$ & 0 & 2 & 2 & 3 & 7 \\
\hline CIRCULATORY SYSTEM & $390-459$ & 0 & 0 & 1 & 14 & 15 \\
\hline -Chronic Rheumatic Heart Dis & 393-398 & 0 & 0 & 0 & 0 & 0 \\
\hline -Hypertensive Dis & $401-405$ & 0 & 0 & 0 & 4 & 4 \\
\hline -Ischemic Heart Dis & $410-414$ & 0 & 0 & 0 & 5 & 5 \\
\hline -Other Heart Dis & $420-429$ & 0 & 0 & 0 & 0 & 0 \\
\hline -Cerebrovascular Dis & $430-438$ & 0 & 0 & 0 & 3 & 3 \\
\hline
\end{tabular}

(Continued)

*Only those diagnostic categories and gender/age combinations with at least one occurrence appear in this table. 


\section{Y-12 National Security Complex 2007}

\section{Absence Data}

Appendix G. Number of Diagnoses in Each Diagnostic Category by Gender and Age*

\begin{tabular}{|c|c|c|c|c|c|c|c|}
\hline & & \multicolumn{5}{|c|}{ Men } & \multirow[b]{3}{*}{ TOTAL } \\
\hline & & \multicolumn{4}{|c|}{ Age Group } & \multirow[b]{2}{*}{ TOTAL } & \\
\hline & & $16-29$ & $30-39$ & $40-49$ & $50+$ & & \\
\hline INFECTIOUS \& PARASITIC DISEASES (DIS) & 001-139 & 3 & 4 & 1 & 12 & 20 & 33 \\
\hline -Intestinal Infectious Dis & 001-009 & 0 & 1 & 0 & 1 & 2 & 4 \\
\hline -Polio \& Other Viral CNS Dis & 045-049 & 0 & 0 & 0 & 0 & 0 & 1 \\
\hline -Viral Dis with Exanthem & $050-057$ & 1 & 1 & 0 & 4 & 6 & 7 \\
\hline -Other Viral Dis \& Chlamydiae & 070-079 & 1 & 1 & 1 & 3 & 6 & 10 \\
\hline MALIGNANT NEOPLASMS & $140-208,230-234$ & 0 & 1 & 2 & 23 & 26 & 42 \\
\hline -Bone, Connective Tissue, Skin & $170-173,176$ & 0 & 0 & 0 & 3 & 3 & 4 \\
\hline -Breast & 174-175 & 0 & 0 & 0 & 0 & 0 & 7 \\
\hline -Genitourinary & 179-189 & 0 & 0 & 1 & 8 & 9 & 9 \\
\hline -Other \& Unspecified Sites & 190, 193-199 & 0 & 0 & 0 & 4 & 4 & 9 \\
\hline -Lymphatic \& Hematopoietic & $200-208$ & 0 & 0 & 0 & 1 & 1 & 2 \\
\hline -Carcinoma in situ & $230-234$ & 0 & 0 & 0 & 0 & 0 & 1 \\
\hline BENIGN \& UNCERTAIN NEOPLASMS & 210-229, 235-239 & 0 & 0 & 0 & 5 & 5 & 15 \\
\hline ENDOCRINE/METABOLIC/IMMUNITY & $240-279$ & 0 & 0 & 4 & 8 & 12 & 24 \\
\hline -Psychoses & 290-299 & 1 & 5 & 3 & 3 & 12 & 17 \\
\hline -Non-Psychotic Disorders & $300-302,306-316$ & 1 & 1 & 4 & 5 & 11 & 17 \\
\hline -Alcohol Dependence & 303 & 0 & 1 & 0 & 0 & 1 & 1 \\
\hline NERVOUS SYSTEM (NS) \& SENSE ORGANS & $320-389$ & 1 & 0 & 6 & 18 & 25 & 45 \\
\hline -Other Disorders of Central NS & $340-349$ & 0 & 0 & 1 & 1 & 2 & 4 \\
\hline -Disorders of Peripheral NS & $350-359$ & 1 & 0 & 2 & 10 & 13 & 21 \\
\hline -Disorders of Eye & $360-379$ & 0 & 0 & 3 & 5 & 8 & 11 \\
\hline -Dis of Ear \& Mastoid & $380-389$ & 0 & 0 & 0 & 2 & 2 & 9 \\
\hline CIRCULATORY SYSTEM & $390-459$ & 0 & 2 & 7 & 50 & 59 & 74 \\
\hline -Chronic Rheumatic Heart Dis & 393-398 & 0 & 0 & 0 & 1 & 1 & 1 \\
\hline -Hypertensive Dis & $401-405$ & 0 & 0 & 0 & 4 & 4 & 8 \\
\hline -Ischemic Heart Dis & $410-414$ & 0 & 1 & 1 & 18 & 20 & 25 \\
\hline -Other Heart Dis & $420-429$ & 0 & 0 & 2 & 9 & 11 & 11 \\
\hline -Cerebrovascular Dis & $430-438$ & 0 & 0 & 0 & 7 & 7 & 10 \\
\hline
\end{tabular}

*Only those diagnostic categories and gender/age combinations with at least one occurrence appear in this table. 


\section{Y-12 National Security Complex 2007}

\section{Absence Data}

Appendix G. Number of Diagnoses in Each Diagnostic Category by Gender and Age*

\begin{tabular}{|c|c|c|c|c|c|c|}
\hline & & \multicolumn{5}{|c|}{ Women } \\
\hline & & \multicolumn{4}{|c|}{ Age Group } & \multirow[b]{2}{*}{ TOTAL } \\
\hline & & $16-29$ & $30-39$ & $40-49$ & $\mathbf{5 0 +}$ & \\
\hline Diagnostic Category & ICD-9-CM Code & \multirow[b]{2}{*}{0} & \multirow[b]{2}{*}{0} & \multirow[b]{2}{*}{0} & \multirow[b]{2}{*}{0} & \multirow[b]{2}{*}{0} \\
\hline -Dis of Arteries \& Capillaries & $440-448$ & & & & & \\
\hline -Dis of Veins, Lymphatics, Other & 451-459 & 0 & 0 & 1 & 2 & 3 \\
\hline RESPIRATORY SYSTEM & $460-519$ & 2 & 10 & 15 & 38 & 65 \\
\hline -Acute Respiratory Infections & $460-466$ & 0 & 6 & 10 & 26 & 42 \\
\hline -Other Dis Upper Respiratory Tract & $470-478$ & 2 & 4 & 4 & 5 & 15 \\
\hline -Pneumonia \& Influenza & $480-487$ & 0 & 0 & 0 & 4 & 4 \\
\hline -Chronic Obstructive Dis & $490-496$ & 0 & 0 & 1 & 3 & 4 \\
\hline -Other Respiratory Dis & $510-519$ & 0 & 0 & 0 & 0 & 0 \\
\hline DIGESTIVE SYSTEM & $520-579$ & 4 & 2 & 10 & 17 & 33 \\
\hline -Oral Cavity, Saliva Glands, Jaw & $520-529$ & 0 & 0 & 1 & 1 & 2 \\
\hline -Esophagus, Stomach, Duodenum & $530-537$ & 0 & 0 & 0 & 0 & 0 \\
\hline -Appendicitis & $540-543$ & 0 & 0 & 0 & 0 & 0 \\
\hline -Hernia & $550-553$ & 0 & 0 & 1 & 1 & 2 \\
\hline -Enteritis, Colitis & $555-558$ & 0 & 1 & 1 & 1 & 3 \\
\hline -Other Intestinal Dis & $560-569$ & 4 & 1 & 1 & 5 & 11 \\
\hline -Other Digestive Dis & $570-579$ & 0 & 0 & 6 & 9 & 15 \\
\hline GENITOURINARY SYSTEM & $580-629$ & 4 & 8 & 16 & 14 & 42 \\
\hline -Nephritis, Nephrosis & $580-589$ & 0 & 0 & 0 & 0 & 0 \\
\hline -Other Urinary Dis & $590-599$ & 1 & 1 & 0 & 5 & 7 \\
\hline -Male Genital Organ Dis & $600-608$ & 0 & 0 & 0 & 0 & 0 \\
\hline -Breast Disorders & 610-611 & 0 & 2 & 1 & 2 & 5 \\
\hline -Pelvic Inflammatory Dis & $614-616$ & 2 & 0 & 1 & 0 & 3 \\
\hline -Other Female Disorders & 617-629 & 1 & 5 & 14 & 7 & 27 \\
\hline SKIN \& SUBCUTANEOUS TISSUE & 680-709 & 0 & 1 & 0 & 2 & 3 \\
\hline -Infections & $680-686$ & 0 & 0 & 0 & 0 & 0 \\
\hline -Other & 700-709 & 0 & 1 & 0 & 2 & 3 \\
\hline $\begin{array}{l}\text { MUSCULOSKELETAL \& CONNECTIVE } \\
\text { TISSUE }\end{array}$ & 710-739 & 1 & 12 & 13 & 53 & 79 \\
\hline -Arthropathies & $710-719$ & 0 & 2 & 3 & 20 & 25 \\
\hline -Dorsopathies & $720-724$ & 0 & 6 & 5 & 11 & 22 \\
\hline -Rheumatism, Excluding Back & \begin{tabular}{|l|l|}
$725-729$ \\
\end{tabular} & 1 & 3 & 3 & 13 & 20 \\
\hline -Other Dis \& Acquired Deformities & $730-739$ & 0 & 1 & 2 & 9 & 12 \\
\hline CONGENITAL ANOMALIES & $740-759$ & 0 & 0 & 0 & 2 & 2 \\
\hline $\begin{array}{l}\text { SYMPTOMS, SIGNS, \& ILL-DEFINED } \\
\text { CONDITIONS }\end{array}$ & 780-799 & 2 & 3 & 12 & 12 & 29 \\
\hline -Symptoms & 780-789 & 2 & 3 & 11 & 12 & 28 \\
\hline -Non-Specific Abnormal Findings & $790-796$ & 0 & 0 & 1 & 0 & 1 \\
\hline
\end{tabular}

(Continued)

*Only those diagnostic categories and gender/age combinations with at least one occurrence appear in this table. 


\section{Y-12 National Security Complex 2007}

\section{Absence Data}

Appendix G. Number of Diagnoses in Each Diagnostic Category by Gender and Age*

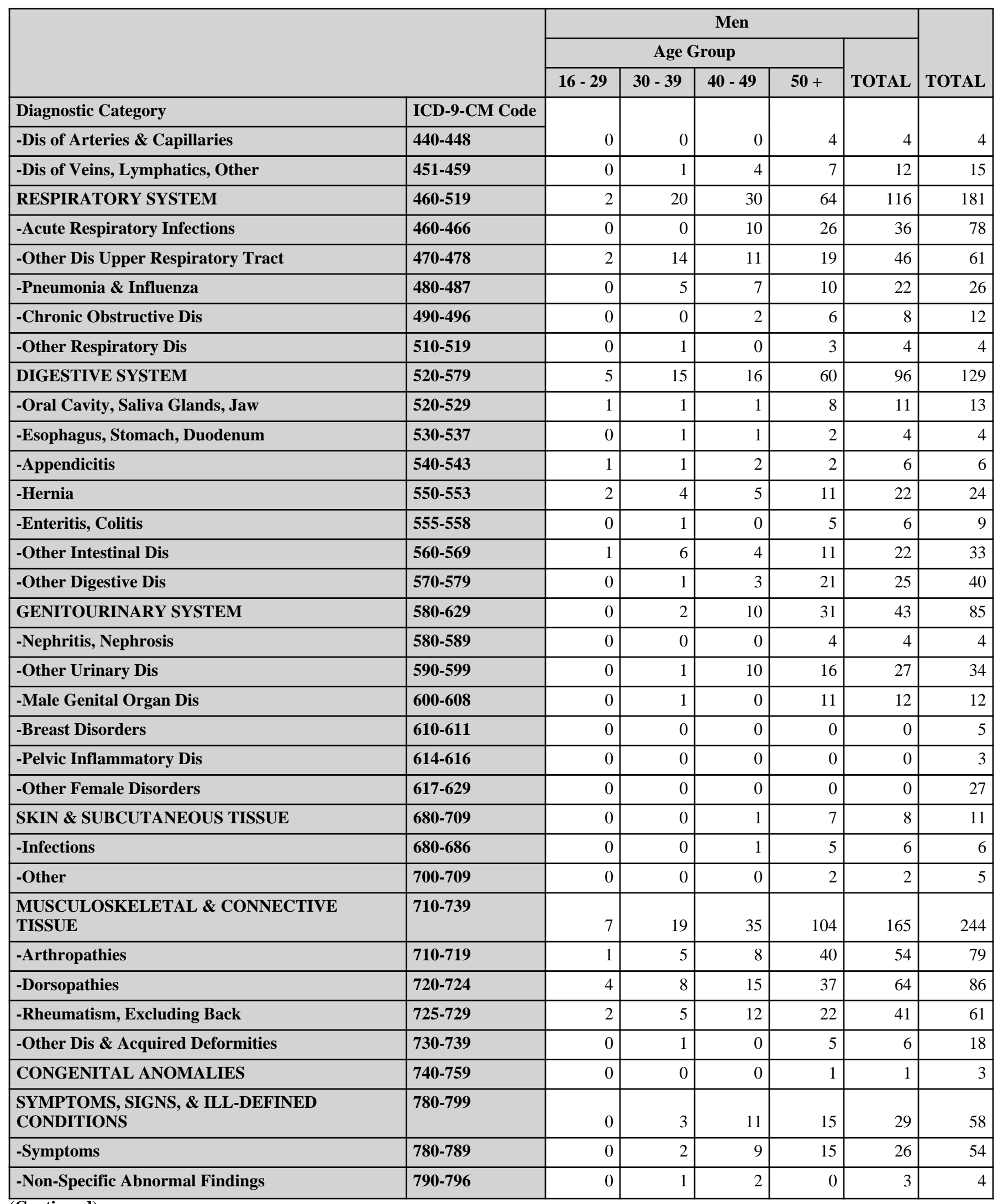

(Continued)

*Only those diagnostic categories and gender/age combinations with at least one occurrence appear in this table. 
Y-12 National Security Complex 2007

Absence Data

Appendix G. Number of Diagnoses in Each Diagnostic Category by Gender and Age*

\begin{tabular}{|c|c|c|c|c|c|c|}
\hline & & \multicolumn{5}{|c|}{ Women } \\
\hline & & \multicolumn{4}{|c|}{ Age Group } & \multirow[b]{2}{*}{ TOTAL } \\
\hline & & $16-29$ & $30-39$ & $40-49$ & $\mathbf{5 0 +}$ & \\
\hline Diagnostic Category & ICD-9-CM Code & \multirow[b]{2}{*}{1} & \multirow[b]{2}{*}{5} & \multirow[b]{2}{*}{13} & \multirow[b]{2}{*}{21} & \multirow[b]{2}{*}{40} \\
\hline INJURY \& POISONING & $800-999$ & & & & & \\
\hline -Fracture - Skull & $800-804$ & 0 & 0 & 1 & 0 & 1 \\
\hline -Fracture - Neck, Trunk & $805-809$ & 1 & 0 & 0 & 0 & 1 \\
\hline -Fracture - Upper Limb & 810-819 & 0 & 0 & 1 & 0 & 1 \\
\hline -Fracture - Lower Limb & $820-829$ & 0 & 0 & 1 & 2 & 3 \\
\hline -Dislocation & $830-839$ & 0 & 1 & 4 & 2 & 7 \\
\hline -Sprains \& Strains - Back & 846-847 & 0 & 0 & 1 & 2 & 3 \\
\hline -Sprains \& Strains - Other & $840-845,848$ & 0 & 2 & 1 & 7 & 10 \\
\hline -Internal Injury - Thorax, Abdomen, Pelvis & $860-869$ & 0 & 0 & 0 & 0 & 0 \\
\hline -Open Wound - Head, Neck, Trunk & 870-879 & 0 & 0 & 0 & 0 & 0 \\
\hline -Open Wound - Upper Limb & $880-887$ & 0 & 0 & 0 & 0 & 0 \\
\hline -Open Wound - Lower Limb & $890-897$ & 0 & 0 & 0 & 0 & 0 \\
\hline -Superficial Injury & $910-919$ & 0 & 0 & 0 & 0 & 0 \\
\hline -Contusion & $920-924$ & 0 & 0 & 3 & 3 & 6 \\
\hline -Crushing Injury & 925-929 & 0 & 0 & 1 & 0 & 1 \\
\hline -Burns & $940-949$ & 0 & 0 & 0 & 1 & 1 \\
\hline -Complications \& Unspecified Injuries & 958-959 & 0 & 0 & 0 & 1 & 1 \\
\hline -Toxic Effects - Non-medicinal & 980-989 & 0 & 0 & 0 & 0 & 0 \\
\hline -Unspecified Effects - External Causes & $990-995$ & 0 & 0 & 0 & 0 & 0 \\
\hline -Complications of Surgical/Medical Care & 996-999 & 0 & 2 & 0 & 3 & 5 \\
\hline $\begin{array}{l}\text { HEALTH STATUS/HEALTH SERVICE } \\
\text { CONTACT }\end{array}$ & V01-V82 & 0 & 0 & 2 & 0 & 2 \\
\hline -Isolation \& Prophylactic Measures & V07-V09 & 0 & 0 & 1 & 0 & 1 \\
\hline -Personal \& Family History & V10-V19 & 0 & 0 & 0 & 0 & 0 \\
\hline -Health Services Reproduction/Development & V20-V29 & 0 & 0 & 0 & 0 & 0 \\
\hline -Health Status & V40-V49 & 0 & 0 & 0 & 0 & 0 \\
\hline -Specific Procedures/Aftercare & V50-V59 & 0 & 0 & 1 & 0 & 1 \\
\hline
\end{tabular}

*Only those diagnostic categories and gender/age combinations with at least one occurrence appear in this table. 


\section{Y-12 National Security Complex 2007}

\section{Absence Data}

Appendix G. Number of Diagnoses in Each Diagnostic Category by Gender and Age*

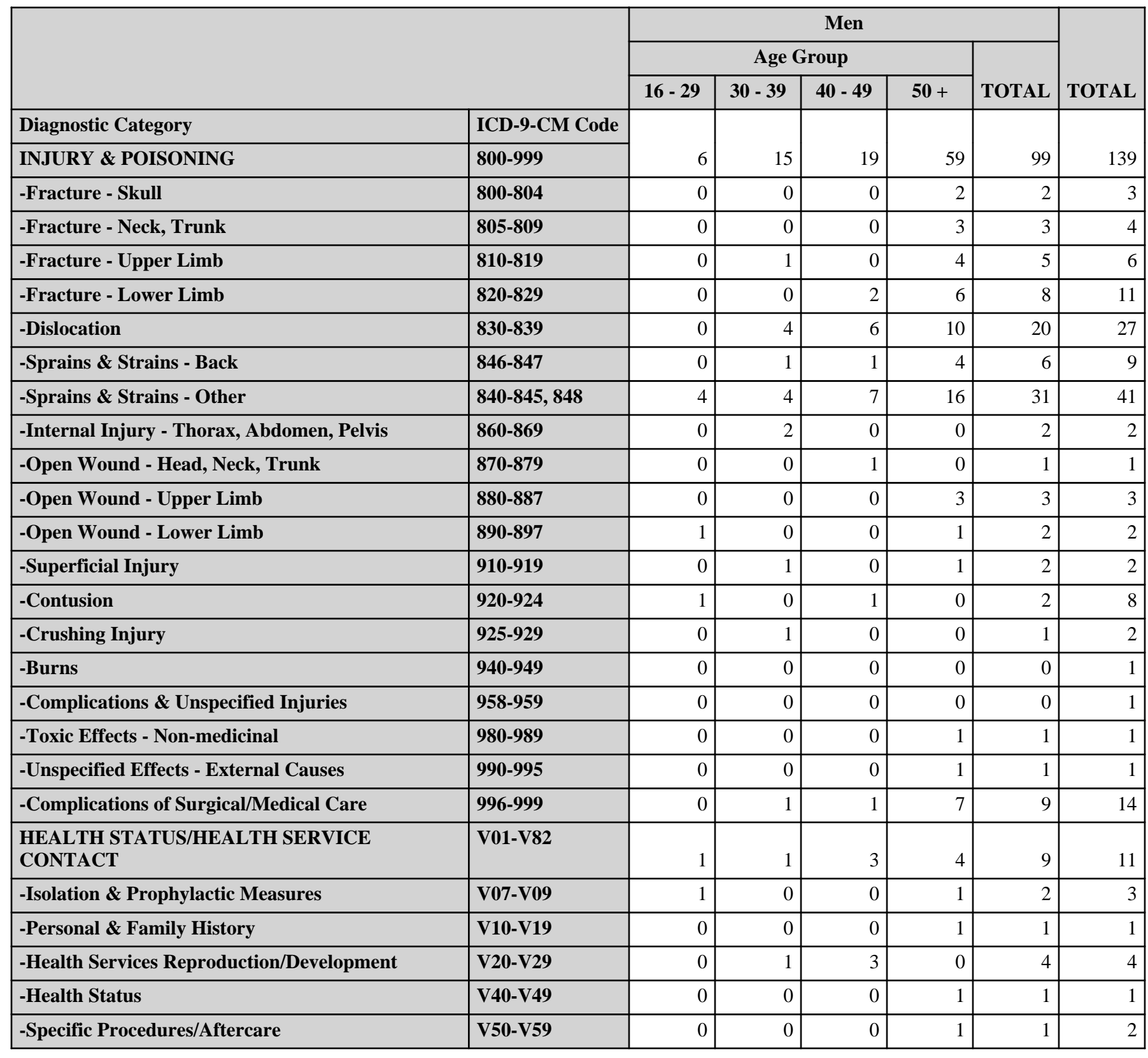

\begin{tabular}{|c|c|c|c|c|c|c|c|c|c|c|c|}
\hline & \multicolumn{5}{|c|}{ Women } & \multicolumn{5}{|c|}{ Men } & \multirow[b]{3}{*}{ TOTAL } \\
\hline & \multicolumn{4}{|c|}{ Age Group } & \multirow[b]{2}{*}{ TOTAL } & \multicolumn{4}{|c|}{ Age Group } & \multirow[b]{2}{*}{ TOTAL } & \\
\hline & $16-29$ & $30-39$ & $40-49$ & $50+$ & & $16-29$ & $30-39$ & $40-49$ & $50+$ & & \\
\hline Diagnostic Category & \multirow[b]{2}{*}{15} & \multirow[b]{2}{*}{53} & \multirow[b]{2}{*}{107} & \multirow[b]{2}{*}{217} & \multirow[b]{2}{*}{392} & \multirow[b]{2}{*}{27} & \multirow[b]{2}{*}{90} & \multirow[b]{2}{*}{154} & \multirow[b]{2}{*}{469} & \multirow[b]{2}{*}{740} & \multirow[b]{2}{*}{1,132} \\
\hline Total & & & & & & & & & & & \\
\hline
\end{tabular}

*Only those diagnostic categories and gender/age combinations with at least one occurrence appear in this table. 
Y-12 National Security Complex 2007

Absence Data

Appendix H. Total Number of Calendar Days Absent in Each Diagnostic Category by Gender and Age*

\begin{tabular}{|c|c|c|c|c|c|c|}
\hline & & \multicolumn{5}{|c|}{ Women } \\
\hline & & \multicolumn{4}{|c|}{ Age Group } & \multirow[b]{2}{*}{ TOTAL } \\
\hline & & $16-29$ & $30-39$ & $40-49$ & $\mathbf{5 0 +}$ & \\
\hline Diagnostic Category & ICD-9-CM Code & \multirow[b]{2}{*}{0} & \multirow[b]{2}{*}{18} & \multirow[b]{2}{*}{194} & \multirow[b]{2}{*}{166} & \multirow[b]{2}{*}{378} \\
\hline INFECTIOUS \& PARASITIC DISEASES (DIS) & 001-139 & & & & & \\
\hline MALIGNANT NEOPLASMS & $140-208,230-234$ & 0 & 50 & 37 & 539 & 626 \\
\hline BENIGN \& UNCERTAIN NEOPLASMS & 210-229, 235-239 & 0 & 18 & 161 & 201 & 380 \\
\hline ENDOCRINE/METABOLIC/IMMUNITY & $240-279$ & 13 & 81 & 37 & 458 & 589 \\
\hline BLOOD \& BLOOD-FORMING ORGANS & $280-289$ & 0 & 0 & 0 & 0 & 0 \\
\hline MENTAL DISORDERS & $290-319$ & 0 & 22 & 377 & 253 & 652 \\
\hline NERVOUS SYSTEM (NS) \& SENSE ORGANS & $320-389$ & 0 & 140 & 291 & 105 & 536 \\
\hline CIRCULATORY SYSTEM & $390-459$ & 0 & 0 & 10 & 801 & 811 \\
\hline RESPIRATORY SYSTEM & $460-519$ & 30 & 81 & 146 & 346 & 603 \\
\hline DIGESTIVE SYSTEM & $520-579$ & 48 & 22 & 280 & 254 & 604 \\
\hline GENITOURINARY SYSTEM & $580-629$ & 59 & 165 & 463 & 281 & 968 \\
\hline SKIN \& SUBCUTANEOUS TISSUE & 680-709 & 0 & 26 & 0 & 34 & 60 \\
\hline $\begin{array}{l}\text { MUSCULOSKELETAL \& CONNECTIVE } \\
\text { TISSUE }\end{array}$ & $710-739$ & 63 & 369 & 642 & 2,428 & 3,502 \\
\hline CONGENITAL ANOMALIES & $740-759$ & 0 & 0 & 0 & 147 & 147 \\
\hline $\begin{array}{l}\text { SYMPTOMS, SIGNS, \& ILL-DEFINED } \\
\text { CONDITIONS }\end{array}$ & 780-799 & 34 & 81 & 290 & 238 & 643 \\
\hline INJURY \& POISONING & $800-999$ & 98 & 177 & 400 & 916 & 1,591 \\
\hline
\end{tabular}

\footnotetext{
*Absences with >1 ICD-9-CM code in the same diagnostic category were counted only once. Only those diagnostic categories and gender/age combinations with at least one occurrence appear in this table.
} 
Y-12 National Security Complex 2007

Absence Data

Appendix H. Total Number of Calendar Days Absent in Each Diagnostic Category by Gender and Age*

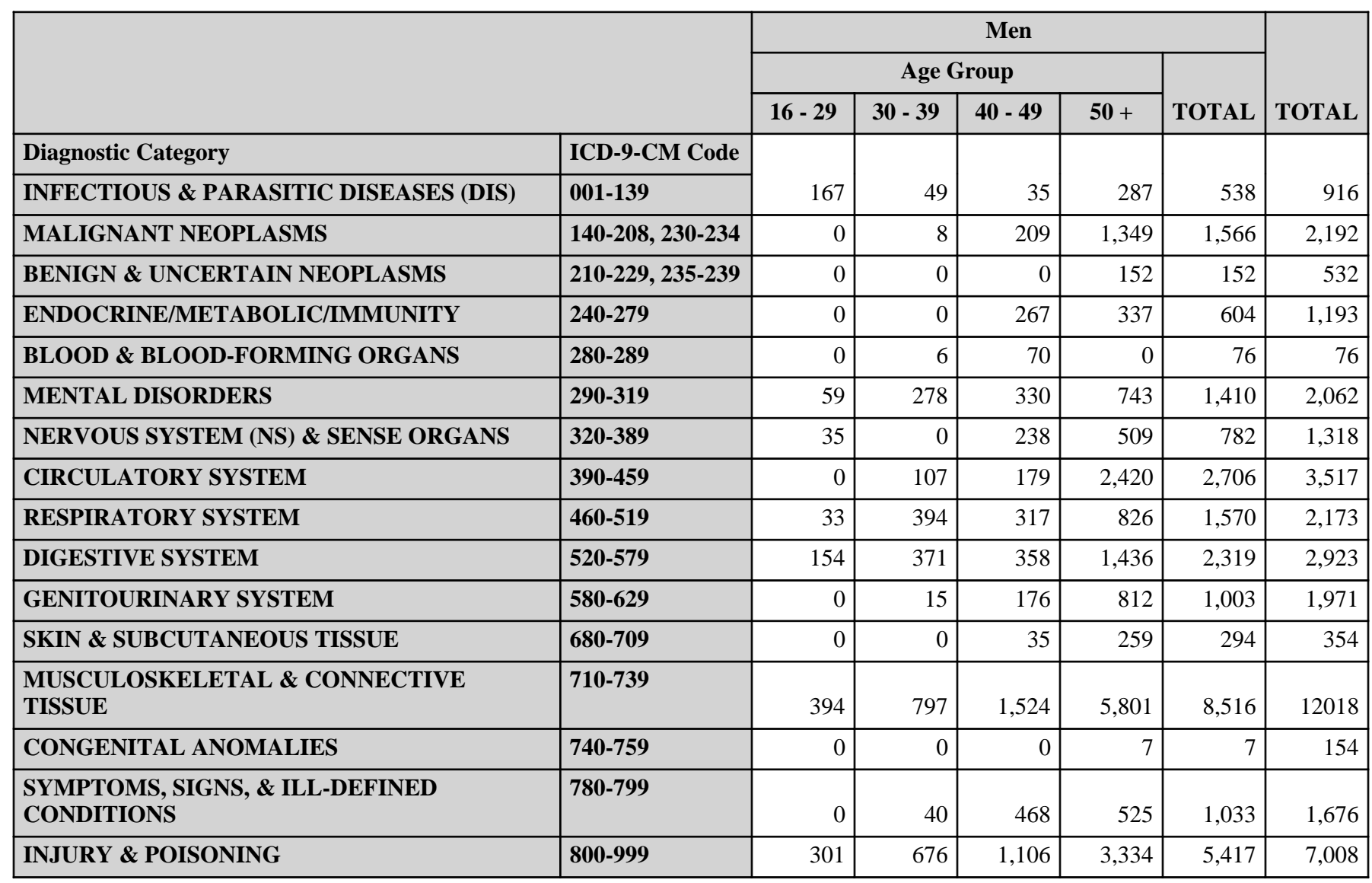

\footnotetext{
*Absences with >1 ICD-9-CM code in the same diagnostic category were counted only once. Only those diagnostic categories and gender/age combinations with at least one occurrence appear in this table.
} 


\section{Y-12 National Security Complex 2007}

\section{Absence Data}

Appendix I. Number of Diagnoses in Each Diagnostic Category by Gender and Job Category*

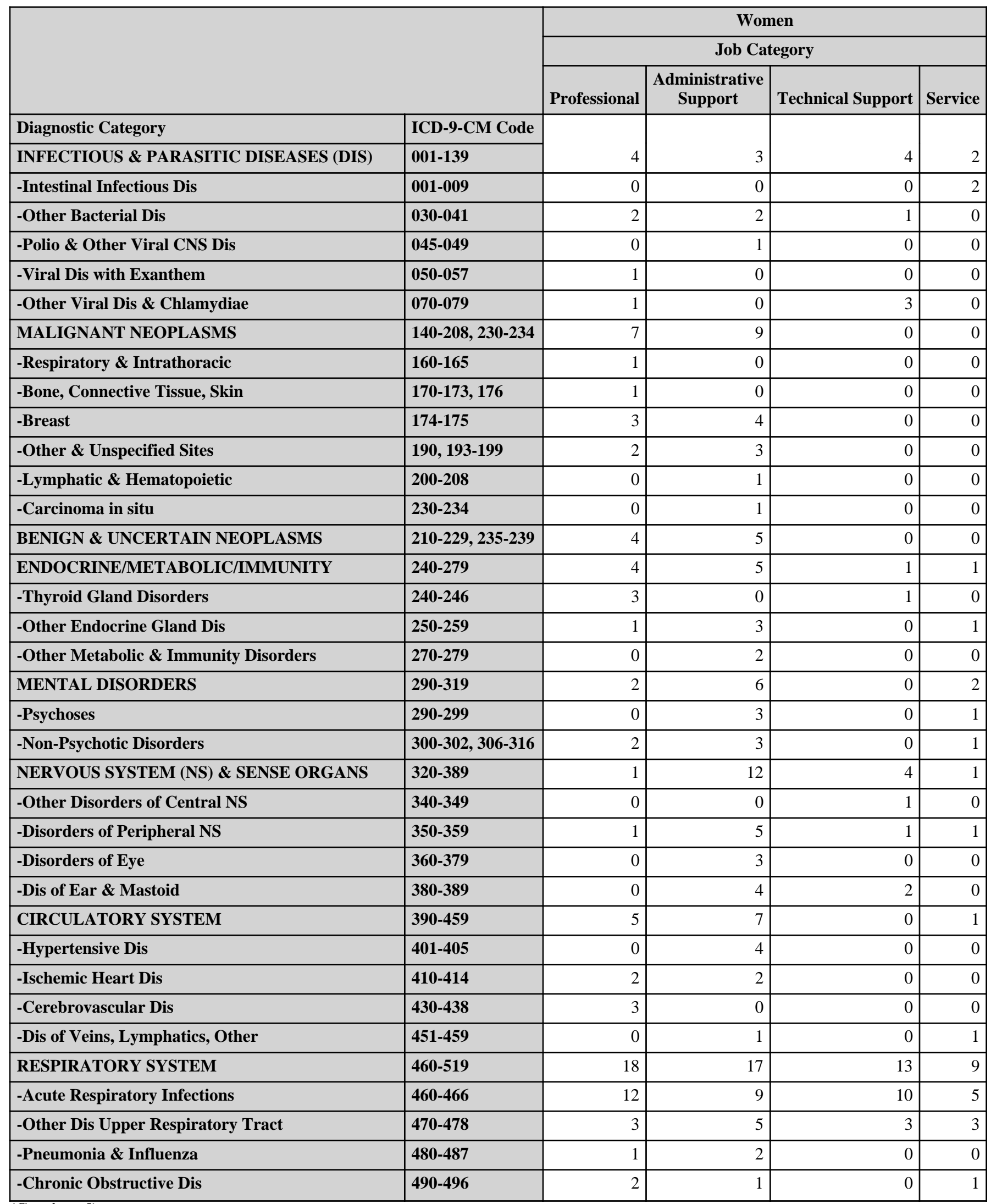

(Continued)

*Only those diagnostic categories and gender/job category combinations with at least one occurrence appear in this table. 


\section{Y-12 National Security Complex 2007}

\section{Absence Data}

Appendix I. Number of Diagnoses in Each Diagnostic Category by Gender and Job Category*

\begin{tabular}{|c|c|c|c|c|c|}
\hline & & \multicolumn{4}{|c|}{ Women } \\
\hline & & \multicolumn{3}{|c|}{ Job Category } & \multirow[b]{2}{*}{ TOTAL } \\
\hline & & Security and Fire & Crafts & Line Operators & \\
\hline Diagnostic Category & ICD-9-CM Code & \multirow[b]{2}{*}{0} & \multirow[b]{2}{*}{0} & \multirow[b]{2}{*}{0} & \multirow[b]{2}{*}{13} \\
\hline INFECTIOUS \& PARASITIC DISEASES (DIS) & 001-139 & & & & \\
\hline -Intestinal Infectious Dis & 001-009 & 0 & 0 & 0 & 2 \\
\hline -Other Bacterial Dis & 030-041 & 0 & 0 & 0 & 5 \\
\hline -Polio \& Other Viral CNS Dis & 045-049 & 0 & 0 & 0 & 1 \\
\hline -Viral Dis with Exanthem & 050-057 & 0 & 0 & 0 & 1 \\
\hline -Other Viral Dis \& Chlamydiae & 070-079 & 0 & 0 & 0 & 4 \\
\hline MALIGNANT NEOPLASMS & 140-208, 230-234 & 0 & 0 & 0 & 16 \\
\hline -Respiratory \& Intrathoracic & $160-165$ & 0 & 0 & 0 & 1 \\
\hline -Bone, Connective Tissue, Skin & $170-173,176$ & 0 & 0 & 0 & 1 \\
\hline -Breast & 174-175 & 0 & 0 & 0 & 7 \\
\hline -Other \& Unspecified Sites & 190, 193-199 & 0 & 0 & 0 & 5 \\
\hline -Lymphatic \& Hematopoietic & $200-208$ & 0 & 0 & 0 & 1 \\
\hline -Carcinoma in situ & $230-234$ & 0 & 0 & 0 & 1 \\
\hline BENIGN \& UNCERTAIN NEOPLASMS & 210-229, 235-239 & 0 & 0 & 1 & 10 \\
\hline ENDOCRINE/METABOLIC/IMMUNITY & $240-279$ & 0 & 0 & 1 & 12 \\
\hline -Thyroid Gland Disorders & $240-246$ & 0 & 0 & 0 & 4 \\
\hline -Other Endocrine Gland Dis & $250-259$ & 0 & 0 & 1 & 6 \\
\hline -Other Metabolic \& Immunity Disorders & $270-279$ & 0 & 0 & 0 & 2 \\
\hline MENTAL DISORDERS & $290-319$ & 0 & 0 & 1 & 11 \\
\hline -Psychoses & $290-299$ & 0 & 0 & 1 & 5 \\
\hline -Non-Psychotic Disorders & $300-302,306-316$ & 0 & 0 & 0 & 6 \\
\hline NERVOUS SYSTEM (NS) \& SENSE ORGANS & 320-389 & 0 & 0 & 2 & 20 \\
\hline -Other Disorders of Central NS & $340-349$ & 0 & 0 & 1 & 2 \\
\hline -Disorders of Peripheral NS & $350-359$ & 0 & 0 & 0 & 8 \\
\hline -Disorders of Eye & $360-379$ & 0 & 0 & 0 & 3 \\
\hline -Dis of Ear \& Mastoid & 380-389 & 0 & 0 & 1 & 7 \\
\hline CIRCULATORY SYSTEM & $390-459$ & 1 & 0 & 1 & 15 \\
\hline -Hypertensive Dis & 401-405 & 0 & 0 & 0 & 4 \\
\hline -Ischemic Heart Dis & $410-414$ & 0 & 0 & 1 & 5 \\
\hline -Cerebrovascular Dis & $430-438$ & 0 & 0 & 0 & 3 \\
\hline -Dis of Veins, Lymphatics, Other & 451-459 & 1 & 0 & 0 & 3 \\
\hline RESPIRATORY SYSTEM & $460-519$ & 2 & 0 & 6 & 65 \\
\hline -Acute Respiratory Infections & $460-466$ & 2 & 0 & 4 & 42 \\
\hline -Other Dis Upper Respiratory Tract & \begin{tabular}{|c|}
$470-478$ \\
\end{tabular} & 0 & 0 & 1 & 15 \\
\hline -Pneumonia \& Influenza & $480-487$ & 0 & 0 & 1 & 4 \\
\hline -Chronic Obstructive Dis & $490-496$ & 0 & 0 & 0 & 4 \\
\hline
\end{tabular}

(Continued)

*Only those diagnostic categories and gender/job category combinations with at least one occurrence appear in this table. 


\section{Y-12 National Security Complex 2007}

\section{Absence Data}

Appendix I. Number of Diagnoses in Each Diagnostic Category by Gender and Job Category*

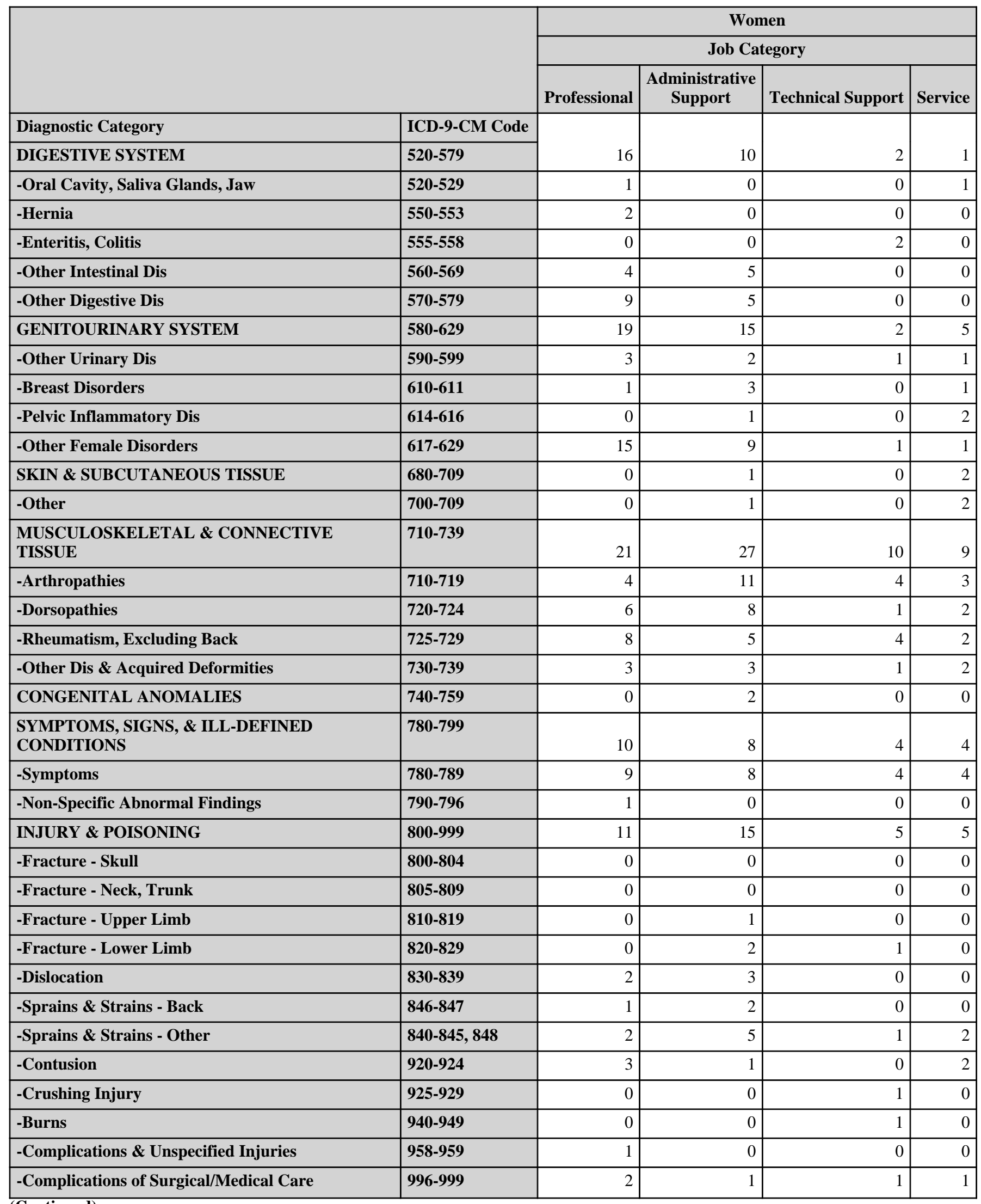

(Continued)

*Only those diagnostic categories and gender/job category combinations with at least one occurrence appear in this table. 


\section{Y-12 National Security Complex 2007}

Absence Data

Appendix I. Number of Diagnoses in Each Diagnostic Category by Gender and Job Category*

\begin{tabular}{|c|c|c|c|c|c|}
\hline & & \multicolumn{4}{|c|}{ Women } \\
\hline & & \multicolumn{3}{|c|}{ Job Category } & \multirow[b]{2}{*}{ TOTAL } \\
\hline & & Security and Fire & Crafts & Line Operators & \\
\hline Diagnostic Category & ICD-9-CM Code & \multirow[b]{2}{*}{0} & \multirow[b]{2}{*}{4} & \multirow[b]{2}{*}{0} & \multirow[b]{2}{*}{33} \\
\hline DIGESTIVE SYSTEM & $520-579$ & & & & \\
\hline -Oral Cavity, Saliva Glands, Jaw & $520-529$ & 0 & 0 & 0 & 2 \\
\hline -Hernia & $550-553$ & 0 & 0 & 0 & 2 \\
\hline -Enteritis, Colitis & $555-558$ & 0 & 1 & 0 & 3 \\
\hline -Other Intestinal Dis & $560-569$ & 0 & 2 & 0 & 11 \\
\hline -Other Digestive Dis & $570-579$ & 0 & 1 & 0 & 15 \\
\hline GENITOURINARY SYSTEM & $580-629$ & 0 & 0 & 1 & 42 \\
\hline -Other Urinary Dis & $590-599$ & 0 & 0 & 0 & 7 \\
\hline -Breast Disorders & 610-611 & 0 & 0 & 0 & 5 \\
\hline -Pelvic Inflammatory Dis & 614-616 & 0 & 0 & 0 & 3 \\
\hline -Other Female Disorders & $617-629$ & 0 & 0 & 1 & 27 \\
\hline SKIN \& SUBCUTANEOUS TISSUE & 680-709 & 0 & 0 & 0 & 3 \\
\hline -Other & 700-709 & 0 & 0 & 0 & 3 \\
\hline $\begin{array}{l}\text { MUSCULOSKELETAL \& CONNECTIVE } \\
\text { TISSUE }\end{array}$ & 710-739 & 2 & 1 & 9 & 79 \\
\hline -Arthropathies & $710-719$ & 1 & 0 & 2 & 25 \\
\hline -Dorsopathies & $720-724$ & 0 & 1 & 4 & 22 \\
\hline -Rheumatism, Excluding Back & 725-729 & 0 & 0 & 1 & 20 \\
\hline -Other Dis \& Acquired Deformities & 730-739 & 1 & 0 & 2 & 12 \\
\hline CONGENITAL ANOMALIES & $740-759$ & 0 & 0 & 0 & 2 \\
\hline $\begin{array}{l}\text { SYMPTOMS, SIGNS, \& ILL-DEFINED } \\
\text { CONDITIONS }\end{array}$ & 780-799 & 0 & 2 & 1 & 29 \\
\hline -Symptoms & 780-789 & 0 & 2 & 1 & 28 \\
\hline -Non-Specific Abnormal Findings & $790-796$ & 0 & 0 & 0 & 1 \\
\hline INJURY \& POISONING & $800-999$ & 0 & 1 & 3 & 40 \\
\hline -Fracture - Skull & $800-804$ & 0 & 0 & 1 & 1 \\
\hline -Fracture - Neck, Trunk & 805-809 & 0 & 1 & 0 & 1 \\
\hline -Fracture - Upper Limb & 810-819 & 0 & 0 & 0 & 1 \\
\hline -Fracture - Lower Limb & 820-829 & 0 & 0 & 0 & 3 \\
\hline -Dislocation & $830-839$ & 0 & 0 & 2 & 7 \\
\hline -Sprains \& Strains - Back & 846-847 & 0 & 0 & 0 & 3 \\
\hline -Sprains \& Strains - Other & $840-845,848$ & 0 & 0 & 0 & 10 \\
\hline -Contusion & 920-924 & 0 & 0 & 0 & 6 \\
\hline -Crushing Injury & 925-929 & 0 & 0 & 0 & 1 \\
\hline -Burns & 940-949 & 0 & 0 & 0 & 1 \\
\hline -Complications \& Unspecified Injuries & 958-959 & 0 & 0 & 0 & 1 \\
\hline -Complications of Surgical/Medical Care & 996-999 & 0 & 0 & 0 & 5 \\
\hline
\end{tabular}

(Continued)

*Only those diagnostic categories and gender/job category combinations with at least one occurrence appear in this table. 
Y-12 National Security Complex 2007

Absence Data

Appendix I. Number of Diagnoses in Each Diagnostic Category by Gender and Job Category*

\begin{tabular}{|c|c|c|c|c|c|}
\hline & & \multicolumn{4}{|c|}{ Women } \\
\hline & & \multicolumn{4}{|c|}{ Job Category } \\
\hline & & Professional & $\begin{array}{c}\text { Administrative } \\
\text { Support }\end{array}$ & Technical Support & Service \\
\hline Diagnostic Category & ICD-9-CM Code & \multirow[b]{2}{*}{1} & \multirow[b]{2}{*}{1} & \multirow[b]{2}{*}{0} & \multirow[b]{2}{*}{0} \\
\hline $\begin{array}{l}\text { HEALTH STATUS/HEALTH SERVICE } \\
\text { CONTACT }\end{array}$ & V01-V82 & & & & \\
\hline -Specific Procedures/Aftercare & V50-V59 & 1 & 0 & 0 & 0 \\
\hline
\end{tabular}

*Only those diagnostic categories and gender/job category combinations with at least one occurrence appear in this table. 
Y-12 National Security Complex 2007

Absence Data

Appendix I. Number of Diagnoses in Each Diagnostic Category by Gender and Job Category*

\begin{tabular}{|c|c|c|c|c|c|}
\hline & & \multicolumn{4}{|c|}{ Women } \\
\hline & & \multicolumn{3}{|c|}{ Job Category } & \multirow[b]{2}{*}{ TOTAL } \\
\hline & & Security and Fire & Crafts & Line Operators & \\
\hline Diagnostic Category & ICD-9-CM Code & & & & \\
\hline $\begin{array}{l}\text { HEALTH STATUS/HEALTH SERVICE } \\
\text { CONTACT }\end{array}$ & V01-V82 & 0 & 0 & 0 & 2 \\
\hline -Isolation \& Prophylactic Measures & V07-V09 & 0 & 0 & 0 & 1 \\
\hline -Specific Procedures/Aftercare & V50-V59 & 0 & 0 & 0 & 1 \\
\hline
\end{tabular}

\begin{tabular}{|c|c|c|c|c|c|c|c|c|}
\hline & \multicolumn{8}{|c|}{ Women } \\
\hline & \multicolumn{7}{|c|}{ Job Category } & \multirow[b]{2}{*}{ TOTAL } \\
\hline & Professional & $\begin{array}{c}\text { Administrative } \\
\text { Support }\end{array}$ & $\begin{array}{l}\text { Technical } \\
\text { Support }\end{array}$ & Service & $\begin{array}{c}\text { Security and } \\
\text { Fire }\end{array}$ & Crafts & $\begin{array}{c}\text { Line } \\
\text { Operators }\end{array}$ & \\
\hline Diagnostic Category & \multirow[b]{2}{*}{123} & \multirow[b]{2}{*}{143} & \multirow[b]{2}{*}{45} & \multirow[b]{2}{*}{42} & \multirow[b]{2}{*}{5} & \multirow[b]{2}{*}{8} & \multirow[b]{2}{*}{26} & \multirow[b]{2}{*}{392} \\
\hline Total & & & & & & & & \\
\hline
\end{tabular}

*Only those diagnostic categories and gender/job category combinations with at least one occurrence appear in this table. 


\section{Y-12 National Security Complex 2007}

\section{Absence Data}

Appendix I. Number of Diagnoses in Each Diagnostic Category by Gender and Job Category*

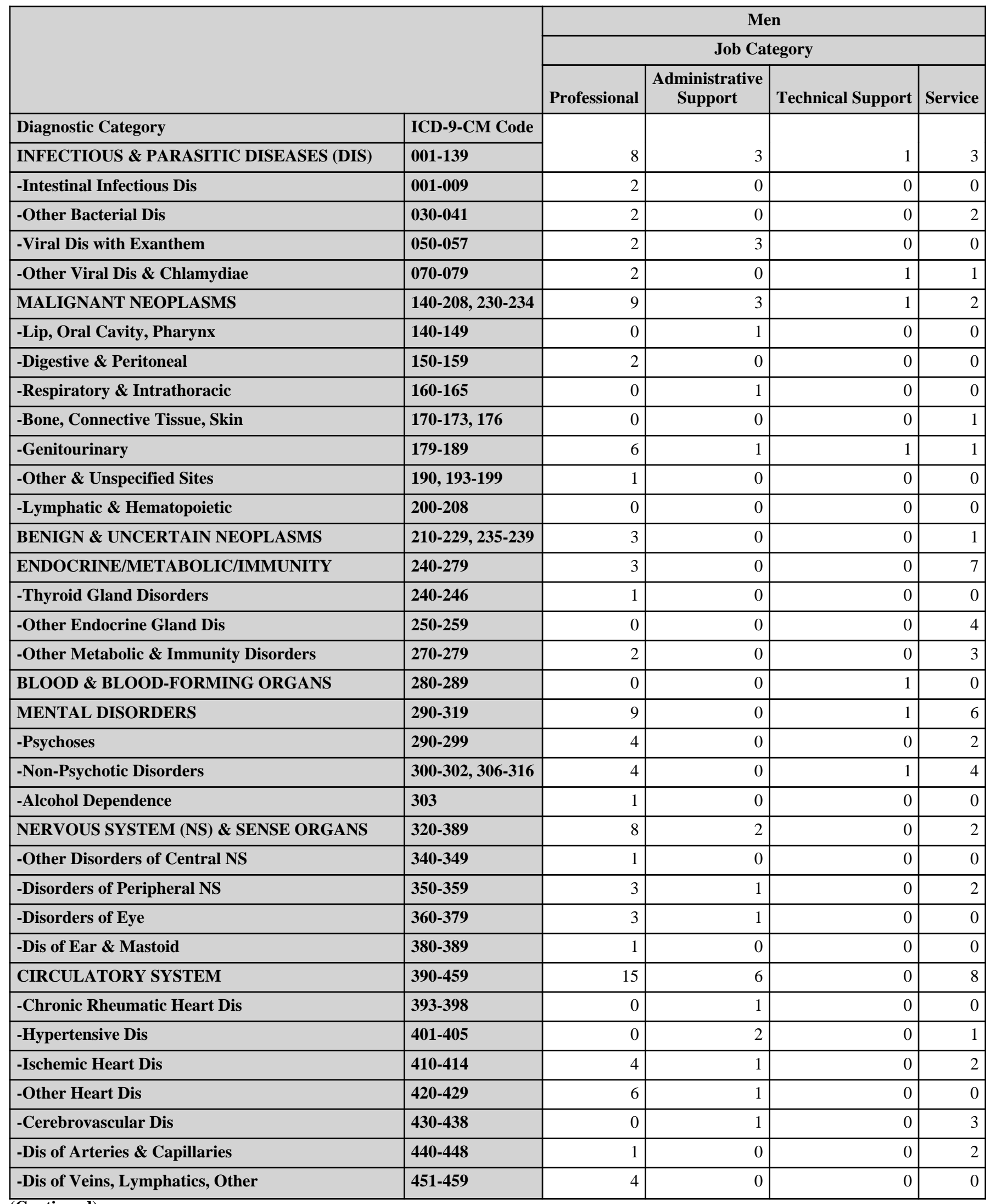

(Continued)

*Only those diagnostic categories and gender/job category combinations with at least one occurrence appear in this table. 


\section{Y-12 National Security Complex 2007}

\section{Absence Data}

Appendix I. Number of Diagnoses in Each Diagnostic Category by Gender and Job Category*

\begin{tabular}{|c|c|c|c|c|c|}
\hline & & \multicolumn{4}{|c|}{ Men } \\
\hline & & \multicolumn{3}{|c|}{ Job Category } & \multirow[b]{2}{*}{ TOTAL } \\
\hline & & Security and Fire & Crafts & Line Operators & \\
\hline Diagnostic Category & ICD-9-CM Code & \multirow[b]{2}{*}{0} & \multirow[b]{2}{*}{3} & \multirow[b]{2}{*}{2} & \multirow[b]{2}{*}{20} \\
\hline INFECTIOUS \& PARASITIC DISEASES (DIS) & 001-139 & & & & \\
\hline -Intestinal Infectious Dis & 001-009 & 0 & 0 & 0 & 2 \\
\hline -Other Bacterial Dis & 030-041 & 0 & 1 & 1 & 6 \\
\hline -Viral Dis with Exanthem & 050-057 & 0 & 1 & 0 & $\overline{6}$ \\
\hline -Other Viral Dis \& Chlamydiae & 070-079 & 0 & 1 & 1 & 6 \\
\hline MALIGNANT NEOPLASMS & 140-208, 230-234 & 0 & 11 & 0 & 26 \\
\hline -Lip, Oral Cavity, Pharynx & $140-149$ & 0 & 1 & 0 & 2 \\
\hline -Digestive \& Peritoneal & 150-159 & 0 & 3 & 0 & 5 \\
\hline -Respiratory \& Intrathoracic & $160-165$ & 0 & 1 & 0 & 2 \\
\hline -Bone, Connective Tissue, Skin & $170-173,176$ & 0 & 2 & 0 & 3 \\
\hline -Genitourinary & 179-189 & 0 & 0 & 0 & 9 \\
\hline -Other \& Unspecified Sites & 190, 193-199 & 0 & 3 & 0 & 4 \\
\hline -Lymphatic \& Hematopoietic & $200-208$ & 0 & 1 & 0 & 1 \\
\hline BENIGN \& UNCERTAIN NEOPLASMS & 210-229, 235-239 & 0 & 1 & 0 & 5 \\
\hline ENDOCRINE/METABOLIC/IMMUNITY & $240-279$ & 0 & 2 & 0 & 12 \\
\hline -Thyroid Gland Disorders & $240-246$ & 0 & 1 & 0 & 2 \\
\hline -Other Endocrine Gland Dis & $250-259$ & 0 & 1 & 0 & 5 \\
\hline -Other Metabolic \& Immunity Disorders & $270-279$ & 0 & 0 & 0 & 5 \\
\hline BLOOD \& BLOOD-FORMING ORGANS & $280-289$ & 0 & 0 & 2 & 3 \\
\hline MENTAL DISORDERS & 290-319 & 2 & 4 & 2 & 24 \\
\hline -Psychoses & $290-299$ & 2 & 3 & 1 & 12 \\
\hline -Non-Psychotic Disorders & $300-302,306-316$ & 0 & 1 & 1 & 11 \\
\hline -Alcohol Dependence & 303 & 0 & 0 & 0 & 1 \\
\hline NERVOUS SYSTEM (NS) \& SENSE ORGANS & 320-389 & 3 & 6 & 4 & 25 \\
\hline -Other Disorders of Central NS & $340-349$ & 0 & 1 & 0 & 2 \\
\hline -Disorders of Peripheral NS & $350-359$ & 2 & 3 & 2 & 13 \\
\hline -Disorders of Eye & $360-379$ & 1 & 1 & 2 & 8 \\
\hline -Dis of Ear \& Mastoid & $380-389$ & 0 & 1 & 0 & 2 \\
\hline CIRCULATORY SYSTEM & $390-459$ & 2 & 20 & 8 & 59 \\
\hline -Chronic Rheumatic Heart Dis & 393-398 & 0 & 0 & 0 & 1 \\
\hline -Hypertensive Dis & $401-405$ & 0 & 1 & 0 & 4 \\
\hline -Ischemic Heart Dis & $410-414$ & 0 & 9 & 4 & 20 \\
\hline -Other Heart Dis & $420-429$ & 1 & 2 & 1 & 11 \\
\hline -Cerebrovascular Dis & $430-438$ & 0 & 3 & 0 & 7 \\
\hline -Dis of Arteries \& Capillaries & $440-448$ & 0 & 1 & 0 & 4 \\
\hline -Dis of Veins, Lymphatics, Other & 451-459 & 1 & 4 & 3 & 12 \\
\hline
\end{tabular}

(Continued)

*Only those diagnostic categories and gender/job category combinations with at least one occurrence appear in this table. 


\section{Y-12 National Security Complex 2007}

\section{Absence Data}

Appendix I. Number of Diagnoses in Each Diagnostic Category by Gender and Job Category*

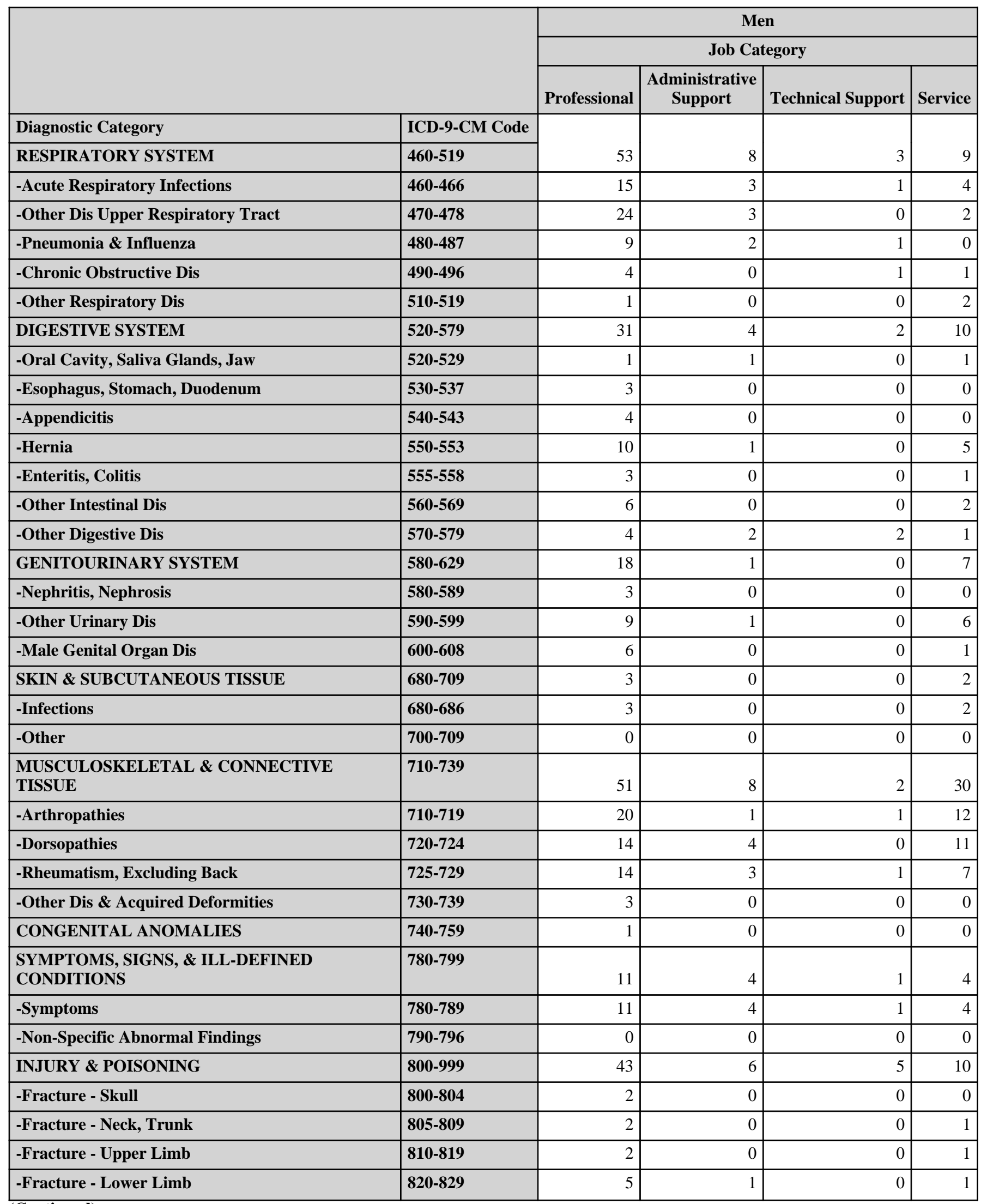

(Continued)

*Only those diagnostic categories and gender/job category combinations with at least one occurrence appear in this table. 


\section{Y-12 National Security Complex 2007}

\section{Absence Data}

Appendix I. Number of Diagnoses in Each Diagnostic Category by Gender and Job Category*

\begin{tabular}{|c|c|c|c|c|c|}
\hline & & \multicolumn{4}{|c|}{ Men } \\
\hline & & \multicolumn{3}{|c|}{ Job Category } & \multirow[b]{2}{*}{ TOTAL } \\
\hline & & Security and Fire & Crafts & Line Operators & \\
\hline Diagnostic Category & ICD-9-CM Code & \multirow[b]{2}{*}{4} & \multirow[b]{2}{*}{23} & \multirow[b]{2}{*}{16} & \multirow[b]{2}{*}{116} \\
\hline RESPIRATORY SYSTEM & $460-519$ & & & & \\
\hline -Acute Respiratory Infections & $460-466$ & 2 & 8 & 3 & 36 \\
\hline -Other Dis Upper Respiratory Tract & $470-478$ & 1 & 7 & 9 & 46 \\
\hline -Pneumonia \& Influenza & $480-487$ & 1 & 6 & 3 & 22 \\
\hline -Chronic Obstructive Dis & $490-496$ & 0 & 1 & 1 & 8 \\
\hline -Other Respiratory Dis & $510-519$ & 0 & 1 & 0 & 4 \\
\hline DIGESTIVE SYSTEM & $520-579$ & 5 & 32 & 12 & 96 \\
\hline -Oral Cavity, Saliva Glands, Jaw & $520-529$ & 0 & 6 & 2 & 11 \\
\hline -Esophagus, Stomach, Duodenum & $530-537$ & 0 & 1 & 0 & 4 \\
\hline -Appendicitis & $540-543$ & 0 & 1 & 1 & 6 \\
\hline -Hernia & $550-553$ & 1 & 3 & 2 & 22 \\
\hline -Enteritis, Colitis & $555-558$ & 0 & 1 & 1 & 6 \\
\hline -Other Intestinal Dis & $560-569$ & 4 & 9 & 1 & 22 \\
\hline -Other Digestive Dis & $570-579$ & 0 & 11 & 5 & 25 \\
\hline GENITOURINARY SYSTEM & $580-629$ & 3 & 11 & 3 & 43 \\
\hline -Nephritis, Nephrosis & $580-589$ & 0 & 1 & 0 & 4 \\
\hline -Other Urinary Dis & $590-599$ & 3 & 5 & 3 & 27 \\
\hline -Male Genital Organ Dis & $600-608$ & 0 & 5 & 0 & 12 \\
\hline SKIN \& SUBCUTANEOUS TISSUE & 680-709 & 0 & 2 & 1 & 8 \\
\hline -Infections & $680-686$ & 0 & 1 & 0 & 6 \\
\hline -Other & 700-709 & 0 & 1 & 1 & 2 \\
\hline $\begin{array}{l}\text { MUSCULOSKELETAL \& CONNECTIVE } \\
\text { TISSUE }\end{array}$ & 710-739 & 12 & 34 & 28 & 165 \\
\hline -Arthropathies & $710-719$ & 3 & 11 & 6 & 54 \\
\hline -Dorsopathies & $720-724$ & 8 & 14 & 13 & 64 \\
\hline -Rheumatism, Excluding Back & 725-729 & 1 & 7 & 8 & 41 \\
\hline -Other Dis \& Acquired Deformities & \begin{tabular}{|l|}
$730-739$ \\
\end{tabular} & 0 & 2 & 1 & 6 \\
\hline CONGENITAL ANOMALIES & $740-759$ & 0 & 0 & 0 & 1 \\
\hline $\begin{array}{l}\text { SYMPTOMS, SIGNS, \& ILL-DEFINED } \\
\text { CONDITIONS }\end{array}$ & $780-799$ & 1 & 3 & 5 & 29 \\
\hline -Symptoms & $780-789$ & 0 & 1 & 5 & 26 \\
\hline -Non-Specific Abnormal Findings & $790-796$ & 1 & 2 & 0 & 3 \\
\hline INJURY \& POISONING & 800-999 & 5 & 21 & 9 & 99 \\
\hline -Fracture - Skull & 800-804 & 0 & 0 & 0 & 2 \\
\hline -Fracture - Neck, Trunk & 805-809 & 0 & 0 & 0 & 3 \\
\hline -Fracture - Upper Limb & 810-819 & 1 & 1 & 0 & 5 \\
\hline -Fracture - Lower Limb & $820-829$ & 0 & 1 & 0 & 8 \\
\hline
\end{tabular}

(Continued)

*Only those diagnostic categories and gender/job category combinations with at least one occurrence appear in this table. 
Y-12 National Security Complex 2007

Absence Data

Appendix I. Number of Diagnoses in Each Diagnostic Category by Gender and Job Category*

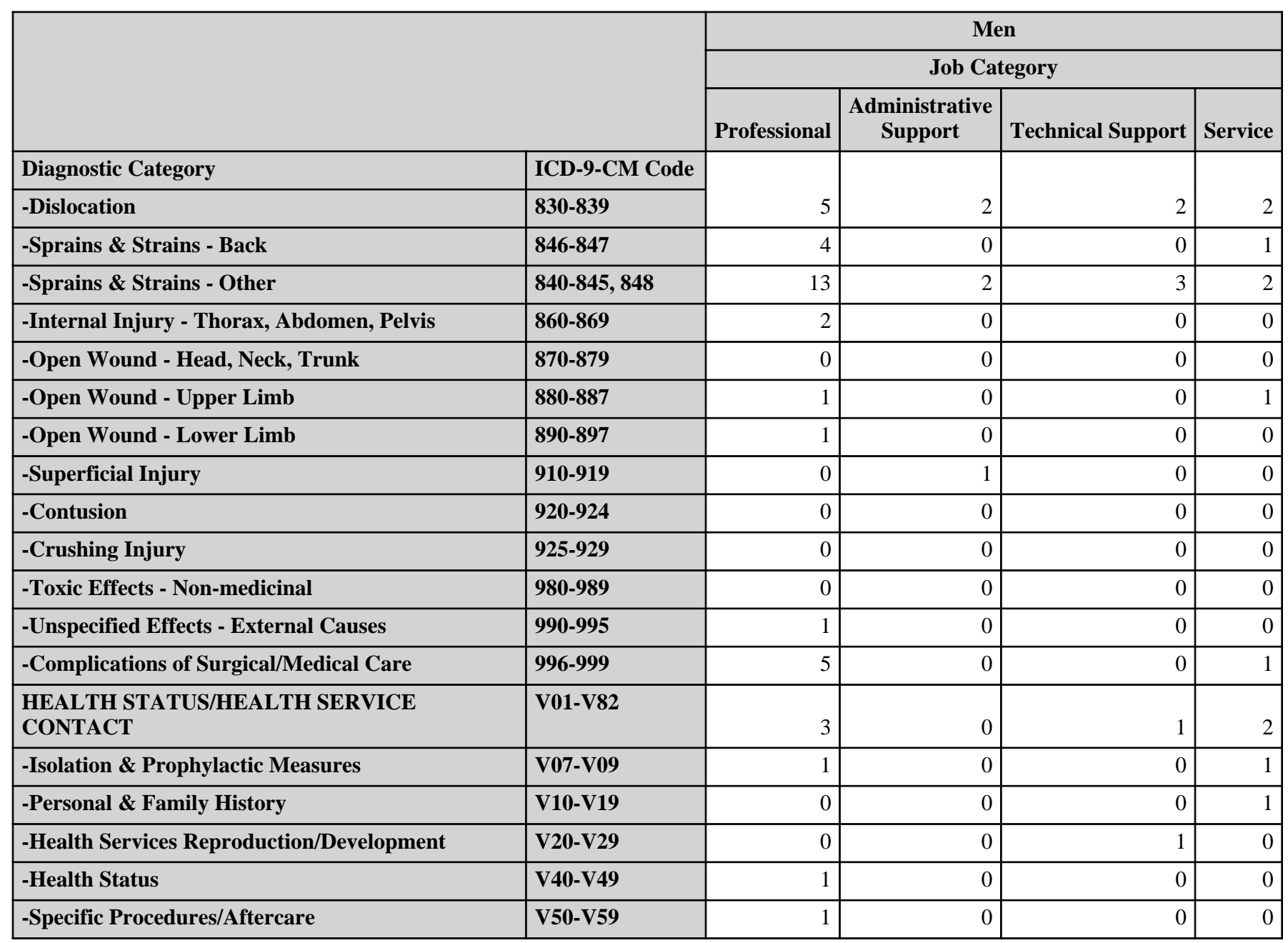

*Only those diagnostic categories and gender/job category combinations with at least one occurrence appear in this table. 
Y-12 National Security Complex 2007

Absence Data

Appendix I. Number of Diagnoses in Each Diagnostic Category by Gender and Job Category*

\begin{tabular}{|c|c|c|c|c|c|}
\hline & & \multicolumn{4}{|c|}{ Men } \\
\hline & & \multicolumn{3}{|c|}{ Job Category } & \multirow[b]{2}{*}{ TOTAL } \\
\hline & & Security and Fire & Crafts & Line Operators & \\
\hline Diagnostic Category & ICD-9-CM Code & \multirow[b]{2}{*}{2} & \multirow[b]{2}{*}{5} & \multirow[b]{2}{*}{2} & \multirow[b]{2}{*}{20} \\
\hline -Dislocation & $830-839$ & & & & \\
\hline -Sprains \& Strains - Back & 846-847 & 0 & 0 & 1 & 6 \\
\hline -Sprains \& Strains - Other & $840-845,848$ & 0 & 8 & 3 & 31 \\
\hline -Internal Injury - Thorax, Abdomen, Pelvis & $860-869$ & 0 & 0 & 0 & 2 \\
\hline -Open Wound - Head, Neck, Trunk & 870-879 & 0 & 1 & 0 & 1 \\
\hline -Open Wound - Upper Limb & $880-887$ & 1 & 0 & 0 & 3 \\
\hline -Open Wound - Lower Limb & $890-897$ & 0 & 1 & 0 & 2 \\
\hline -Superficial Injury & $910-919$ & 0 & 1 & 0 & 2 \\
\hline -Contusion & $920-924$ & 0 & 1 & 1 & 2 \\
\hline -Crushing Injury & $925-929$ & 0 & 1 & 0 & 1 \\
\hline -Toxic Effects - Non-medicinal & $980-989$ & 0 & 0 & 1 & 1 \\
\hline -Unspecified Effects - External Causes & $990-995$ & 0 & 0 & 0 & 1 \\
\hline -Complications of Surgical/Medical Care & 996-999 & 1 & 1 & 1 & 9 \\
\hline $\begin{array}{l}\text { HEALTH STATUS/HEALTH SERVICE } \\
\text { CONTACT }\end{array}$ & V01-V82 & 0 & 3 & 0 & 9 \\
\hline -Isolation \& Prophylactic Measures & V07-V09 & 0 & 0 & 0 & 2 \\
\hline -Personal \& Family History & V10-V19 & 0 & 0 & 0 & 1 \\
\hline -Health Services Reproduction/Development & V20-V29 & 0 & 3 & 0 & 4 \\
\hline -Health Status & V40-V49 & 0 & 0 & 0 & 1 \\
\hline -Specific Procedures/Aftercare & V50-V59 & 0 & 0 & 0 & 1 \\
\hline
\end{tabular}

\begin{tabular}{|c|c|c|c|c|c|c|c|c|}
\hline & \multicolumn{8}{|c|}{ Men } \\
\hline & \multicolumn{7}{|c|}{ Job Category } & \multirow[b]{2}{*}{ TOTAL } \\
\hline & Professional & $\begin{array}{c}\text { Administrative } \\
\text { Support }\end{array}$ & $\begin{array}{l}\text { Technical } \\
\text { Support }\end{array}$ & Service & $\begin{array}{c}\text { Security and } \\
\text { Fire }\end{array}$ & Crafts & $\begin{array}{c}\text { Line } \\
\text { Operators }\end{array}$ & \\
\hline Diagnostic Category & \multirow[b]{2}{*}{269} & \multirow[b]{2}{*}{45} & \multirow[b]{2}{*}{18} & \multirow[b]{2}{*}{103} & \multirow[b]{2}{*}{37} & \multirow[b]{2}{*}{176} & \multirow[b]{2}{*}{92} & \multirow[b]{2}{*}{740} \\
\hline Total & & & & & & & & \\
\hline
\end{tabular}

*Only those diagnostic categories and gender/job category combinations with at least one occurrence appear in this table. 
Y-12 National Security Complex 2007

Absence Data

Appendix J. Total Number of Calendar Days Absent in Each Diagnostic Category by Gender and Job Category*

\begin{tabular}{|c|c|c|c|c|c|}
\hline & & \multicolumn{4}{|c|}{ Women } \\
\hline & & \multicolumn{4}{|c|}{ Job Category } \\
\hline & & Professional & $\underset{\text { Support }}{\text { Administrative }}$ & Technical Support & Service \\
\hline Diagnostic Category & ICD-9-CM Code & \multirow[b]{2}{*}{48} & \multirow[b]{2}{*}{259} & \multirow[b]{2}{*}{43} & \multirow[b]{2}{*}{28} \\
\hline INFECTIOUS \& PARASITIC DISEASES (DIS) & 001-139 & & & & \\
\hline MALIGNANT NEOPLASMS & $140-208,230-234$ & 307 & 319 & 0 & 0 \\
\hline BENIGN \& UNCERTAIN NEOPLASMS & 210-229, 235-239 & 117 & 239 & 0 & 0 \\
\hline ENDOCRINE/METABOLIC/IMMUNITY & $240-279$ & 216 & 292 & 44 & 26 \\
\hline MENTAL DISORDERS & $290-319$ & 62 & 384 & 0 & 184 \\
\hline NERVOUS SYSTEM (NS) \& SENSE ORGANS & $320-389$ & 60 & 251 & 149 & 26 \\
\hline CIRCULATORY SYSTEM & $390-459$ & 326 & 402 & 0 & 49 \\
\hline RESPIRATORY SYSTEM & $460-519$ & 141 & 180 & 110 & 101 \\
\hline DIGESTIVE SYSTEM & $520-579$ & 205 & 279 & 24 & 31 \\
\hline GENITOURINARY SYSTEM & $580-629$ & 342 & 341 & 68 & 200 \\
\hline SKIN \& SUBCUTANEOUS TISSUE & 680-709 & 0 & 12 & 0 & 48 \\
\hline $\begin{array}{l}\text { MUSCULOSKELETAL \& CONNECTIVE } \\
\text { TISSUE }\end{array}$ & 710-739 & 833 & 725 & 262 & 807 \\
\hline CONGENITAL ANOMALIES & 740-759 & 0 & 147 & 0 & 0 \\
\hline $\begin{array}{l}\text { SYMPTOMS, SIGNS, \& ILL-DEFINED } \\
\text { CONDITIONS }\end{array}$ & 780-799 & 112 & 175 & 40 & 217 \\
\hline INJURY \& POISONING & $800-999$ & 274 & 792 & 135 & 152 \\
\hline
\end{tabular}

\footnotetext{
*Absences with >1 ICD-9-CM code in the same diagnostic category were counted only once. Only those diagnostic categories and gender/job category combinations with at least one occurrence appear in this table.
} 
Y-12 National Security Complex 2007

Absence Data

Appendix J. Total Number of Calendar Days Absent in Each Diagnostic Category by Gender and Job Category*

\begin{tabular}{|c|c|c|c|c|c|}
\hline & & \multicolumn{4}{|c|}{ Women } \\
\hline & & \multicolumn{3}{|c|}{ Job Category } & \multirow[b]{2}{*}{ TOTAL } \\
\hline & & Security and Fire & Crafts & Line Operators & \\
\hline Diagnostic Category & ICD-9-CM Code & \multirow[b]{2}{*}{0} & \multirow[b]{2}{*}{0} & \multirow[b]{2}{*}{0} & \multirow[b]{2}{*}{378} \\
\hline INFECTIOUS \& PARASITIC DISEASES (DIS) & 001-139 & & & & \\
\hline MALIGNANT NEOPLASMS & $140-208,230-234$ & 0 & 0 & 0 & 626 \\
\hline BENIGN \& UNCERTAIN NEOPLASMS & 210-229, 235-239 & 0 & 0 & 24 & 380 \\
\hline ENDOCRINE/METABOLIC/IMMUNITY & $240-279$ & 0 & 0 & 11 & 589 \\
\hline MENTAL DISORDERS & 290-319 & 0 & 0 & 22 & 652 \\
\hline NERVOUS SYSTEM (NS) \& SENSE ORGANS & 320-389 & 0 & 0 & 50 & 536 \\
\hline CIRCULATORY SYSTEM & $390-459$ & 10 & 0 & 24 & 811 \\
\hline RESPIRATORY SYSTEM & $460-519$ & 22 & 0 & 49 & 603 \\
\hline DIGESTIVE SYSTEM & $520-579$ & 0 & 65 & 0 & 604 \\
\hline GENITOURINARY SYSTEM & $580-629$ & 0 & 0 & 17 & 968 \\
\hline SKIN \& SUBCUTANEOUS TISSUE & 680-709 & 0 & 0 & 0 & 60 \\
\hline $\begin{array}{l}\text { MUSCULOSKELETAL \& CONNECTIVE } \\
\text { TISSUE }\end{array}$ & $710-739$ & 146 & 8 & 721 & 3,502 \\
\hline CONGENITAL ANOMALIES & 740-759 & 0 & 0 & 0 & 147 \\
\hline $\begin{array}{l}\text { SYMPTOMS, SIGNS, \& ILL-DEFINED } \\
\text { CONDITIONS }\end{array}$ & 780-799 & 0 & 76 & 23 & 643 \\
\hline INJURY \& POISONING & 800-999 & 0 & 98 & 140 & 1,591 \\
\hline
\end{tabular}

\footnotetext{
*Absences with >1 ICD-9-CM code in the same diagnostic category were counted only once. Only those diagnostic categories and gender/job category combinations with at least one occurrence appear in this table.
} 
Y-12 National Security Complex 2007

Absence Data

Appendix J. Total Number of Calendar Days Absent in Each Diagnostic Category by Gender and Job Category*

\begin{tabular}{|c|c|c|c|c|c|}
\hline & \multicolumn{4}{|c|}{ Men } \\
\hline & & \multicolumn{4}{|c|}{ Job Category } \\
\hline & & Professional & $\begin{array}{c}\text { Administrative } \\
\text { Support }\end{array}$ & Technical Support & Service \\
\hline Diagnostic Category & ICD-9-CM Code & \multirow[b]{2}{*}{163} & \multirow[b]{2}{*}{45} & \multirow[b]{2}{*}{7} & \multirow[b]{2}{*}{201} \\
\hline INFECTIOUS \& PARASITIC DISEASES (DIS) & 001-139 & & & & \\
\hline MALIGNANT NEOPLASMS & $140-208,230-234$ & 465 & 413 & 7 & 23 \\
\hline BENIGN \& UNCERTAIN NEOPLASMS & 210-229, 235-239 & 70 & 0 & 0 & 13 \\
\hline ENDOCRINE/METABOLIC/IMMUNITY & $240-279$ & 30 & 0 & 0 & 543 \\
\hline BLOOD \& BLOOD-FORMING ORGANS & $280-289$ & 0 & 0 & 6 & 0 \\
\hline MENTAL DISORDERS & $290-319$ & 309 & 0 & 181 & 555 \\
\hline NERVOUS SYSTEM (NS) \& SENSE ORGANS & $320-389$ & 113 & 17 & 0 & 222 \\
\hline CIRCULATORY SYSTEM & $390-459$ & 675 & 267 & 0 & 417 \\
\hline RESPIRATORY SYSTEM & $460-519$ & 593 & 103 & 20 & 141 \\
\hline DIGESTIVE SYSTEM & $520-579$ & 942 & 83 & 145 & 446 \\
\hline GENITOURINARY SYSTEM & $580-629$ & 440 & 18 & 0 & 131 \\
\hline SKIN \& SUBCUTANEOUS TISSUE & $680-709$ & 191 & 0 & 0 & 31 \\
\hline $\begin{array}{l}\text { MUSCULOSKELETAL \& CONNECTIVE } \\
\text { TISSUE }\end{array}$ & 710-739 & 1,898 & 268 & 66 & 1,814 \\
\hline CONGENITAL ANOMALIES & 740-759 & 7 & 0 & 0 & 0 \\
\hline $\begin{array}{l}\text { SYMPTOMS, SIGNS, \& ILL-DEFINED } \\
\text { CONDITIONS }\end{array}$ & 780-799 & 260 & 45 & 7 & 406 \\
\hline INJURY \& POISONING & $800-999$ & 1,618 & 234 & 404 & 374 \\
\hline
\end{tabular}

\footnotetext{
*Absences with >1 ICD-9-CM code in the same diagnostic category were counted only once. Only those diagnostic categories and gender/job category combinations with at least one occurrence appear in this table.
} 
Y-12 National Security Complex 2007

Absence Data

Appendix J. Total Number of Calendar Days Absent in Each Diagnostic Category by Gender and Job Category*

\begin{tabular}{|c|c|c|c|c|c|}
\hline & & \multicolumn{4}{|c|}{ Men } \\
\hline & & \multicolumn{3}{|c|}{ Job Category } & \multirow[b]{2}{*}{ TOTAL } \\
\hline & & Security and Fire & Crafts & Line Operators & \\
\hline Diagnostic Category & ICD-9-CM Code & \multirow[b]{2}{*}{0} & \multirow[b]{2}{*}{69} & \multirow[b]{2}{*}{53} & \multirow[b]{2}{*}{538} \\
\hline INFECTIOUS \& PARASITIC DISEASES (DIS) & $001-139$ & & & & \\
\hline MALIGNANT NEOPLASMS & $140-208,230-234$ & 0 & 658 & 0 & 1,566 \\
\hline BENIGN \& UNCERTAIN NEOPLASMS & 210-229, 235-239 & 0 & 69 & 0 & 152 \\
\hline ENDOCRINE/METABOLIC/IMMUNITY & $240-279$ & 0 & 31 & 0 & 604 \\
\hline BLOOD \& BLOOD-FORMING ORGANS & $280-289$ & 0 & 0 & 70 & 76 \\
\hline MENTAL DISORDERS & $290-319$ & 117 & 74 & 174 & 1,410 \\
\hline NERVOUS SYSTEM (NS) \& SENSE ORGANS & $320-389$ & 112 & 245 & 73 & 782 \\
\hline CIRCULATORY SYSTEM & $390-459$ & 110 & 1,025 & 212 & 2,706 \\
\hline RESPIRATORY SYSTEM & $460-519$ & 14 & 306 & 393 & 1,570 \\
\hline DIGESTIVE SYSTEM & $520-579$ & 88 & 408 & 207 & 2,319 \\
\hline GENITOURINARY SYSTEM & $580-629$ & 23 & 361 & 30 & 1,003 \\
\hline SKIN \& SUBCUTANEOUS TISSUE & $680-709$ & 0 & 59 & 13 & 294 \\
\hline $\begin{array}{l}\text { MUSCULOSKELETAL \& CONNECTIVE } \\
\text { TISSUE }\end{array}$ & $710-739$ & 591 & 2,538 & 1,341 & 8,516 \\
\hline CONGENITAL ANOMALIES & 740-759 & 0 & 0 & 0 & 7 \\
\hline $\begin{array}{l}\text { SYMPTOMS, SIGNS, \& ILL-DEFINED } \\
\text { CONDITIONS }\end{array}$ & 780-799 & 7 & 148 & 160 & 1,033 \\
\hline INJURY \& POISONING & $800-999$ & 579 & 1,618 & 590 & 5,417 \\
\hline
\end{tabular}

\footnotetext{
*Absences with >1 ICD-9-CM code in the same diagnostic category were counted only once. Only those diagnostic categories and gender/job category combinations with at least one occurrence appear in this table.
} 


\section{Y-12 National Security Complex 2007}

\section{Absence Data}

Appendix K. Age-Adjusted Illness and Injury Rates by Diagnostic Category*

Part 1. Men

\begin{tabular}{|c|c|c|c|c|c|}
\hline & & $\begin{array}{l}\text { Number of } \\
\text { Diagnoses }\end{array}$ & $\begin{array}{c}\text { Age-Adjusted } \\
\text { Rate per } 1,000 * *\end{array}$ & $\begin{array}{c}\text { Lower } 95 \% \\
\text { Confidence } \\
\text { Limit per 1,000 }\end{array}$ & $\begin{array}{c}\text { Upper } 95 \% \\
\text { Confidence } \\
\text { Limit per 1,000 }\end{array}$ \\
\hline Diagnostic Category & ICD-9-CM Code & \multirow[b]{2}{*}{20} & \multirow[b]{2}{*}{7.0} & \multirow[b]{2}{*}{3.9} & \multirow[b]{2}{*}{12.6} \\
\hline INFECTIOUS \& PARASITIC DISEASES (DIS) & 001-139 & & & & \\
\hline -Intestinal Infectious Dis & 001-009 & 2 & 0.7 & 0.1 & 3.5 \\
\hline -Other Bacterial Dis & 030-041 & 6 & 2.0 & 0.6 & 6.2 \\
\hline -Viral Dis with Exanthem & 050-057 & 6 & 2.2 & 0.8 & 6.3 \\
\hline -Other Viral Dis \& Chlamydiae & 070-079 & 6 & 2.2 & 0.8 & 6.3 \\
\hline MALIGNANT NEOPLASMS & 140-208, 230-234 & 26 & 4.5 & 2.9 & 7.0 \\
\hline -Lip, Oral Cavity, Pharynx & $140-149$ & 2 & 0.3 & 0.1 & 1.4 \\
\hline -Digestive \& Peritoneal & 150-159 & 5 & 1.2 & 0.4 & 3.5 \\
\hline -Respiratory \& Intrathoracic & $160-165$ & 2 & 0.3 & 0.1 & 1.4 \\
\hline -Bone, Connective Tissue, Skin & $170-173,176$ & 3 & 0.4 & 0.1 & 1.4 \\
\hline -Genitourinary & 179-189 & 9 & 1.3 & 0.7 & 2.7 \\
\hline -Other \& Unspecified Sites & $190,193-199$ & 4 & 0.6 & 0.2 & 1.8 \\
\hline -Lymphatic \& Hematopoietic & $200-208$ & 1 & 0.2 & 0.0 & 1.5 \\
\hline BENIGN \& UNCERTAIN NEOPLASMS & 210-229, 235-239 & 5 & 0.8 & 0.3 & 1.9 \\
\hline ENDOCRINE/METABOLIC/IMMUNITY & $240-279$ & 12 & 2.1 & 1.1 & 3.9 \\
\hline -Thyroid Gland Disorders & $240-246$ & 2 & 0.4 & 0.1 & 1.7 \\
\hline -Other Endocrine Gland Dis & $250-259$ & 5 & 1.0 & 0.4 & 2.5 \\
\hline -Other Metabolic \& Immunity Disorders & 270-279 & 5 & 0.7 & 0.3 & 1.8 \\
\hline BLOOD \& BLOOD-FORMING ORGANS & $280-289$ & 3 & 1.1 & 0.3 & 3.6 \\
\hline MENTAL DISORDERS & 290-319 & 24 & 8.4 & 5.1 & 13.9 \\
\hline -Psychoses & $290-299$ & 12 & 4.8 & 2.5 & 9.4 \\
\hline -Non-Psychotic Disorders & $300-302,306-316$ & 11 & 3.1 & 1.4 & 6.9 \\
\hline -Alcohol Dependence & 303 & 1 & 0.5 & 0.1 & 3.9 \\
\hline NERVOUS SYSTEM (NS) \& SENSE ORGANS & 320-389 & 25 & 4.9 & 2.9 & 8.2 \\
\hline -Other Disorders of Central NS & $340-349$ & 2 & 0.4 & 0.1 & 1.6 \\
\hline -Disorders of Peripheral NS & $350-359$ & 13 & 2.8 & 1.3 & 6.2 \\
\hline -Disorders of Eye & $360-379$ & 8 & 1.5 & 0.7 & 3.2 \\
\hline -Dis of Ear \& Mastoid & 380-389 & 2 & 0.2 & 0.1 & 0.9 \\
\hline CIRCULATORY SYSTEM & $390-459$ & 59 & 9.9 & 7.4 & 13.2 \\
\hline -Chronic Rheumatic Heart Dis & 393-398 & 1 & 0.1 & 0.0 & 0.8 \\
\hline -Hypertensive Dis & $401-405$ & 4 & 0.6 & 0.2 & 1.8 \\
\hline -Ischemic Heart Dis & $410-414$ & 20 & 3.2 & 1.9 & 5.3 \\
\hline -Other Heart Dis & $420-429$ & 11 & 1.9 & 1.0 & 3.6 \\
\hline -Cerebrovascular Dis & $430-438$ & 7 & 1.1 & 0.5 & 2.4 \\
\hline -Dis of Arteries \& Capillaries & $440-448$ & 4 & 0.4 & 0.2 & 1.1 \\
\hline
\end{tabular}

(Continued)

*Only those diagnostic categories with at least one occurrence appear in this table.

**Standardized to age distribution of 2000 U.S. population. 


\section{Y-12 National Security Complex 2007}

\section{Absence Data}

Appendix K. Age-Adjusted Illness and Injury Rates by Diagnostic Category*

Part 1. Men

\begin{tabular}{|c|c|c|c|c|c|}
\hline & & $\begin{array}{l}\text { Number of } \\
\text { Diagnoses }\end{array}$ & $\begin{array}{c}\text { Age-Adjusted } \\
\text { Rate per } 1,000 * *\end{array}$ & $\begin{array}{c}\text { Lower } 95 \% \\
\text { Confidence } \\
\text { Limit per 1,000 }\end{array}$ & $\begin{array}{c}\text { Upper 95\% } \\
\text { Confidence } \\
\text { Limit per 1,000 }\end{array}$ \\
\hline Diagnostic Category & ICD-9-CM Code & \multirow[b]{2}{*}{12} & \multirow[b]{2}{*}{2.5} & \multirow[b]{2}{*}{1.3} & \multirow[b]{2}{*}{4.9} \\
\hline -Dis of Veins, Lymphatics, Other & 451-459 & & & & \\
\hline RESPIRATORY SYSTEM & $460-519$ & 116 & 29.3 & 23.4 & 36.6 \\
\hline -Acute Respiratory Infections & $460-466$ & 36 & 6.1 & 4.3 & 8.7 \\
\hline -Other Dis Upper Respiratory Tract & $470-478$ & 46 & 14.8 & 10.4 & 21.1 \\
\hline -Pneumonia \& Influenza & $480-487$ & 22 & 6.0 & 3.7 & 9.8 \\
\hline -Chronic Obstructive Dis & $490-496$ & 8 & 1.5 & 0.7 & 3.1 \\
\hline -Other Respiratory Dis & $510-519$ & 4 & 0.9 & 0.2 & 3.2 \\
\hline DIGESTIVE SYSTEM & $520-579$ & 96 & 25.2 & 19.3 & 32.8 \\
\hline -Oral Cavity, Saliva Glands, Jaw & $520-529$ & 11 & 2.6 & 1.1 & 6.4 \\
\hline -Esophagus, Stomach, Duodenum & $530-537$ & 4 & 1.2 & 0.4 & 3.6 \\
\hline -Appendicitis & $540-543$ & 6 & 2.4 & 0.9 & 6.4 \\
\hline -Hernia & $550-553$ & 22 & 7.2 & 4.2 & 12.2 \\
\hline -Enteritis, Colitis & $555-558$ & 6 & 1.1 & 0.4 & 3.2 \\
\hline -Other Intestinal Dis & $560-569$ & 22 & 6.7 & 3.9 & 11.3 \\
\hline -Other Digestive Dis & $570-579$ & 25 & 4.0 & 2.5 & 6.3 \\
\hline GENITOURINARY SYSTEM & $580-629$ & 43 & 8.2 & 5.8 & 11.5 \\
\hline -Nephritis, Nephrosis & $580-589$ & 4 & 0.5 & 0.2 & 1.5 \\
\hline -Other Urinary Dis & $590-599$ & 27 & 5.6 & 3.7 & 8.4 \\
\hline -Male Genital Organ Dis & $600-608$ & 12 & 2.1 & 1.0 & 4.1 \\
\hline SKIN \& SUBCUTANEOUS TISSUE & 680-709 & 8 & 1.2 & 0.6 & 2.6 \\
\hline -Infections & $680-686$ & 6 & 1.0 & 0.4 & 2.4 \\
\hline -Other & 700-709 & 2 & 0.2 & 0.1 & 0.9 \\
\hline $\begin{array}{l}\text { MUSCULOSKELETAL \& CONNECTIVE } \\
\text { TISSUE }\end{array}$ & $710-739$ & 165 & 40.2 & 32.9 & 49.1 \\
\hline -Arthropathies & $710-719$ & 54 & 11.5 & 8.2 & 16.1 \\
\hline -Dorsopathies & $720-724$ & 64 & 17.1 & 12.4 & 23.6 \\
\hline -Rheumatism, Excluding Back & 725-729 & 41 & 10.6 & 7.1 & 15.7 \\
\hline -Other Dis \& Acquired Deformities & $730-739$ & 6 & 1.1 & 0.4 & 3.2 \\
\hline CONGENITAL ANOMALIES & 740-759 & 1 & 0.1 & 0.0 & 0.8 \\
\hline $\begin{array}{l}\text { SYMPTOMS, SIGNS, \& ILL-DEFINED } \\
\text { CONDITIONS }\end{array}$ & $780-799$ & 29 & 6.5 & 4.3 & 9.9 \\
\hline -Symptoms & 780-789 & 26 & 5.4 & 3.5 & 8.5 \\
\hline -Non-Specific Abnormal Findings & $790-796$ & 3 & 1.1 & 0.3 & 3.6 \\
\hline INJURY \& POISONING & $800-999$ & 99 & 26.3 & 20.2 & 34.2 \\
\hline -Fracture - Skull & $800-804$ & 5 & 0.5 & 0.2 & 1.3 \\
\hline -Fracture - Upper Limb & $810-819$ & 5 & 1.1 & 0.4 & 3.3 \\
\hline
\end{tabular}

(Continued)

*Only those diagnostic categories with at least one occurrence appear in this table.

**Standardized to age distribution of 2000 U.S. population. 
Y-12 National Security Complex 2007

Absence Data

Appendix K. Age-Adjusted IIIness and Injury Rates by Diagnostic Category*

Part 1. Men

\begin{tabular}{|c|c|c|c|c|c|}
\hline & & $\begin{array}{c}\text { Number of } \\
\text { Diagnoses }\end{array}$ & $\begin{array}{c}\text { Age-Adjusted } \\
\text { Rate per } 1,000 * *\end{array}$ & $\begin{array}{c}\text { Lower } 95 \% \\
\text { Confidence } \\
\text { Limit per 1,000 }\end{array}$ & $\begin{array}{c}\text { Upper } 95 \% \\
\text { Confidence } \\
\text { Limit per 1,000 }\end{array}$ \\
\hline Diagnostic Category & ICD-9-CM Code & \multirow[b]{2}{*}{8} & \multirow[b]{2}{*}{1.2} & \multirow[b]{2}{*}{0.5} & \multirow[b]{2}{*}{2.5} \\
\hline -Fracture - Lower Limb & $820-829$ & & & & \\
\hline -Dislocation & $830-839$ & 20 & 4.8 & 2.8 & 8.2 \\
\hline -Sprains \& Strains - Back & 846-847 & 6 & 1.2 & 0.4 & 3.4 \\
\hline -Sprains \& Strains - Other & $840-845,848$ & 31 & 10.2 & 6.4 & 16.2 \\
\hline -Internal Injury - Thorax, Abdomen, Pelvis & $860-869$ & 2 & 1.1 & 0.3 & 4.4 \\
\hline -Open Wound - Head, Neck, Trunk & $870-879$ & 6 & 1.7 & 0.5 & 5.6 \\
\hline -Superficial Injury & 910-919 & 2 & 0.7 & 0.1 & 3.5 \\
\hline -Contusion & $920-924$ & 2 & 1.2 & 0.2 & 6.2 \\
\hline -Crushing Injury & 925-929 & 1 & 0.5 & 0.1 & 3.9 \\
\hline -Toxic Effects - Non-medicinal & $980-989$ & 1 & 0.2 & 0.0 & 1.5 \\
\hline -Unspecified Effects - External Causes & $990-995$ & 1 & 0.2 & 0.0 & 1.5 \\
\hline -Complications of Surgical/Medical Care & 996-999 & 9 & 1.7 & 0.7 & 3.8 \\
\hline Total & & 731 & 175.6 & 159.8 & 192.9 \\
\hline
\end{tabular}

* Only those diagnostic categories with at least one occurrence appear in this table.

**Standardized to age distribution of 2000 U.S. population. 


\section{Y-12 National Security Complex 2007}

\section{Absence Data}

Appendix K. Age-Adjusted Illness and Injury Rates by Diagnostic Category*

Part 2. Women

\begin{tabular}{|c|c|c|c|c|c|}
\hline & & $\begin{array}{l}\text { Number of } \\
\text { Diagnoses }\end{array}$ & $\begin{array}{c}\text { Age-Adjusted } \\
\text { Rate per } 1,000^{* *}\end{array}$ & \begin{tabular}{|c|} 
Lower $95 \%$ \\
Confidence \\
Limit per 1,000
\end{tabular} & $\begin{array}{c}\text { Upper } 95 \% \\
\text { Confidence } \\
\text { Limit per 1,000 }\end{array}$ \\
\hline Diagnostic Category & ICD-9-CM Code & & & & \\
\hline INFECTIOUS \& PARASITIC DISEASES (DIS) & 001-139 & 13 & 8.1 & 4.2 & 15.7 \\
\hline -Intestinal Infectious Dis & 001-009 & 2 & 2.6 & 0.6 & 10.5 \\
\hline -Other Bacterial Dis & 030-041 & 5 & 1.8 & 0.8 & 4.5 \\
\hline -Polio \& Other Viral CNS Dis & 045-049 & 1 & 0.5 & 0.1 & 3.7 \\
\hline -Viral Dis with Exanthem & 050-057 & 1 & 0.3 & 0.0 & 2.3 \\
\hline -Other Viral Dis \& Chlamydiae & 070-079 & 4 & 2.9 & 0.9 & 9.1 \\
\hline MALIGNANT NEOPLASMS & $140-208,230-234$ & 16 & 8.7 & 4.8 & 16.1 \\
\hline -Respiratory \& Intrathoracic & $160-165$ & 1 & 0.3 & 0.0 & 2.3 \\
\hline -Bone, Connective Tissue, Skin & 170-173, 176 & 1 & 0.5 & 0.1 & 3.7 \\
\hline -Breast & 174-175 & 7 & 3.7 & 1.4 & 9.3 \\
\hline -Other \& Unspecified Sites & $190,193-199$ & 5 & 2.8 & 0.9 & 8.8 \\
\hline -Lymphatic \& Hematopoietic & 200-208 & 1 & 1.1 & 0.2 & 7.7 \\
\hline -Carcinoma in situ & 230-234 & 1 & 0.3 & 0.0 & 2.3 \\
\hline BENIGN \& UNCERTAIN NEOPLASMS & 210-229, 235-239 & 10 & 5.2 & 2.5 & 10.9 \\
\hline ENDOCRINE/METABOLIC/IMMUNITY & $240-279$ & 12 & 11.0 & 5.3 & 22.6 \\
\hline -Thyroid Gland Disorders & $240-246$ & 4 & 4.6 & 1.6 & 13.0 \\
\hline -Other Endocrine Gland Dis & 250-259 & 6 & 3.3 & 1.2 & 9.1 \\
\hline -Other Metabolic \& Immunity Disorders & 270-279 & 2 & 3.0 & 0.5 & 17.7 \\
\hline MENTAL DISORDERS & $290-319$ & 11 & 5.7 & 2.9 & 11.5 \\
\hline -Psychoses & 290-299 & 5 & 3.4 & 1.2 & 9.5 \\
\hline -Non-Psychotic Disorders & $300-302,306-316$ & 6 & 2.4 & 1.0 & 5.4 \\
\hline NERVOUS SYSTEM (NS) \& SENSE ORGANS & 320-389 & 20 & 15.4 & 9.4 & 25.3 \\
\hline -Other Disorders of Central NS & $340-349$ & 2 & 2.0 & 0.4 & 9.4 \\
\hline -Disorders of Peripheral NS & 350-359 & 8 & 3.6 & 1.8 & 7.3 \\
\hline -Disorders of Eye & $360-379$ & 3 & 3.3 & 1.1 & 10.1 \\
\hline -Dis of Ear \& Mastoid & 380-389 & 7 & 6.5 & 2.9 & 14.8 \\
\hline CIRCULATORY SYSTEM & $390-459$ & 15 & 8.9 & 5.0 & 16.1 \\
\hline -Hypertensive Dis & 401-405 & 4 & 2.1 & 0.7 & 6.6 \\
\hline -Ischemic Heart Dis & 410-414 & 5 & 3.2 & 1.1 & 8.8 \\
\hline -Cerebrovascular Dis & $430-438$ & 3 & 1.7 & 0.5 & 6.6 \\
\hline -Dis of Veins, Lymphatics, Other & 451-459 & 3 & 1.9 & 0.5 & 6.9 \\
\hline RESPIRATORY SYSTEM & $460-519$ & 65 & 46.0 & 33.8 & 62.7 \\
\hline -Acute Respiratory Infections & $460-466$ & 42 & 25.8 & 17.9 & 37.2 \\
\hline -Other Dis Upper Respiratory Tract & $470-478$ & 15 & 15.9 & 8.4 & 29.9 \\
\hline -Pneumonia \& Influenza & $480-487$ & 4 & 1.3 & 0.5 & 3.5 \\
\hline
\end{tabular}

(Continued)

* Only those diagnostic categories with at least one occurrence appear in this table.

**Standardized to age distribution of 2000 U.S. population. 


\section{Y-12 National Security Complex 2007}

\section{Absence Data}

Appendix K. Age-Adjusted Illness and Injury Rates by Diagnostic Category*

Part 2. Women

\begin{tabular}{|c|c|c|c|c|c|}
\hline & & $\begin{array}{l}\text { Number of } \\
\text { Diagnoses }\end{array}$ & $\begin{array}{c}\text { Age-Adjusted } \\
\text { Rate per } 1,000 * *\end{array}$ & $\begin{array}{c}\text { Lower } 95 \% \\
\text { Confidence } \\
\text { Limit per 1,000 }\end{array}$ & $\begin{array}{c}\text { Upper } 95 \% \\
\text { Confidence } \\
\text { Limit per } 1,000\end{array}$ \\
\hline Diagnostic Category & ICD-9-CM Code & \multirow[b]{2}{*}{4} & \multirow[b]{2}{*}{3.0} & \multirow[b]{2}{*}{1.0} & \multirow[b]{2}{*}{8.9} \\
\hline -Chronic Obstructive Dis & $490-496$ & & & & \\
\hline DIGESTIVE SYSTEM & $520-579$ & 33 & 27.7 & 17.4 & 44.0 \\
\hline -Oral Cavity, Saliva Glands, Jaw & $520-529$ & 2 & 0.9 & 0.2 & 3.5 \\
\hline -Hernia & $550-553$ & 2 & 0.9 & 0.2 & 3.5 \\
\hline -Enteritis, Colitis & $555-558$ & 3 & 2.3 & 0.6 & 9.0 \\
\hline -Other Intestinal Dis & $560-569$ & 11 & 16.0 & 7.8 & 32.9 \\
\hline -Other Digestive Dis & $570-579$ & 15 & 7.6 & 4.3 & 13.4 \\
\hline GENITOURINARY SYSTEM & $580-629$ & 42 & 36.5 & 24.6 & 54.2 \\
\hline -Other Urinary Dis & $590-599$ & 7 & 5.8 & 2.0 & 17.0 \\
\hline -Breast Disorders & $610-611$ & 5 & 4.9 & 1.9 & 13.1 \\
\hline -Pelvic Inflammatory Dis & 614-616 & 3 & 5.9 & 1.7 & 21.3 \\
\hline -Other Female Disorders & 617-629 & 27 & 19.8 & 12.3 & 31.8 \\
\hline SKIN \& SUBCUTANEOUS TISSUE & $680-709$ & 3 & 2.9 & 0.8 & 10.3 \\
\hline -Other & 700-709 & 3 & 2.9 & 0.8 & 10.3 \\
\hline $\begin{array}{l}\text { MUSCULOSKELETAL \& CONNECTIVE } \\
\text { TISSUE }\end{array}$ & $710-739$ & 79 & 50.9 & 38.6 & 67.2 \\
\hline -Arthropathies & $710-719$ & 25 & 13.4 & 8.3 & 21.6 \\
\hline -Dorsopathies & $720-724$ & 22 & 15.9 & 9.6 & 26.5 \\
\hline -Rheumatism, Excluding Back & 725-729 & 20 & 15.3 & 8.7 & 26.9 \\
\hline -Other Dis \& Acquired Deformities & $730-739$ & 12 & 6.3 & 3.1 & 12.5 \\
\hline CONGENITAL ANOMALIES & $740-759$ & 2 & 0.7 & 0.2 & 2.6 \\
\hline $\begin{array}{l}\text { SYMPTOMS, SIGNS, \& ILL-DEFINED } \\
\text { CONDITIONS }\end{array}$ & $780-799$ & 29 & 22.4 & 14.0 & 35.9 \\
\hline -Symptoms & $780-789$ & 28 & 21.9 & 13.5 & 35.4 \\
\hline -Non-Specific Abnormal Findings & $790-796$ & 1 & 0.5 & 0.1 & 3.7 \\
\hline INJURY \& POISONING & $800-999$ & 40 & 24.6 & 16.5 & 36.8 \\
\hline -Fracture - Skull & $800-804$ & 2 & 3.2 & 0.6 & 17.2 \\
\hline -Fracture - Upper Limb & 810-819 & 1 & 0.5 & 0.1 & 3.7 \\
\hline -Fracture - Lower Limb & $820-829$ & 3 & 1.9 & 0.5 & 6.9 \\
\hline -Dislocation & $830-839$ & 7 & 4.2 & 1.8 & 10.1 \\
\hline -Sprains \& Strains - Back & 846-847 & 3 & 1.2 & 0.4 & 3.8 \\
\hline -Sprains \& Strains - Other & $840-845,848$ & 10 & 5.8 & 2.6 & 12.8 \\
\hline -Contusion & $920-924$ & 6 & 2.6 & 1.1 & 5.8 \\
\hline -Crushing Injury & 925-929 & 1 & 0.5 & 0.1 & 3.7 \\
\hline -Burns & $940-949$ & 1 & 0.3 & 0.0 & 2.3 \\
\hline -Complications \& Unspecified Injuries & 958-959 & 1 & 0.3 & 0.0 & 2.3 \\
\hline
\end{tabular}

(Continued)

*Only those diagnostic categories with at least one occurrence appear in this table.

**Standardized to age distribution of 2000 U.S. population. 
Y-12 National Security Complex 2007

Absence Data

Appendix K. Age-Adjusted Illness and Injury Rates by Diagnostic Category*

Part 2. Women

\begin{tabular}{|c|c|c|c|c|c|}
\hline & & $\begin{array}{l}\text { Number of } \\
\text { Diagnoses }\end{array}$ & $\begin{array}{c}\text { Age-Adjusted } \\
\text { Rate per } 1,000^{* *}\end{array}$ & $\begin{array}{c}\text { Lower } 95 \% \\
\text { Confidence } \\
\text { Limit per } 1,000\end{array}$ & $\begin{array}{c}\text { Upper } 95 \% \\
\text { Confidence } \\
\text { Limit per 1,000 }\end{array}$ \\
\hline Diagnostic Category & ICD-9-CM Code & \multirow[b]{2}{*}{5} & \multirow[b]{2}{*}{4.0} & \multirow[b]{2}{*}{1.4} & \multirow[b]{2}{*}{11.7} \\
\hline -Complications of Surgical/Medical Care & 996-999 & & & & \\
\hline Total & & 390 & 274.9 & 241.9 & 312.3 \\
\hline
\end{tabular}

* Only those diagnostic categories with at least one occurrence appear in this table.

**Standardized to age distribution of 2000 U.S. population. 


\section{Y-12 National Security Complex 2007}

\section{Absence Data}

Appendix K. Age-Adjusted Illness and Injury Rates by Diagnostic Category*

Part 3. Men and Women

\begin{tabular}{|c|c|c|c|c|c|}
\hline & & $\begin{array}{c}\text { Number of } \\
\text { Diagnoses }\end{array}$ & $\begin{array}{c}\text { Age-Adjusted } \\
\text { Rate per } 1,000^{* *}\end{array}$ & \begin{tabular}{|c|} 
Lower $95 \%$ \\
Confidence \\
Limit per 1,000
\end{tabular} & $\begin{array}{c}\text { Upper } 95 \% \\
\text { Confidence } \\
\text { Limit per 1,000 }\end{array}$ \\
\hline Diagnostic Category & ICD-9-CM Code & & & & \\
\hline INFECTIOUS \& PARASITIC DISEASES (DIS) & 001-139 & 33 & 7.4 & 4.7 & 11.5 \\
\hline -Intestinal Infectious Dis & 001-009 & 4 & 1.1 & 0.4 & 3.2 \\
\hline -Other Bacterial Dis & 030-041 & 11 & 1.9 & 0.8 & 4.6 \\
\hline -Polio \& Other Viral CNS Dis & 045-049 & 1 & 0.2 & 0.0 & 1.2 \\
\hline -Viral Dis with Exanthem & 050-057 & 7 & 1.7 & 0.6 & 4.6 \\
\hline -Other Viral Dis \& Chlamydiae & 070-079 & 10 & 2.5 & 1.1 & 5.4 \\
\hline MALIGNANT NEOPLASMS & $140-208,230-234$ & 42 & 5.8 & 4.1 & 8.3 \\
\hline -Lip, Oral Cavity, Pharynx & $140-149$ & 2 & 0.3 & 0.1 & 1.2 \\
\hline -Digestive \& Peritoneal & 150-159 & 5 & 0.9 & 0.3 & 2.6 \\
\hline -Respiratory \& Intrathoracic & $160-165$ & 3 & 0.4 & 0.1 & 1.2 \\
\hline -Bone, Connective Tissue, Skin & 170-173, 176 & 4 & 0.5 & 0.2 & 1.5 \\
\hline -Breast & 174-175 & 7 & 1.0 & 0.4 & 2.5 \\
\hline -Genitourinary & 179-189 & 9 & 1.0 & 0.5 & 2.1 \\
\hline -Other \& Unspecified Sites & $190,193-199$ & 9 & 1.3 & 0.6 & 2.8 \\
\hline -Lymphatic \& Hematopoietic & $200-208$ & 2 & 0.4 & 0.1 & 1.5 \\
\hline -Carcinoma in situ & 230-234 & 1 & 0.1 & 0.0 & 0.6 \\
\hline BENIGN \& UNCERTAIN NEOPLASMS & 210-229, 235-239 & 15 & 2.1 & 1.2 & 3.8 \\
\hline ENDOCRINE/METABOLIC/IMMUNITY & $240-279$ & 24 & 4.4 & 2.6 & 7.4 \\
\hline -Thyroid Gland Disorders & $240-246$ & 6 & 1.5 & 0.6 & 3.6 \\
\hline -Other Endocrine Gland Dis & 250-259 & 11 & 1.6 & 0.8 & 3.2 \\
\hline -Other Metabolic \& Immunity Disorders & 270-279 & 7 & 1.3 & 0.4 & 4.1 \\
\hline BLOOD \& BLOOD-FORMING ORGANS & 280-289 & 3 & 0.7 & 0.2 & 2.5 \\
\hline MENTAL DISORDERS & 290-319 & 35 & 7.7 & 5.1 & 11.7 \\
\hline -Psychoses & 290-299 & 17 & 4.5 & 2.5 & 7.9 \\
\hline -Non-Psychotic Disorders & $300-302,306-316$ & 17 & 2.9 & 1.5 & 5.5 \\
\hline -Alcohol Dependence & 303 & 1 & 0.4 & 0.1 & 2.8 \\
\hline NERVOUS SYSTEM (NS) \& SENSE ORGANS & 320-389 & 45 & 7.5 & 5.2 & 10.7 \\
\hline -Other Disorders of Central NS & 340-349 & 4 & 0.8 & 0.3 & 2.5 \\
\hline -Disorders of Peripheral NS & 350-359 & 21 & 3.2 & 1.8 & 5.6 \\
\hline -Disorders of Eye & $360-379$ & 11 & 1.7 & 0.9 & 3.1 \\
\hline -Dis of Ear \& Mastoid & 380-389 & 9 & 1.8 & 0.8 & 3.8 \\
\hline CIRCULATORY SYSTEM & $390-459$ & 74 & 9.5 & 7.4 & 12.3 \\
\hline -Chronic Rheumatic Heart Dis & 393-398 & 1 & 0.1 & 0.0 & 0.6 \\
\hline -Hypertensive Dis & $401-405$ & 8 & 1.0 & 0.5 & 2.1 \\
\hline -Ischemic Heart Dis & $410-414$ & 25 & 3.1 & 2.0 & 4.9 \\
\hline
\end{tabular}

(Continued)

*Only those diagnostic categories with at least one occurrence appear in this table.

**Standardized to age distribution of 2000 U.S. population. 


\section{Y-12 National Security Complex 2007}

\section{Absence Data}

Appendix K. Age-Adjusted Illness and Injury Rates by Diagnostic Category*

Part 3. Men and Women

\begin{tabular}{|c|c|c|c|c|c|}
\hline & & $\begin{array}{l}\text { Number of } \\
\text { Diagnoses }\end{array}$ & $\begin{array}{c}\text { Age-Adjusted } \\
\text { Rate per } 1,000 * *\end{array}$ & $\begin{array}{c}\text { Lower } 95 \% \\
\text { Confidence } \\
\text { Limit per 1,000 }\end{array}$ & $\begin{array}{c}\text { Upper 95\% } \\
\text { Confidence } \\
\text { Limit per 1,000 }\end{array}$ \\
\hline Diagnostic Category & ICD-9-CM Code & \multirow[b]{2}{*}{11} & \multirow[b]{2}{*}{1.5} & \multirow[b]{2}{*}{0.8} & \multirow[b]{2}{*}{2.8} \\
\hline -Other Heart Dis & $420-429$ & & & & \\
\hline -Cerebrovascular Dis & $430-438$ & 10 & 1.2 & 0.6 & 2.4 \\
\hline -Dis of Arteries \& Capillaries & $440-448$ & 4 & 0.3 & 0.1 & 0.9 \\
\hline -Dis of Veins, Lymphatics, Other & $451-459$ & 15 & 2.3 & 1.3 & 4.1 \\
\hline RESPIRATORY SYSTEM & $460-519$ & 181 & 33.4 & 27.9 & 40.0 \\
\hline -Acute Respiratory Infections & $460-466$ & 78 & 11.2 & 8.7 & $\overline{14.6}$ \\
\hline -Other Dis Upper Respiratory Tract & $470-478$ & 61 & 15.0 & 11.0 & 20.4 \\
\hline -Pneumonia \& Influenza & $480-487$ & 26 & 4.8 & 3.0 & 7.5 \\
\hline -Chronic Obstructive Dis & $490-496$ & 12 & 1.8 & 1.0 & 3.2 \\
\hline -Other Respiratory Dis & $510-519$ & 4 & 0.6 & 0.2 & 2.3 \\
\hline DIGESTIVE SYSTEM & $520-579$ & 129 & 25.8 & 20.6 & 32.5 \\
\hline -Oral Cavity, Saliva Glands, Jaw & $520-529$ & 13 & 2.2 & 1.0 & 4.8 \\
\hline -Esophagus, Stomach, Duodenum & $530-537$ & 4 & 0.9 & 0.3 & 2.7 \\
\hline -Appendicitis & $540-543$ & 6 & 1.7 & 0.6 & 4.7 \\
\hline -Hernia & $550-553$ & 24 & 5.6 & 3.4 & 9.2 \\
\hline -Enteritis, Colitis & $555-558$ & 9 & 1.5 & 0.6 & 3.4 \\
\hline -Other Intestinal Dis & $560-569$ & 33 & 8.9 & 5.8 & 13.9 \\
\hline -Other Digestive Dis & $570-579$ & 40 & 5.0 & 3.6 & 7.1 \\
\hline GENITOURINARY SYSTEM & $580-629$ & 85 & 16.2 & 12.4 & 21.3 \\
\hline -Nephritis, Nephrosis & $580-589$ & 4 & 0.4 & 0.1 & 1.3 \\
\hline -Other Urinary Dis & $590-599$ & 34 & 5.7 & 3.7 & 8.6 \\
\hline -Male Genital Organ Dis & $600-608$ & 12 & 1.6 & 0.8 & 3.2 \\
\hline -Breast Disorders & $610-611$ & 5 & 1.2 & 0.5 & 3.3 \\
\hline -Pelvic Inflammatory Dis & 614-616 & 3 & 1.6 & 0.5 & 5.6 \\
\hline -Other Female Disorders & $617-629$ & 27 & 5.7 & 3.6 & 9.0 \\
\hline SKIN \& SUBCUTANEOUS TISSUE & $680-709$ & 11 & 1.6 & 0.8 & 3.3 \\
\hline -Infections & $680-686$ & 6 & 0.8 & 0.3 & 1.9 \\
\hline -Other & 700-709 & 5 & 0.8 & 0.3 & 2.5 \\
\hline $\begin{array}{l}\text { MUSCULOSKELETAL \& CONNECTIVE } \\
\text { TISSUE }\end{array}$ & $710-739$ & 244 & 42.7 & 36.3 & 50.2 \\
\hline -Arthropathies & $710-719$ & 79 & 12.0 & 9.1 & 15.8 \\
\hline -Dorsopathies & $720-724$ & 86 & 16.8 & 12.8 & 22.1 \\
\hline -Rheumatism, Excluding Back & 725-729 & 61 & 11.5 & 8.3 & 15.9 \\
\hline -Other Dis \& Acquired Deformities & 730-739 & 18 & 2.4 & 1.3 & 4.3 \\
\hline CONGENITAL ANOMALIES & $740-759$ & 3 & 0.2 & 0.1 & 0.8 \\
\hline
\end{tabular}

(Continued)

*Only those diagnostic categories with at least one occurrence appear in this table.

**Standardized to age distribution of 2000 U.S. population. 
Y-12 National Security Complex 2007

Absence Data

Appendix K. Age-Adjusted Illness and Injury Rates by Diagnostic Category*

Part 3. Men and Women

\begin{tabular}{|c|c|c|c|c|c|}
\hline & & $\begin{array}{l}\text { Number of } \\
\text { Diagnoses }\end{array}$ & $\begin{array}{c}\text { Age-Adjusted } \\
\text { Rate per 1,000** }\end{array}$ & $\begin{array}{c}\text { Lower } 95 \% \\
\text { Confidence } \\
\text { Limit per } 1,000\end{array}$ & $\begin{array}{c}\text { Upper 95\% } \\
\text { Confidence } \\
\text { Limit per 1,000 }\end{array}$ \\
\hline Diagnostic Category & ICD-9-CM Code & & & & \\
\hline $\begin{array}{l}\text { SYMPTOMS, SIGNS, \& ILL-DEFINED } \\
\text { CONDITIONS }\end{array}$ & $780-799$ & 58 & 10.7 & 7.8 & 14.7 \\
\hline -Symptoms & 780-789 & 54 & 9.8 & 7.0 & 13.7 \\
\hline -Non-Specific Abnormal Findings & $790-796$ & 4 & 0.9 & 0.3 & 2.7 \\
\hline INJURY \& POISONING & $800-999$ & 139 & 26.0 & 20.9 & 32.4 \\
\hline -Fracture - Skull & $800-804$ & 7 & 1.3 & 0.4 & 4.1 \\
\hline -Fracture - Upper Limb & $810-819$ & 6 & 1.0 & 0.4 & 2.6 \\
\hline -Fracture - Lower Limb & $820-829$ & 11 & 1.3 & 0.7 & 2.4 \\
\hline -Dislocation & 830-839 & 27 & 4.7 & 3.0 & 7.4 \\
\hline -Sprains \& Strains - Back & 846-847 & 9 & 1.2 & 0.5 & 2.8 \\
\hline -Sprains \& Strains - Other & $840-845,848$ & 41 & 9.0 & 6.0 & 13.5 \\
\hline -Internal Injury - Thorax, Abdomen, Pelvis & $860-869$ & 2 & 0.8 & 0.2 & 3.2 \\
\hline -Open Wound - Head, Neck, Trunk & 870-879 & 6 & 1.2 & 0.4 & 4.1 \\
\hline -Superficial Injury & 910-919 & 2 & 0.5 & 0.1 & 2.5 \\
\hline -Contusion & $920-924$ & 8 & 1.6 & 0.6 & 4.3 \\
\hline -Crushing Injury & 925-929 & 2 & 0.6 & 0.1 & 2.5 \\
\hline -Burns & $940-949$ & 1 & 0.1 & 0.0 & 0.6 \\
\hline -Complications \& Unspecified Injuries & 958-959 & 1 & 0.1 & 0.0 & 0.6 \\
\hline -Toxic Effects - Non-medicinal & $980-989$ & 1 & 0.2 & 0.0 & 1.3 \\
\hline -Unspecified Effects - External Causes & $990-995$ & 1 & 0.2 & 0.0 & 1.3 \\
\hline -Complications of Surgical/Medical Care & 996-999 & 14 & 2.3 & 1.2 & 4.4 \\
\hline Total & & 1121 & 201.9 & 187.3 & 217.6 \\
\hline
\end{tabular}

* Only those diagnostic categories with at least one occurrence appear in this table.

**Standardized to age distribution of 2000 U.S. population. 


\section{Y-12 National Security Complex 2007}

OSHA Data

Appendix L. Number of Workers with at Least One OSHA Event by Gender, Age, and Job Category*

\begin{tabular}{|c|c|c|c|c|c|c|c|c|c|c|}
\hline \multirow{3}{*}{ Job Category } & \multicolumn{4}{|c|}{ Women } & \multicolumn{5}{|c|}{ Men } & \multirow[b]{3}{*}{ TOTAI } \\
\hline & \multicolumn{3}{|c|}{ Age Group } & \multirow[b]{2}{*}{ TOTAL } & \multicolumn{4}{|c|}{ Age Group } & \multirow[b]{2}{*}{ TOTAL } & \\
\hline & $30-39$ & $40-49$ & $\mathbf{5 0}+$ & & $16-29$ & $30-39$ & $40-49$ & $50+$ & & \\
\hline Professional & 0 & 3 & 1 & 4 & 0 & 0 & 1 & 3 & 4 & 8 \\
\hline Administrative Support & 0 & 4 & 7 & 11 & 0 & 1 & 0 & 0 & 1 & 12 \\
\hline Technical Support & 0 & 0 & 0 & 0 & 0 & 0 & 1 & 0 & 1 & 1 \\
\hline Service & 1 & 2 & 0 & 3 & 0 & 1 & 3 & 4 & 8 & 11 \\
\hline Security and Fire & 0 & 0 & 0 & 0 & 0 & 0 & 1 & 0 & 1 & 1 \\
\hline Crafts & 0 & 0 & 0 & 0 & 2 & 1 & 7 & 25 & 35 & 35 \\
\hline Line Operators & 0 & 0 & 2 & 2 & 1 & 1 & 3 & 0 & 5 & 7 \\
\hline TOTAL & 1 & 9 & 10 & 20 & 3 & 4 & 16 & 32 & 55 & 75 \\
\hline
\end{tabular}

*Only those job categories and gender/age combinations with at least one OSHA event appear in this table.

Appendix M. Total Number of Workdays Lost or with Restricted Activity from OSHA Events by Gender and Age

\begin{tabular}{|c|c|c|c|c|c|c|c|c|c|}
\hline \multirow[b]{2}{*}{ Age Group } & \multicolumn{3}{|c|}{ Women } & \multicolumn{3}{|c|}{ Men } & \multicolumn{3}{|c|}{ TOTAL } \\
\hline & $\begin{array}{l}\text { Number of } \\
\text { Events }\end{array}$ & $\begin{array}{c}\text { Days } \\
\text { Restricted }\end{array}$ & Days Lost & $\begin{array}{c}\text { Number of } \\
\text { Events }\end{array}$ & $\begin{array}{c}\text { Days } \\
\text { Restricted }\end{array}$ & Days Lost & $\begin{array}{l}\text { Number of } \\
\text { Events }\end{array}$ & $\begin{array}{c}\text { Days } \\
\text { Restricted }\end{array}$ & Days Lost \\
\hline $16-29$ & 0 & 0 & 0 & 3 & 0 & 0 & 3 & 0 & 0 \\
\hline $30-39$ & 1 & 57 & 0 & 4 & 0 & 0 & 5 & 57 & 0 \\
\hline $40-49$ & 9 & 36 & 0 & 16 & 153 & 133 & 25 & 189 & 133 \\
\hline $50+$ & 10 & 153 & 113 & 33 & 333 & 573 & 43 & 486 & 686 \\
\hline TOTAL & 20 & 246 & 113 & 56 & 486 & 706 & 76 & 732 & 819 \\
\hline
\end{tabular}

Appendix N. Total Number of Workdays Lost or with Restricted Activity from OSHA Events by Gender and Job Category*

\begin{tabular}{|c|c|c|c|c|c|c|c|c|c|}
\hline \multirow[b]{2}{*}{ Job Category } & \multicolumn{3}{|c|}{ Women } & \multicolumn{3}{|c|}{ Men } & \multicolumn{3}{|c|}{ TOTAL } \\
\hline & $\begin{array}{l}\text { Number of } \\
\text { Events }\end{array}$ & $\begin{array}{c}\text { Days } \\
\text { Restricted }\end{array}$ & Days Lost & $\begin{array}{l}\text { Number of } \\
\text { Events }\end{array}$ & $\begin{array}{c}\text { Days } \\
\text { Restricted }\end{array}$ & Days Lost & $\begin{array}{l}\text { Number of } \\
\text { Events }\end{array}$ & $\begin{array}{c}\text { Days } \\
\text { Restricted }\end{array}$ & Days Lost \\
\hline $\begin{array}{l}\text { Administrative } \\
\text { Support }\end{array}$ & 11 & 53 & 46 & 1 & 0 & 0 & 12 & 53 & 46 \\
\hline Technical Support & 0 & 0 & 0 & 1 & 0 & 55 & 1 & 0 & 55 \\
\hline Security and Fire & 0 & 0 & 0 & 1 & 0 & 0 & 1 & 0 & 0 \\
\hline Crafts & 0 & 0 & 0 & 36 & 437 & 608 & 36 & 437 & 608 \\
\hline Line Operators & 2 & 100 & 67 & 5 & 0 & 13 & 7 & 100 & 80 \\
\hline TOTAL & 20 & 246 & 113 & 56 & 486 & 706 & 76 & 732 & 819 \\
\hline
\end{tabular}

*Only those job categories with at least one OSHA event appear in this table. 
Y-12 National Security Complex 2007

OSHA Data

Appendix O. Number of Diagnoses in Each Diagnostic Category by Gender and Age*

\begin{tabular}{|c|c|c|c|c|c|}
\hline & & \multicolumn{4}{|c|}{ Women } \\
\hline & & \multicolumn{3}{|c|}{ Age Group } & \multirow[b]{2}{*}{ TOTAL } \\
\hline & & 30 - 39 & $40-49$ & $50+$ & \\
\hline Diagnostic Category & ICD-9-CM code & \multirow[b]{2}{*}{0} & \multirow[b]{2}{*}{3} & \multirow[b]{2}{*}{2} & \multirow[b]{2}{*}{5} \\
\hline NERVOUS SYSTEM (NS) \& SENSE ORGANS & $320-389$ & & & & \\
\hline -Disorders of Peripheral NS & 350-359 & 0 & 3 & 2 & 5 \\
\hline -Disorders of Eye & $360-379$ & 0 & 0 & 0 & 0 \\
\hline -Dis of Ear \& Mastoid & $380-389$ & 0 & 0 & 0 & 0 \\
\hline RESPIRATORY SYSTEM & $460-519$ & 0 & 1 & 0 & 1 \\
\hline -Acute Respiratory Infections & $460-466$ & 0 & 0 & 0 & 0 \\
\hline -Other Dis Upper Respiratory Tract & $470-478$ & 0 & 1 & 0 & 1 \\
\hline -Chronic Obstructive Dis & $490-496$ & 0 & 0 & 0 & 0 \\
\hline -Lung Dis from External Agents & $500-508$ & 0 & 0 & 0 & 0 \\
\hline -Other Respiratory Dis & $510-519$ & 0 & 0 & 0 & 0 \\
\hline SKIN \& SUBCUTANEOUS TISSUE & $680-709$ & 0 & 0 & 0 & 0 \\
\hline -Other Inflammatory Conditions & 690-698 & 0 & 0 & 0 & 0 \\
\hline $\begin{array}{l}\text { MUSCULOSKELETAL \& CONNECTIVE } \\
\text { TISSUE }\end{array}$ & $710-739$ & 3 & 9 & 13 & 25 \\
\hline -Arthropathies & $710-719$ & 1 & 5 & 8 & 14 \\
\hline -Dorsopathies & $720-724$ & 0 & 0 & 0 & 0 \\
\hline -Rheumatism, Excluding Back & 725-729 & 2 & 4 & 5 & 11 \\
\hline $\begin{array}{l}\text { SYMPTOMS, SIGNS, \& ILL-DEFINED } \\
\text { CONDITIONS }\end{array}$ & 780-799 & 0 & 6 & 5 & 11 \\
\hline -Symptoms & 780-789 & 0 & 6 & 5 & 11 \\
\hline INJURY \& POISONING & $800-999$ & 0 & 9 & 6 & 15 \\
\hline -Fracture - Upper Limb & 810-819 & 0 & 0 & 1 & 1 \\
\hline -Sprains \& Strains - Back & 846-847 & 0 & 1 & 0 & 1 \\
\hline -Sprains \& Strains - Other & $840-845,848$ & 0 & 2 & 1 & 3 \\
\hline -Open Wound - Head, Neck, Trunk & $870-879$ & 0 & 1 & 0 & 1 \\
\hline -Open Wound - Upper Limb & $880-887$ & 0 & 0 & 0 & 0 \\
\hline -Open Wound - Lower Limb & $890-897$ & 0 & 0 & 0 & 0 \\
\hline -Superficial Injury & 910-919 & 0 & 0 & 0 & 0 \\
\hline -Contusion & $920-924$ & 0 & 4 & 1 & 5 \\
\hline -Crushing Injury & $925-929$ & 0 & 0 & 0 & 0 \\
\hline -Foreign Body Entering Orifice & \begin{tabular}{|l|}
$930-939$ \\
\end{tabular} & 0 & 0 & 0 & 0 \\
\hline -Burns & $940-949$ & 0 & 0 & 0 & 0 \\
\hline -Complications \& Unspecified Injuries & 958-959 & 0 & 0 & 3 & 3 \\
\hline -Toxic Effects - Non-medicinal & 980-989 & 0 & 1 & 0 & 1 \\
\hline
\end{tabular}

*Only those diagnostic categories and gender/age combinations with at least one OSHA event appear in this table. 
Y-12 National Security Complex 2007

OSHA Data

Appendix O. Number of Diagnoses in Each Diagnostic Category by Gender and Age*

\begin{tabular}{|c|c|c|c|c|c|c|c|}
\hline & & \multicolumn{5}{|c|}{ Men } & \multirow[b]{3}{*}{ TOTAL } \\
\hline & & \multicolumn{4}{|c|}{ Age Group } & \multirow[b]{2}{*}{ TOTAL } & \\
\hline & & $16-29$ & 30 - 39 & $40-49$ & $\mathbf{5 0 +}$ & & \\
\hline Diagnostic Category & ICD-9-CM code & & & & & & \\
\hline NERVOUS SYSTEM (NS) \& SENSE ORGANS & $320-389$ & 1 & 1 & 2 & 10 & 14 & 19 \\
\hline -Disorders of Peripheral NS & 350-359 & 0 & 0 & 1 & 2 & 3 & 8 \\
\hline -Disorders of Eye & $360-379$ & 1 & 1 & 0 & 1 & 3 & 3 \\
\hline -Dis of Ear \& Mastoid & $380-389$ & 0 & 0 & 1 & 7 & 8 & 8 \\
\hline RESPIRATORY SYSTEM & $460-519$ & 0 & 0 & 0 & 10 & 10 & 11 \\
\hline -Acute Respiratory Infections & $460-466$ & 0 & 0 & 0 & 2 & 2 & 2 \\
\hline -Other Dis Upper Respiratory Tract & $470-478$ & 0 & 0 & 0 & 5 & 5 & 6 \\
\hline -Chronic Obstructive Dis & $490-496$ & 0 & 0 & 0 & 1 & 1 & 1 \\
\hline -Lung Dis from External Agents & $500-508$ & 0 & 0 & 0 & 1 & 1 & 1 \\
\hline -Other Respiratory Dis & $510-519$ & 0 & 0 & 0 & 1 & 1 & 1 \\
\hline SKIN \& SUBCUTANEOUS TISSUE & $680-709$ & 0 & 0 & 0 & 1 & 1 & 1 \\
\hline -Other Inflammatory Conditions & 690-698 & 0 & 0 & 0 & 1 & 1 & 1 \\
\hline $\begin{array}{l}\text { MUSCULOSKELETAL \& CONNECTIVE } \\
\text { TISSUE }\end{array}$ & $710-739$ & 1 & 1 & 14 & 13 & 29 & 54 \\
\hline -Arthropathies & $710-719$ & 1 & 0 & 10 & 7 & 18 & 32 \\
\hline -Dorsopathies & $720-724$ & 0 & 0 & 1 & 4 & 5 & 5 \\
\hline -Rheumatism, Excluding Back & 725-729 & 0 & 1 & 3 & 2 & 6 & 17 \\
\hline $\begin{array}{l}\text { SYMPTOMS, SIGNS, \& ILL-DEFINED } \\
\text { CONDITIONS }\end{array}$ & $780-799$ & 0 & 0 & 4 & 11 & 15 & 26 \\
\hline -Symptoms & 780-789 & 0 & 0 & 4 & 11 & 15 & 26 \\
\hline INJURY \& POISONING & $800-999$ & 3 & 4 & 9 & 28 & 44 & 59 \\
\hline -Fracture - Upper Limb & $810-819$ & 0 & 0 & 0 & 1 & 1 & 2 \\
\hline -Sprains \& Strains - Back & 846-847 & 0 & 0 & 3 & 3 & 6 & 7 \\
\hline -Sprains \& Strains - Other & $840-845,848$ & 0 & 0 & 2 & 8 & 10 & 13 \\
\hline -Open Wound - Head, Neck, Trunk & $870-879$ & 1 & 1 & 1 & 0 & 3 & 4 \\
\hline -Open Wound - Upper Limb & $880-887$ & 1 & 1 & 1 & 0 & 3 & 3 \\
\hline -Open Wound - Lower Limb & \begin{tabular}{|l|}
$890-897$ \\
\end{tabular} & 0 & 0 & 1 & 0 & 1 & 1 \\
\hline -Superficial Injury & 910-919 & 0 & 1 & 0 & 0 & 1 & 1 \\
\hline -Contusion & $920-924$ & 0 & 0 & 1 & 7 & 8 & 13 \\
\hline -Crushing Injury & $925-929$ & 0 & 0 & 0 & 1 & 1 & 1 \\
\hline -Foreign Body Entering Orifice & \begin{tabular}{|l|}
$930-939$ \\
\end{tabular} & 1 & 1 & 0 & 1 & 3 & 3 \\
\hline -Burns & $940-949$ & 0 & 0 & 0 & 1 & 1 & 1 \\
\hline -Complications \& Unspecified Injuries & 958-959 & 0 & 0 & 0 & 2 & 2 & 5 \\
\hline -Toxic Effects - Non-medicinal & 980-989 & 0 & 0 & 0 & 4 & 4 & 5 \\
\hline
\end{tabular}

*Only those diagnostic categories and gender/age combinations with at least one OSHA event appear in this table. 
Y-12 National Security Complex 2007

OSHA Data

Appendix O. Number of Diagnoses in Each Diagnostic Category by Gender and Age*

\begin{tabular}{|c|c|c|c|c|c|c|c|c|c|c|}
\hline & \multicolumn{4}{|c|}{ Women } & \multicolumn{5}{|c|}{ Men } & \multirow[b]{3}{*}{ TOTAL } \\
\hline & \multicolumn{3}{|c|}{ Age Group } & \multirow[b]{2}{*}{ TOTAL } & \multicolumn{4}{|c|}{ Age Group } & \multirow[b]{2}{*}{ TOTAL } & \\
\hline & 30 - 39 & $40-49$ & $50+$ & & $16-29$ & $30-39$ & $40-49$ & $50+$ & & \\
\hline Diagnostic Category & \multirow[b]{2}{*}{3} & \multirow[b]{2}{*}{28} & \multirow[b]{2}{*}{26} & \multirow[b]{2}{*}{57} & \multirow[b]{2}{*}{5} & \multirow[b]{2}{*}{6} & \multirow[b]{2}{*}{29} & \multirow[b]{2}{*}{73} & \multirow[b]{2}{*}{113} & \multirow[b]{2}{*}{170} \\
\hline Total & & & & & & & & & & \\
\hline
\end{tabular}

*Only those diagnostic categories and gender/age combinations with at least one OSHA event appear in this table. 


\section{Y-12 National Security Complex 2007}

OSHA Data

Appendix P. Number of Workdays Lost or with Restricted Activity in Each Diagnostic Category by Gender and Age*

\begin{tabular}{|c|c|c|c|c|c|c|c|}
\hline & & \multicolumn{6}{|c|}{ Women } \\
\hline & & \multicolumn{6}{|c|}{ Age Group } \\
\hline & & \multicolumn{2}{|c|}{30 - 39} & \multicolumn{2}{|c|}{$40-49$} & \multicolumn{2}{|c|}{$50+$} \\
\hline & & $\begin{array}{c}\text { Days } \\
\text { Restricted }\end{array}$ & Days Lost & $\begin{array}{c}\text { Days } \\
\text { Restricted }\end{array}$ & Days Lost & $\begin{array}{c}\text { Days } \\
\text { Restricted }\end{array}$ & Days Lost \\
\hline Diagnostic Category & ICD-9-CM Codes & \multirow[b]{2}{*}{0} & \multirow[b]{2}{*}{0} & \multirow[b]{2}{*}{0} & \multirow[b]{2}{*}{0} & \multirow[b]{2}{*}{16} & \multirow[b]{2}{*}{28} \\
\hline -Disorders of Peripheral NS & $350-359$ & & & & & & \\
\hline $\begin{array}{l}\text {-Other Dis Upper Respiratory } \\
\text { Tract }\end{array}$ & $470-478$ & 0 & 0 & 0 & 0 & 0 & 0 \\
\hline -Arthropathies & 710-719 & 57 & 0 & 36 & 0 & 153 & 99 \\
\hline -Rheumatism, Excluding Back & $725-729$ & 57 & 0 & 36 & 0 & 16 & 14 \\
\hline -Symptoms & $780-789$ & 0 & 0 & 0 & 0 & 53 & 32 \\
\hline -Fracture - Upper Limb & $810-819$ & 0 & 0 & 0 & 0 & 100 & 67 \\
\hline -Sprains \& Strains - Back & 846-847 & 0 & 0 & 0 & 0 & 0 & 0 \\
\hline -Sprains \& Strains - Other & $840-845,848$ & 0 & 0 & 0 & 0 & 100 & 67 \\
\hline -Open Wound - Head, Neck, Trunk & 870-879 & 0 & 0 & 0 & 0 & 0 & 0 \\
\hline -Contusion & $920-924$ & 0 & 0 & 0 & 0 & 0 & 0 \\
\hline $\begin{array}{l}\text {-Complications \& Unspecified } \\
\text { Injuries }\end{array}$ & 958-959 & 0 & 0 & 0 & 0 & 0 & 0 \\
\hline -Toxic Effects - Non-medicinal & 980-989 & 0 & 0 & 0 & 0 & 0 & 0 \\
\hline
\end{tabular}

\begin{tabular}{|c|c|c|c|c|c|c|c|c|c|}
\hline & & \multicolumn{8}{|c|}{ Men } \\
\hline & & \multicolumn{8}{|c|}{ Age Group } \\
\hline & & \multicolumn{2}{|c|}{$16-29$} & \multicolumn{2}{|c|}{$30-39$} & \multicolumn{2}{|c|}{$40-49$} & \multicolumn{2}{|c|}{$50+$} \\
\hline & & $\begin{array}{c}\text { Days } \\
\text { Restricted }\end{array}$ & $\begin{array}{l}\text { Days } \\
\text { Lost }\end{array}$ & $\begin{array}{c}\text { Days } \\
\text { Restricted }\end{array}$ & $\begin{array}{l}\text { Days } \\
\text { Lost }\end{array}$ & \begin{tabular}{|c|} 
Days \\
Restricted
\end{tabular} & $\begin{array}{l}\text { Days } \\
\text { Lost }\end{array}$ & $\begin{array}{c}\text { Days } \\
\text { Restricted }\end{array}$ & $\begin{array}{l}\text { Days } \\
\text { Lost }\end{array}$ \\
\hline Diagnostic Category & ICD-9-CM Codes & & & & & & & & \\
\hline -Disorders of Peripheral NS & $350-359$ & 0 & 0 & 0 & 0 & 0 & 25 & 34 & 45 \\
\hline -Disorders of Eye & $360-379$ & 0 & 0 & 0 & 0 & 0 & 0 & 11 & 14 \\
\hline -Dis of Ear \& Mastoid & $380-389$ & 0 & 0 & 0 & 0 & 0 & 0 & 0 & 0 \\
\hline -Acute Respiratory Infections & $460-466$ & 0 & 0 & 0 & 0 & 0 & 0 & 11 & 14 \\
\hline $\begin{array}{l}\text {-Other Dis Upper Respiratory } \\
\text { Tract }\end{array}$ & $470-478$ & 0 & 0 & 0 & 0 & 0 & 0 & 11 & 14 \\
\hline -Chronic Obstructive Dis & $490-496$ & 0 & 0 & 0 & 0 & 0 & 0 & 0 & 0 \\
\hline -Lung Dis from External Agents & $500-508$ & 0 & 0 & 0 & 0 & 0 & 0 & 0 & 0 \\
\hline -Other Respiratory Dis & $510-519$ & 0 & 0 & 0 & 0 & 0 & 0 & 6 & 46 \\
\hline -Other Inflammatory Conditions & 690-698 & 0 & 0 & 0 & 0 & 0 & 0 & 0 & 0 \\
\hline -Arthropathies & $710-719$ & 0 & 0 & 0 & 0 & 74 & 103 & 60 & 216 \\
\hline -Dorsopathies & $720-724$ & 0 & 0 & 0 & 0 & 0 & 0 & 47 & 155 \\
\hline -Rheumatism, Excluding Back & $725-729$ & 0 & 0 & 0 & 0 & 74 & 48 & 58 & 156 \\
\hline -Symptoms & 780-789 & 0 & 0 & 0 & 0 & 0 & 25 & 48 & 91 \\
\hline -Fracture - Upper Limb & $810-819$ & 0 & 0 & 0 & 0 & 0 & 0 & 0 & 0 \\
\hline
\end{tabular}

(Continued)

*OSHA events with >1 ICD-9-CM code in the same diagnostic category were counted only once. Only those diagnostic categories and gender/age combinations with at least one occurrence appear in this table. 
Y-12 National Security Complex 2007

OSHA Data

Appendix P. Number of Workdays Lost or with Restricted Activity in Each Diagnostic Category by Gender and Age*

\begin{tabular}{|c|c|c|c|c|c|c|c|c|c|}
\hline & & \multicolumn{8}{|c|}{ Men } \\
\hline & & \multicolumn{8}{|c|}{ Age Group } \\
\hline & & \multicolumn{2}{|c|}{$16-29$} & \multicolumn{2}{|c|}{$30-39$} & \multicolumn{2}{|c|}{$40-49$} & \multicolumn{2}{|c|}{$50+$} \\
\hline & & $\begin{array}{c}\text { Days } \\
\text { Restricted }\end{array}$ & $\begin{array}{l}\text { Days } \\
\text { Lost }\end{array}$ & $\begin{array}{c}\text { Days } \\
\text { Restricted }\end{array}$ & $\begin{array}{l}\text { Days } \\
\text { Lost }\end{array}$ & $\begin{array}{c}\text { Days } \\
\text { Restricted }\end{array}$ & $\begin{array}{l}\text { Days } \\
\text { Lost }\end{array}$ & \begin{tabular}{c|} 
Days \\
Restricted
\end{tabular} & $\begin{array}{l}\text { Days } \\
\text { Lost }\end{array}$ \\
\hline Diagnostic Category & ICD-9-CM Codes & \multirow[b]{2}{*}{0} & \multirow[b]{2}{*}{0} & \multirow[b]{2}{*}{0} & \multirow[b]{2}{*}{0} & \multirow[b]{2}{*}{79} & \multirow[b]{2}{*}{5} & \multirow[b]{2}{*}{161} & \multirow[b]{2}{*}{9} \\
\hline -Sprains \& Strains - Back & 846-847 & & & & & & & & \\
\hline -Sprains \& Strains - Other & $840-845,848$ & 0 & 0 & 0 & 0 & 74 & 90 & 75 & 285 \\
\hline -Open Wound - Head, Neck, Trunk & $870-879$ & 0 & 0 & 0 & 0 & 0 & 0 & 0 & 0 \\
\hline -Open Wound - Upper Limb & 880-887 & 0 & 0 & 0 & 0 & 0 & 0 & 0 & 0 \\
\hline -Open Wound - Lower Limb & $890-897$ & 0 & 0 & 0 & 0 & 0 & 0 & 0 & 0 \\
\hline -Superficial Injury & $910-919$ & 0 & 0 & 0 & 0 & 0 & 0 & 0 & 0 \\
\hline -Contusion & $920-924$ & 0 & 0 & 0 & 0 & 0 & 0 & 154 & 0 \\
\hline -Crushing Injury & 925-929 & 0 & 0 & 0 & 0 & 0 & 0 & 0 & 0 \\
\hline -Foreign Body Entering Orifice & 930-939 & 0 & 0 & 0 & 0 & 0 & 0 & 0 & 0 \\
\hline -Burns & $940-949$ & 0 & 0 & 0 & 0 & 0 & 0 & 0 & 0 \\
\hline $\begin{array}{l}\text {-Complications \& Unspecified } \\
\text { Injuries }\end{array}$ & 958-959 & 0 & 0 & 0 & 0 & 0 & 0 & 40 & 146 \\
\hline -Toxic Effects - Non-medicinal & $980-989$ & 0 & 0 & 0 & 0 & 0 & 0 & 17 & 60 \\
\hline
\end{tabular}

*OSHA events with >1 ICD-9-CM code in the same diagnostic category were counted only once. Only those diagnostic categories and gender/age combinations with at least one occurrence appear in this table. 
Y-12 National Security Complex 2007

OSHA Data

Appendix Q. Number of Occurrences in Each Accident Category by Gender and Age*

\begin{tabular}{|c|c|c|c|c|c|c|c|c|c|c|c|}
\hline & & \multicolumn{4}{|c|}{ Women } & \multicolumn{5}{|c|}{ Men } & \multirow[b]{3}{*}{ TOTAL } \\
\hline & & \multicolumn{3}{|c|}{ Age Group } & \multirow[b]{2}{*}{ TOTAL } & \multicolumn{4}{|c|}{ Age Group } & \multirow[b]{2}{*}{ TOTAL } & \\
\hline & & $30-39$ & 40 - 49 & $\begin{array}{l}50 \\
+\end{array}$ & & $16-29$ & 30 - 39 & $40-49$ & $\begin{array}{l}50 \\
+\end{array}$ & & \\
\hline Type of Accident & E Codes & & & & & & & & & & \\
\hline Accidental Poisoning - Non-medicinal & E860-E869 & 0 & 1 & 0 & 1 & 0 & 0 & 0 & 5 & 5 & 6 \\
\hline Falls & E880-E888 & 0 & 2 & 2 & 4 & 0 & 0 & 0 & 5 & 5 & 9 \\
\hline Natural/Environmental Factors & E900-E909 & 0 & 0 & 0 & 0 & 0 & 1 & 0 & 0 & 1 & 1 \\
\hline $\begin{array}{l}\text { Submersion/Suffocation/Foreign } \\
\text { Bodies }\end{array}$ & E910-E915 & 0 & 0 & 0 & 0 & 1 & 1 & 0 & 1 & 3 & 3 \\
\hline Other Accidents & E916-E928 & 1 & 6 & 8 & 15 & 2 & 2 & 16 & 20 & 40 & 55 \\
\hline
\end{tabular}

*Only those accident types and gender/age combinations with at least one occurrence appear in this table. 
Y-12 National Security Complex 2007

OSHA Data

Appendix R. Number of Workdays Lost or with Restricted Activity in Each Accident Category by Gender and Age*

\begin{tabular}{|c|c|c|c|c|c|c|c|}
\hline & & \multicolumn{6}{|c|}{ Women } \\
\hline & & \multicolumn{6}{|c|}{ Age Group } \\
\hline & & \multicolumn{2}{|c|}{30 - 39} & \multicolumn{2}{|c|}{$40-49$} & \multicolumn{2}{|c|}{$50+$} \\
\hline & & $\begin{array}{c}\text { Days } \\
\text { Restricted }\end{array}$ & Days Lost & $\begin{array}{c}\text { Days } \\
\text { Restricted }\end{array}$ & Days Lost & $\begin{array}{c}\text { Days } \\
\text { Restricted }\end{array}$ & Days Lost \\
\hline Type of Accident & E Codes & \multirow[b]{2}{*}{0} & \multirow[b]{2}{*}{0} & \multirow[b]{2}{*}{0} & \multirow[b]{2}{*}{0} & \multirow[b]{2}{*}{0} & \multirow[b]{2}{*}{0} \\
\hline Accidental Poisoning - Non-medicinal & E860-E869 & & & & & & \\
\hline Falls & E880-E888 & 0 & 0 & 0 & 0 & 0 & 0 \\
\hline Other Accidents & E916-E928 & 57 & 0 & 36 & 0 & 153 & 113 \\
\hline
\end{tabular}

\begin{tabular}{|c|c|c|c|c|c|c|c|c|c|}
\hline & & \multicolumn{8}{|c|}{ Men } \\
\hline & & \multicolumn{8}{|c|}{ Age Group } \\
\hline & & \multicolumn{2}{|c|}{$16-29$} & \multicolumn{2}{|c|}{30 - 39} & \multicolumn{2}{|c|}{40 - 49} & \multicolumn{2}{|c|}{$\mathbf{5 0 +}$} \\
\hline & & $\begin{array}{c}\text { Days } \\
\text { Restricted }\end{array}$ & $\begin{array}{l}\text { Days } \\
\text { Lost }\end{array}$ & $\begin{array}{c}\text { Days } \\
\text { Restricted }\end{array}$ & $\begin{array}{l}\text { Days } \\
\text { Lost }\end{array}$ & $\begin{array}{c}\text { Days } \\
\text { Restricted }\end{array}$ & $\begin{array}{l}\text { Days } \\
\text { Lost }\end{array}$ & $\begin{array}{c}\text { Days } \\
\text { Restricted }\end{array}$ & $\begin{array}{l}\text { Days } \\
\text { Lost }\end{array}$ \\
\hline Type of Accident & E Codes & & & & & & & & \\
\hline Accidental Poisoning - Non-medicinal & E860-E869 & 0 & 0 & 0 & 0 & 0 & 0 & 17 & 60 \\
\hline Falls & E880-E888 & 0 & 0 & 0 & 0 & 0 & 0 & 6 & 0 \\
\hline Natural/Environmental Factors & E900-E909 & 0 & 0 & 0 & 0 & 0 & 0 & 0 & 0 \\
\hline $\begin{array}{l}\text { Submersion/Suffocation/Foreign } \\
\text { Bodies }\end{array}$ & E910-E915 & 0 & 0 & 0 & 0 & 0 & 0 & 0 & 0 \\
\hline Other Accidents & E916-E928 & 0 & 0 & 0 & 0 & 153 & 133 & 310 & 513 \\
\hline
\end{tabular}

*OSHA events with $>1 \mathrm{E}$ code in the same accident type were counted only once. Only those accident types and gender/age combinations with at least one occurrence appear in this table. 
Y-12 National Security Complex 2007

OSHA Data

Appendix S. Number of Diagnoses in Each Diagnostic Category by Gender and Job Category*

\begin{tabular}{|c|c|c|c|c|c|c|}
\hline & & \multicolumn{5}{|c|}{ Women } \\
\hline & & \multicolumn{4}{|c|}{ Job Category } & \multirow[b]{2}{*}{ TOTAL } \\
\hline & & Professional & $\begin{array}{c}\text { Administrative } \\
\text { Support }\end{array}$ & Service & Line Operators & \\
\hline Diagnostic Category & ICD-9-CM Code & & & & & \\
\hline $\begin{array}{l}\text { NERVOUS SYSTEM } \\
\text { (NS) \& SENSE ORGANS }\end{array}$ & $320-389$ & 1 & 4 & 0 & 0 & 5 \\
\hline $\begin{array}{l}\text {-Disorders of Peripheral } \\
\text { NS }\end{array}$ & $350-359$ & 1 & 4 & 0 & 0 & 5 \\
\hline $\begin{array}{l}\text { RESPIRATORY } \\
\text { SYSTEM }\end{array}$ & 460-519 & 0 & 0 & 1 & 0 & 1 \\
\hline $\begin{array}{l}\text {-Other Dis Upper } \\
\text { Respiratory Tract }\end{array}$ & $470-478$ & 0 & 0 & 1 & 0 & 1 \\
\hline $\begin{array}{l}\text { MUSCULOSKELETAL } \\
\text { \& CONNECTIVE } \\
\text { TISSUE }\end{array}$ & $710-739$ & 7 & 14 & 3 & 1 & 25 \\
\hline -Arthropathies & $710-719$ & 4 & 8 & 1 & 1 & 14 \\
\hline $\begin{array}{l}\text {-Rheumatism, Excluding } \\
\text { Back }\end{array}$ & 725-729 & 3 & 6 & 2 & 0 & 11 \\
\hline $\begin{array}{l}\text { SYMPTOMS, } \\
\text { SIGNS, \& ILL-DEFINED } \\
\text { CONDITIONS }\end{array}$ & $780-799$ & 2 & 6 & 3 & 0 & 11 \\
\hline -Symptoms & $780-789$ & 2 & 6 & 3 & 0 & 11 \\
\hline INJURY \& POISONING & 800-999 & 1 & 6 & 5 & 3 & 15 \\
\hline -Fracture - Upper Limb & $810-819$ & 0 & 0 & 0 & 1 & 1 \\
\hline -Sprains \& Strains - Back & 846-847 & 0 & 0 & 1 & 0 & 1 \\
\hline $\begin{array}{l}\text {-Sprains \& Strains - } \\
\text { Other }\end{array}$ & $840-845,848$ & 1 & 0 & 1 & 1 & 3 \\
\hline $\begin{array}{l}\text {-Open Wound - Head, } \\
\text { Neck, Trunk }\end{array}$ & 870-879 & 0 & 0 & 1 & 0 & 1 \\
\hline -Contusion & $920-924$ & 0 & 3 & 1 & 1 & 5 \\
\hline $\begin{array}{l}\text {-Complications \& } \\
\text { Unspecified Injuries }\end{array}$ & 958-959 & 0 & 3 & 0 & 0 & 3 \\
\hline $\begin{array}{l}\text {-Toxic } \\
\text { Effects - Non-medicinal }\end{array}$ & $980-989$ & 0 & 0 & 1 & 0 & 1 \\
\hline
\end{tabular}

\begin{tabular}{|c|c|c|c|c|c|}
\hline & \multicolumn{5}{|c|}{ Women } \\
\hline & \multicolumn{4}{|c|}{ Job Category } & \multirow[b]{2}{*}{ TOTAL } \\
\hline & Professional & $\begin{array}{c}\text { Administrative } \\
\text { Support }\end{array}$ & Service & Line Operators & \\
\hline Diagnostic Category & \multirow[b]{2}{*}{11} & \multirow[b]{2}{*}{30} & \multirow[b]{2}{*}{12} & \multirow[b]{2}{*}{4} & \multirow[b]{2}{*}{57} \\
\hline Total & & & & & \\
\hline
\end{tabular}

*Only those diagnostic categories and gender/job category combinations with at least one occurrence appear in this table. 


\section{Y-12 National Security Complex 2007}

OSHA Data

Appendix S. Number of Diagnoses in Each Diagnostic Category by Gender and Job Category*

\begin{tabular}{|c|c|c|c|c|c|c|c|c|c|}
\hline & & \multicolumn{8}{|c|}{ Men } \\
\hline & & \multicolumn{7}{|c|}{ Job Category } & \multirow[b]{2}{*}{ TOTAL } \\
\hline & & Professional & $\begin{array}{c}\text { Administrative } \\
\text { Support }\end{array}$ & \begin{tabular}{|c|} 
Technical \\
Support
\end{tabular} & Service & $\begin{array}{l}\text { Security } \\
\text { and Fire }\end{array}$ & Crafts & \begin{tabular}{|c|} 
Line \\
Operators
\end{tabular} & \\
\hline Diagnostic Category & ICD-9-CM Code & & & & & & & & \\
\hline $\begin{array}{l}\text { NERVOUS SYSTEM } \\
\text { (NS) \& SENSE ORGANS }\end{array}$ & $320-389$ & 1 & 1 & 0 & 3 & 1 & 8 & 0 & 14 \\
\hline $\begin{array}{l}\text {-Disorders of Peripheral } \\
\text { NS }\end{array}$ & $350-359$ & 1 & 0 & 0 & 0 & 0 & 2 & 0 & 3 \\
\hline -Disorders of Eye & $360-379$ & 0 & 1 & 0 & 0 & 0 & 2 & 0 & 3 \\
\hline -Dis of Ear \& Mastoid & $380-389$ & 0 & 0 & 0 & 3 & 1 & 4 & 0 & 8 \\
\hline $\begin{array}{l}\text { RESPIRATORY } \\
\text { SYSTEM }\end{array}$ & $460-519$ & 0 & 0 & 0 & 1 & 0 & 9 & 0 & 10 \\
\hline $\begin{array}{l}\text {-Acute Respiratory } \\
\text { Infections }\end{array}$ & $460-466$ & 0 & 0 & 0 & 0 & 0 & 2 & 0 & 2 \\
\hline $\begin{array}{l}\text {-Other Dis Upper } \\
\text { Respiratory Tract }\end{array}$ & $470-478$ & 0 & 0 & 0 & 1 & 0 & 4 & 0 & 5 \\
\hline -Chronic Obstructive Dis & $490-496$ & 0 & 0 & 0 & 0 & 0 & 1 & 0 & 1 \\
\hline $\begin{array}{l}\text {-Lung Dis from External } \\
\text { Agents }\end{array}$ & $500-508$ & 0 & 0 & 0 & 0 & 0 & 1 & 0 & 1 \\
\hline -Other Respiratory Dis & $510-519$ & 0 & 0 & 0 & 0 & 0 & 1 & 0 & 1 \\
\hline $\begin{array}{l}\text { SKIN \& } \\
\text { SUBCUTANEOUS } \\
\text { TISSUE }\end{array}$ & $680-709$ & 0 & 0 & 0 & 0 & 0 & 1 & 0 & 1 \\
\hline $\begin{array}{l}\text {-Other Inflammatory } \\
\text { Conditions }\end{array}$ & $690-698$ & 0 & 0 & 0 & 0 & 0 & 1 & 0 & 1 \\
\hline $\begin{array}{l}\text { MUSCULOSKELETAL } \\
\text { \& CONNECTIVE } \\
\text { TISSUE }\end{array}$ & $710-739$ & 0 & 0 & 1 & 2 & 0 & 19 & 7 & 29 \\
\hline -Arthropathies & $710-719$ & 0 & 0 & 1 & 1 & 0 & 11 & 5 & 18 \\
\hline -Dorsopathies & $720-724$ & 0 & 0 & 0 & 0 & 0 & 5 & 0 & 5 \\
\hline $\begin{array}{l}\text {-Rheumatism, Excluding } \\
\text { Back }\end{array}$ & $725-729$ & 0 & 0 & 0 & 1 & 0 & 3 & 2 & 6 \\
\hline $\begin{array}{l}\text { SYMPTOMS, } \\
\text { SIGNS, \& ILL-DEFINED } \\
\text { CONDITIONS } \\
\end{array}$ & $780-799$ & 2 & 0 & 0 & 2 & 0 & 9 & 2 & 15 \\
\hline -Symptoms & $780-789$ & 2 & 0 & 0 & 2 & 0 & 9 & 2 & 15 \\
\hline INJURY \& POISONING & $800-999$ & 7 & 1 & 1 & 4 & 0 & 29 & 2 & 44 \\
\hline -Fracture - Upper Limb & 810-819 & 0 & 0 & 0 & 0 & 0 & 1 & 0 & 1 \\
\hline -Sprains \& Strains - Back & 846-847 & 0 & 0 & 0 & 1 & 0 & 5 & 0 & 6 \\
\hline $\begin{array}{l}\text {-Sprains \& Strains - } \\
\text { Other }\end{array}$ & $840-845,848$ & 2 & 0 & 1 & 0 & 0 & 7 & 0 & 10 \\
\hline $\begin{array}{l}\text {-Open Wound - Head, } \\
\text { Neck, Trunk }\end{array}$ & \begin{tabular}{|c|}
$870-879$ \\
\end{tabular} & 0 & 0 & 0 & 1 & 0 & 0 & 2 & 3 \\
\hline $\begin{array}{l}\text {-Open Wound - Upper } \\
\text { Limb }\end{array}$ & 880-887 & 0 & 0 & 0 & 0 & 0 & 3 & 0 & 3 \\
\hline
\end{tabular}

(Continued)

*Only those diagnostic categories and gender/job category combinations with at least one occurrence appear in this table. 
Y-12 National Security Complex 2007

OSHA Data

Appendix S. Number of Diagnoses in Each Diagnostic Category by Gender and Job Category*

\begin{tabular}{|c|c|c|c|c|c|c|c|c|c|}
\hline & & \multicolumn{8}{|c|}{ Men } \\
\hline & & \multicolumn{7}{|c|}{ Job Category } & \multirow[b]{2}{*}{ TOTAL } \\
\hline & & Professional & $\begin{array}{c}\text { Administrative } \\
\text { Support }\end{array}$ & $\begin{array}{l}\text { Technical } \\
\text { Support }\end{array}$ & Service & $\begin{array}{l}\text { Security } \\
\text { and Fire }\end{array}$ & Crafts & $\begin{array}{c}\text { Line } \\
\text { Operators }\end{array}$ & \\
\hline Diagnostic Category & ICD-9-CM Code & & & & & & & & \\
\hline $\begin{array}{l}\text {-Open Wound - Lower } \\
\text { Limb }\end{array}$ & $890-897$ & 0 & 0 & 0 & 0 & 0 & 1 & 0 & 1 \\
\hline -Superficial Injury & 910-919 & 0 & 0 & 0 & 1 & 0 & 0 & 0 & 1 \\
\hline -Contusion & $920-924$ & 4 & 0 & 0 & 0 & 0 & 4 & 0 & 8 \\
\hline -Crushing Injury & $925-929$ & 0 & 0 & 0 & 0 & 0 & 1 & 0 & 1 \\
\hline $\begin{array}{l}\text {-Foreign Body Entering } \\
\text { Orifice }\end{array}$ & $930-939$ & 0 & 1 & 0 & 0 & 0 & 2 & 0 & 3 \\
\hline -Burns & 940-949 & 0 & 0 & 0 & 0 & 0 & 1 & 0 & 1 \\
\hline $\begin{array}{l}\text {-Complications \& } \\
\text { Unspecified Injuries }\end{array}$ & 958-959 & 1 & 0 & 0 & 0 & 0 & 1 & 0 & 2 \\
\hline $\begin{array}{l}\text {-Toxic } \\
\text { Effects - Non-medicinal }\end{array}$ & 980-989 & 0 & 0 & 0 & 1 & 0 & 3 & 0 & 4 \\
\hline
\end{tabular}

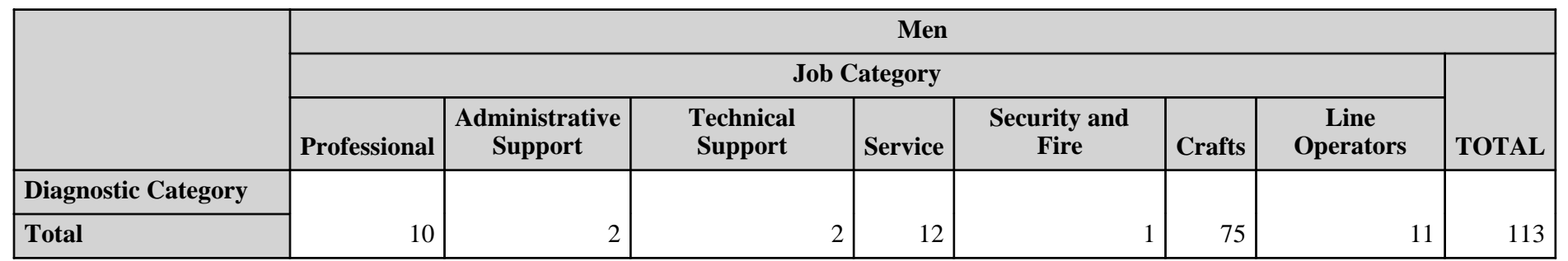

*Only those diagnostic categories and gender/job category combinations with at least one occurrence appear in this table. 
Y-12 National Security Complex 2007

OSHA Data

Appendix T. Number of Workdays Lost or with Restricted Activity in Each Diagnostic Category by Gender and Job Category*

\begin{tabular}{|c|c|c|c|c|c|c|c|c|c|}
\hline & & \multicolumn{8}{|c|}{ Women } \\
\hline & & \multicolumn{8}{|c|}{ Job Category } \\
\hline & & \multicolumn{2}{|c|}{ Professional } & \multicolumn{2}{|c|}{$\begin{array}{l}\text { Administrative } \\
\text { Support }\end{array}$} & \multicolumn{2}{|c|}{ Service } & \multicolumn{2}{|c|}{ Line Operators } \\
\hline & & $\begin{array}{c}\text { Days } \\
\text { Restricted }\end{array}$ & $\begin{array}{l}\text { Days } \\
\text { Lost }\end{array}$ & \begin{tabular}{|c|} 
Days \\
Restricted
\end{tabular} & $\begin{array}{l}\text { Days } \\
\text { Lost }\end{array}$ & $\begin{array}{c}\text { Days } \\
\text { Restricted }\end{array}$ & \begin{tabular}{c|} 
Days \\
Lost
\end{tabular} & $\begin{array}{c}\text { Days } \\
\text { Restricted }\end{array}$ & $\begin{array}{l}\text { Days } \\
\text { Lost }\end{array}$ \\
\hline Diagnostic Category & ICD-9-CM Codes & \multirow[b]{2}{*}{0} & \multirow[b]{2}{*}{0} & \multirow[b]{2}{*}{16} & \multirow[b]{2}{*}{28} & \multirow[b]{2}{*}{0} & \multirow[b]{2}{*}{0} & \multirow[b]{2}{*}{0} & \multirow[b]{2}{*}{0} \\
\hline -Disorders of Peripheral NS & $350-359$ & & & & & & & & \\
\hline $\begin{array}{l}\text {-Other Dis Upper Respiratory } \\
\text { Tract }\end{array}$ & $470-478$ & 0 & 0 & 0 & 0 & 0 & 0 & 0 & 0 \\
\hline -Arthropathies & \begin{tabular}{|l|}
$710-719$ \\
\end{tabular} & 36 & 0 & 53 & 32 & 57 & 0 & 100 & 67 \\
\hline -Rheumatism, Excluding Back & $725-729$ & 36 & 0 & 16 & 14 & 57 & 0 & 0 & 0 \\
\hline -Symptoms & \begin{tabular}{|l|}
$780-789$ \\
\end{tabular} & 0 & 0 & 53 & 32 & 0 & 0 & 0 & 0 \\
\hline -Fracture - Upper Limb & $810-819$ & 0 & 0 & 0 & 0 & 0 & 0 & 100 & 67 \\
\hline -Sprains \& Strains - Back & \begin{tabular}{|l|}
$846-847$ \\
\end{tabular} & 0 & 0 & 0 & 0 & 0 & 0 & 0 & 0 \\
\hline -Sprains \& Strains - Other & $840-845,848$ & 0 & 0 & 0 & 0 & 0 & 0 & 100 & 67 \\
\hline -Open Wound - Head, Neck, Trunk & $870-879$ & 0 & 0 & 0 & 0 & 0 & 0 & 0 & 0 \\
\hline -Contusion & $920-924$ & 0 & 0 & 0 & 0 & 0 & 0 & 0 & 0 \\
\hline $\begin{array}{l}\text {-Complications \& Unspecified } \\
\text { Injuries }\end{array}$ & 958-959 & 0 & 0 & 0 & 0 & 0 & 0 & 0 & 0 \\
\hline -Toxic Effects - Non-medicinal & $980-989$ & 0 & 0 & \begin{tabular}{l|l}
0 \\
\end{tabular} & 0 & 0 & 0 & 0 & 0 \\
\hline
\end{tabular}

*OSHA events with >1 ICD-9-CM code in the same diagnostic category were counted only once. Only those diagnostic categories and gender/job category combinations with at least one occurrence appear in this table. 


\section{Y-12 National Security Complex 2007}

\section{OSHA Data}

Appendix T. Number of Workdays Lost or with Restricted Activity in Each Diagnostic Category by Gender and Job Category*

\begin{tabular}{|c|c|c|c|c|c|c|c|c|c|}
\hline & & \multicolumn{8}{|c|}{ Men } \\
\hline & & \multicolumn{8}{|c|}{ Job Category } \\
\hline & & \multicolumn{2}{|c|}{ Professional } & \multicolumn{2}{|c|}{$\begin{array}{l}\text { Administrative } \\
\text { Support }\end{array}$} & \multicolumn{2}{|c|}{$\begin{array}{l}\text { Technical } \\
\text { Support }\end{array}$} & \multicolumn{2}{|c|}{ Service } \\
\hline & & $\begin{array}{c}\text { Days } \\
\text { Restricted }\end{array}$ & $\begin{array}{l}\text { Days } \\
\text { Lost }\end{array}$ & $\begin{array}{c}\text { Days } \\
\text { Restricted }\end{array}$ & $\begin{array}{l}\text { Days } \\
\text { Lost }\end{array}$ & \begin{tabular}{|c|} 
Days \\
Restricted
\end{tabular} & $\begin{array}{l}\text { Days } \\
\text { Lost }\end{array}$ & $\begin{array}{c}\text { Days } \\
\text { Restricted }\end{array}$ & $\begin{array}{l}\text { Days } \\
\text { Lost }\end{array}$ \\
\hline Diagnostic Category & ICD-9-CM Codes & \multirow[b]{2}{*}{0} & \multirow[b]{2}{*}{25} & \multirow[b]{2}{*}{0} & \multirow[b]{2}{*}{0} & \multirow[b]{2}{*}{0} & \multirow[b]{2}{*}{0} & \multirow[b]{2}{*}{0} & \multirow[b]{2}{*}{0} \\
\hline -Disorders of Peripheral NS & $350-359$ & & & & & & & & \\
\hline -Disorders of Eye & $360-379$ & 0 & 0 & 0 & 0 & 0 & 0 & 0 & 0 \\
\hline -Dis of Ear \& Mastoid & 380-389 & 0 & 0 & 0 & 0 & 0 & 0 & 0 & 0 \\
\hline -Acute Respiratory Infections & $460-466$ & 0 & 0 & 0 & 0 & 0 & 0 & 0 & 0 \\
\hline $\begin{array}{l}\text {-Other Dis Upper Respiratory } \\
\text { Tract }\end{array}$ & $470-478$ & 0 & 0 & 0 & 0 & 0 & 0 & 0 & 0 \\
\hline -Chronic Obstructive Dis & $490-496$ & 0 & 0 & 0 & 0 & 0 & 0 & 0 & 0 \\
\hline -Lung Dis from External Agents & \begin{tabular}{|l|}
$500-508$ \\
\end{tabular} & 0 & 0 & 0 & 0 & 0 & 0 & 0 & $\overline{0}$ \\
\hline -Other Respiratory Dis & \begin{tabular}{|l|}
$510-519$ \\
\end{tabular} & 0 & 0 & 0 & 0 & 0 & 0 & 0 & 0 \\
\hline -Other Inflammatory Conditions & $690-698$ & 0 & 0 & 0 & 0 & 0 & 0 & 0 & 0 \\
\hline -Arthropathies & $710-719$ & 0 & 0 & 0 & 0 & 0 & 55 & 0 & $\overline{0}$ \\
\hline -Dorsopathies & 720-724 & 0 & 0 & 0 & 0 & 0 & 0 & 0 & 0 \\
\hline -Rheumatism, Excluding Back & $725-729$ & 0 & 0 & 0 & 0 & 0 & 0 & 0 & 0 \\
\hline -Symptoms & 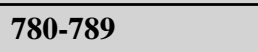 & 0 & 25 & 0 & 0 & 0 & 0 & 0 & 0 \\
\hline -Fracture - Upper Limb & $810-819$ & 0 & 0 & 0 & 0 & 0 & 0 & 0 & 0 \\
\hline -Sprains \& Strains - Back & $846-847$ & 0 & 0 & 0 & 0 & 0 & 0 & 43 & 5 \\
\hline -Sprains \& Strains - Other & $840-845,848$ & 0 & 0 & 0 & 0 & 0 & 55 & 0 & 0 \\
\hline -Open Wound - Head, Neck, Trunk & $870-879$ & 0 & 0 & 0 & 0 & 0 & 0 & 0 & 0 \\
\hline -Open Wound - Upper Limb & $880-887$ & 0 & 0 & 0 & 0 & 0 & 0 & 0 & 0 \\
\hline -Open Wound - Lower Limb & $890-897$ & 0 & 0 & 0 & 0 & 0 & 0 & 0 & 0 \\
\hline -Superficial Injury & $910-919$ & 0 & 0 & 0 & 0 & 0 & 0 & 0 & 0 \\
\hline -Contusion & $920-924$ & 6 & 0 & 0 & 0 & 0 & 0 & 0 & 0 \\
\hline -Crushing Injury & $925-929$ & 0 & 0 & 0 & 0 & 0 & 0 & 0 & 0 \\
\hline -Foreign Body Entering Orifice & $930-939$ & 0 & 0 & 0 & 0 & 0 & 0 & 0 & 0 \\
\hline -Burns & $940-949$ & 0 & 0 & 0 & 0 & 0 & 0 & 0 & 0 \\
\hline $\begin{array}{l}\text {-Complications \& Unspecified } \\
\text { Injuries }\end{array}$ & $958-959$ & 6 & 0 & 0 & 0 & 0 & 0 & 0 & 0 \\
\hline -Toxic Effects - Non-medicinal & $980-989$ & 0 & 0 & 0 & 0 & 0 & 0 & 0 & 0 \\
\hline
\end{tabular}

*OSHA events with >1 ICD-9-CM code in the same diagnostic category were counted only once. Only those diagnostic categories and gender/job category combinations with at least one occurrence appear in this table. 
Y-12 National Security Complex 2007

OSHA Data

Appendix T. Number of Workdays Lost or with Restricted Activity in Each Diagnostic Category by Gender and Job Category*

\begin{tabular}{|c|c|c|c|c|c|c|c|}
\hline & \multicolumn{6}{|c|}{ Men } \\
\hline & & \multicolumn{6}{|c|}{ Job Category } \\
\hline & & \multicolumn{2}{|c|}{ Security and Fire } & \multicolumn{2}{|c|}{ Crafts } & \multicolumn{2}{|c|}{ Line Operators } \\
\hline & & \begin{tabular}{c|} 
Days \\
Restricted
\end{tabular} & $\begin{array}{l}\text { Days } \\
\text { Lost }\end{array}$ & $\begin{array}{c}\text { Days } \\
\text { Restricted }\end{array}$ & $\begin{array}{l}\text { Days } \\
\text { Lost }\end{array}$ & $\begin{array}{c}\text { Days } \\
\text { Restricted }\end{array}$ & $\begin{array}{l}\text { Days } \\
\text { Lost }\end{array}$ \\
\hline Diagnostic Category & ICD-9-CM Codes & \multirow[b]{2}{*}{0} & \multirow[b]{2}{*}{0} & \multirow[b]{2}{*}{34} & \multirow[b]{2}{*}{45} & \multirow[b]{2}{*}{0} & \multirow[b]{2}{*}{0} \\
\hline -Disorders of Peripheral NS & $350-359$ & & & & & & \\
\hline -Disorders of Eye & $360-379$ & 0 & 0 & 11 & 14 & 0 & 0 \\
\hline -Dis of Ear \& Mastoid & $380-389$ & 0 & 0 & 0 & 0 & 0 & 0 \\
\hline -Acute Respiratory Infections & $460-466$ & 0 & 0 & 11 & 14 & 0 & 0 \\
\hline $\begin{array}{l}\text {-Other Dis Upper Respiratory } \\
\text { Tract }\end{array}$ & $470-478$ & 0 & 0 & 11 & 14 & 0 & 0 \\
\hline -Chronic Obstructive Dis & $490-496$ & 0 & 0 & 0 & 0 & 0 & 0 \\
\hline -Lung Dis from External Agents & $500-508$ & 0 & 0 & 0 & 0 & 0 & 0 \\
\hline -Other Respiratory Dis & $510-519$ & 0 & 0 & 6 & 46 & 0 & 0 \\
\hline -Other Inflammatory Conditions & $690-698$ & 0 & 0 & 0 & 0 & 0 & 0 \\
\hline -Arthropathies & $710-719$ & 0 & 0 & 134 & 251 & 0 & 13 \\
\hline -Dorsopathies & $720-724$ & 0 & 0 & 47 & 155 & 0 & 0 \\
\hline -Rheumatism, Excluding Back & $725-729$ & 0 & 0 & 132 & 191 & 0 & 13 \\
\hline -Symptoms & $780-789$ & 0 & 0 & 48 & 91 & 0 & 0 \\
\hline -Fracture - Upper Limb & $810-819$ & 0 & 0 & 0 & 0 & 0 & 0 \\
\hline -Sprains \& Strains - Back & $846-847$ & 0 & 0 & 197 & 9 & 0 & 0 \\
\hline -Sprains \& Strains - Other & $840-845,848$ & 0 & 0 & 149 & 320 & 0 & 0 \\
\hline -Open Wound - Head, Neck, Trunk & $870-879$ & 0 & 0 & 0 & 0 & 0 & 0 \\
\hline -Open Wound - Upper Limb & $880-887$ & 0 & 0 & 0 & 0 & 0 & 0 \\
\hline -Open Wound - Lower Limb & $890-897$ & 0 & 0 & 0 & 0 & 0 & 0 \\
\hline -Superficial Injury & 910-919 & 0 & 0 & 0 & 0 & 0 & 0 \\
\hline -Contusion & $920-924$ & 0 & 0 & 148 & 0 & 0 & 0 \\
\hline -Crushing Injury & $925-929$ & 0 & 0 & 0 & 0 & 0 & 0 \\
\hline -Foreign Body Entering Orifice & 930-939 & 0 & 0 & 0 & 0 & 0 & 0 \\
\hline -Burns & 940-949 & 0 & 0 & 0 & 0 & 0 & 0 \\
\hline $\begin{array}{l}\text {-Complications \& Unspecified } \\
\text { Injuries }\end{array}$ & 958-959 & 0 & 0 & 34 & 146 & 0 & 0 \\
\hline -Toxic Effects - Non-medicinal & 980-989 & 0 & 0 & 17 & 60 & 0 & 0 \\
\hline
\end{tabular}

*OSHA events with >1 ICD-9-CM code in the same diagnostic category were counted only once. Only those diagnostic categories and gender/job category combinations with at least one occurrence appear in this table. 
Y-12 National Security Complex 2007

OSHA Data

Appendix U. Number of Occurrences in Each Accident Category by Gender and Job Category*

\begin{tabular}{|c|c|c|c|c|c|c|}
\hline & & \multicolumn{5}{|c|}{ Women } \\
\hline & & \multicolumn{4}{|c|}{ Job Category } & \multirow[b]{2}{*}{ TOTAL } \\
\hline & & Professional & $\begin{array}{c}\text { Administrative } \\
\text { Support }\end{array}$ & Service & $\begin{array}{c}\text { Line } \\
\text { Operators }\end{array}$ & \\
\hline Type of Accident & E CODES & \multirow[b]{2}{*}{0} & \multirow[b]{2}{*}{0} & \multirow[b]{2}{*}{1} & \multirow[b]{2}{*}{0} & \multirow[b]{2}{*}{1} \\
\hline Accidental Poisoning - Non-medicinal & E860-E869 & & & & & \\
\hline Falls & E880-E888 & 0 & 2 & 1 & 1 & 4 \\
\hline Other Accidents & E916-E928 & 4 & 9 & 1 & 1 & 15 \\
\hline
\end{tabular}

\begin{tabular}{|c|c|c|c|c|c|c|c|c|}
\hline & & \multicolumn{7}{|c|}{ Men } \\
\hline & & \multicolumn{7}{|c|}{ Job Category } \\
\hline & & Professional & $\begin{array}{l}\text { Administrative } \\
\text { Support }\end{array}$ & \begin{tabular}{|l|} 
Technical \\
Support
\end{tabular} & Service & $\begin{array}{l}\text { Security } \\
\text { and Fire }\end{array}$ & Crafts & $\begin{array}{c}\text { Line } \\
\text { Operators }\end{array}$ \\
\hline Type of Accident & E CODES & \multirow[b]{2}{*}{0} & \multirow[b]{2}{*}{0} & \multirow[b]{2}{*}{0} & \multirow[b]{2}{*}{1} & \multirow[b]{2}{*}{0} & \multirow[b]{2}{*}{4} & \multirow[b]{2}{*}{0} \\
\hline Accidental Poisoning - Non-medicinal & E860-E869 & & & & & & & \\
\hline Falls & E880-E888 & 3 & 0 & 0 & 0 & 0 & 2 & 0 \\
\hline Natural/Environmental Factors & E900-E909 & 0 & 0 & 0 & 1 & 0 & 0 & 0 \\
\hline $\begin{array}{l}\text { Submersion/Suffocation/Foreign } \\
\text { Bodies }\end{array}$ & E910-E915 & 0 & 1 & 0 & 0 & 0 & 2 & 0 \\
\hline Other Accidents & E916-E928 & 1 & 0 & 1 & 5 & 1 & 27 & 5 \\
\hline
\end{tabular}

\begin{tabular}{|l|l|r|}
\hline \multicolumn{2}{|l|}{} & Men \\
& \\
\multicolumn{2}{|l|}{} & TOTAL \\
\hline Type of Accident & E CODES & \\
\hline Accidental Poisoning - Non-medicinal & E860-E869 & 5 \\
\hline Falls & E880-E888 & 5 \\
\hline Natural/Environmental Factors & E900-E909 & 1 \\
\hline $\begin{array}{l}\text { Submersion/Suffocation/Foreign } \\
\text { Bodies }\end{array}$ & E910-E915 & 3 \\
\hline Other Accidents & E916-E928 & 40 \\
\hline
\end{tabular}

*Only those accident types and gender/job category combinations with at least one occurrence appear in this table. 


\section{Y-12 National Security Complex 2007}

OSHA Data

Appendix V. Number of Workdays Lost or with Restricted Activity in Each Accident Category by Gender and Job Category*

\begin{tabular}{|c|c|c|c|c|c|c|c|c|c|}
\hline & & \multicolumn{8}{|c|}{ Women } \\
\hline & & \multicolumn{8}{|c|}{ Job Category } \\
\hline & & \multicolumn{2}{|c|}{ Professional } & \multicolumn{2}{|c|}{$\begin{array}{l}\text { Administrative } \\
\text { Support }\end{array}$} & \multicolumn{2}{|c|}{ Service } & \multicolumn{2}{|c|}{ Line Operators } \\
\hline & & $\begin{array}{c}\text { Days } \\
\text { Restricted }\end{array}$ & $\begin{array}{l}\text { Days } \\
\text { Lost }\end{array}$ & $\begin{array}{c}\text { Days } \\
\text { Restricted }\end{array}$ & $\begin{array}{l}\text { Days } \\
\text { Lost }\end{array}$ & $\begin{array}{c}\text { Days } \\
\text { Restricted }\end{array}$ & $\begin{array}{l}\text { Days } \\
\text { Lost }\end{array}$ & $\begin{array}{c}\text { Days } \\
\text { Restricted }\end{array}$ & $\begin{array}{l}\text { Days } \\
\text { Lost }\end{array}$ \\
\hline Type of Accident & E Codes & \multirow[b]{2}{*}{0} & \multirow[b]{2}{*}{0} & \multirow[b]{2}{*}{0} & \multirow[b]{2}{*}{0} & \multirow[b]{2}{*}{0} & \multirow[b]{2}{*}{0} & \multirow[b]{2}{*}{0} & \multirow[b]{2}{*}{0} \\
\hline Accidental Poisoning - Non-medicinal & E860-E869 & & & & & & & & \\
\hline Falls & E880-E888 & 0 & 0 & 0 & 0 & 0 & 0 & 0 & 0 \\
\hline Other Accidents & E916-E928 & 36 & 0 & 53 & 46 & 57 & 0 & 100 & 67 \\
\hline
\end{tabular}

\begin{tabular}{|c|c|c|c|c|c|c|c|c|c|}
\hline & & \multicolumn{8}{|c|}{ Men } \\
\hline & & \multicolumn{8}{|c|}{ Job Category } \\
\hline & & \multicolumn{2}{|c|}{ Professional } & \multicolumn{2}{|c|}{$\begin{array}{c}\text { Administrative } \\
\text { Support }\end{array}$} & \multicolumn{2}{|c|}{$\begin{array}{l}\text { Technical } \\
\text { Support }\end{array}$} & \multicolumn{2}{|c|}{ Service } \\
\hline & & $\begin{array}{c}\text { Days } \\
\text { Restricted }\end{array}$ & $\begin{array}{l}\text { Days } \\
\text { Lost }\end{array}$ & $\begin{array}{c}\text { Days } \\
\text { Restricted }\end{array}$ & $\begin{array}{l}\text { Days } \\
\text { Lost }\end{array}$ & $\begin{array}{c}\text { Days } \\
\text { Restricted }\end{array}$ & $\begin{array}{l}\text { Days } \\
\text { Lost }\end{array}$ & $\begin{array}{c}\text { Days } \\
\text { Restricted }\end{array}$ & $\begin{array}{l}\text { Days } \\
\text { Lost }\end{array}$ \\
\hline Type of Accident & E Codes & \multirow[b]{2}{*}{0} & \multirow[b]{2}{*}{0} & \multirow[b]{2}{*}{0} & \multirow[b]{2}{*}{0} & \multirow[b]{2}{*}{0} & \multirow[b]{2}{*}{0} & \multirow[b]{2}{*}{0} & \multirow[b]{2}{*}{0} \\
\hline Accidental Poisoning - Non-medicinal & E860-E869 & & & & & & & & \\
\hline Falls & E880-E888 & 6 & 0 & 0 & 0 & 0 & 0 & 0 & 0 \\
\hline Natural/Environmental Factors & E900-E909 & 0 & 0 & 0 & 0 & 0 & 0 & 0 & 0 \\
\hline $\begin{array}{l}\text { Submersion/Suffocation/Foreign } \\
\text { Bodies }\end{array}$ & E910-E915 & 0 & 0 & 0 & 0 & 0 & 0 & 0 & 0 \\
\hline Other Accidents & E916-E928 & 0 & 25 & 0 & 0 & 0 & 55 & 43 & 5 \\
\hline
\end{tabular}

\begin{tabular}{|c|c|c|c|c|c|c|c|}
\hline & \multicolumn{6}{|c|}{ Men } \\
\hline & & \multicolumn{6}{|c|}{ Job Category } \\
\hline & & \multicolumn{2}{|c|}{ Security and Fire } & \multicolumn{2}{|c|}{ Crafts } & \multicolumn{2}{|c|}{ Line Operators } \\
\hline & & $\begin{array}{c}\text { Days } \\
\text { Restricted }\end{array}$ & $\begin{array}{l}\text { Days } \\
\text { Lost }\end{array}$ & $\begin{array}{c}\text { Days } \\
\text { Restricted }\end{array}$ & $\begin{array}{l}\text { Days } \\
\text { Lost }\end{array}$ & \begin{tabular}{|c|} 
Days \\
Restricted
\end{tabular} & $\begin{array}{l}\text { Days } \\
\text { Lost }\end{array}$ \\
\hline Type of Accident & E Codes & \multirow[b]{2}{*}{0} & \multirow[b]{2}{*}{0} & \multirow[b]{2}{*}{17} & \multirow[b]{2}{*}{60} & \multirow[b]{2}{*}{0} & \multirow[b]{2}{*}{0} \\
\hline Accidental Poisoning - Non-medicinal & E860-E869 & & & & & & \\
\hline Falls & E880-E888 & 0 & 0 & 0 & 0 & 0 & 0 \\
\hline Natural/Environmental Factors & E900-E909 & 0 & 0 & 0 & 0 & 0 & 0 \\
\hline $\begin{array}{l}\text { Submersion/Suffocation/Foreign } \\
\text { Bodies }\end{array}$ & E910-E915 & 0 & 0 & 0 & 0 & 0 & 0 \\
\hline Other Accidents & E916-E928 & 0 & 0 & 420 & 548 & 0 & 13 \\
\hline
\end{tabular}

*OSHA events with >1 E code in the same accident type were counted only once. Only those accident types and gender/job category combinations with at least one occurrence appear in this table. 
Y-12 National Security Complex 2007

OSHA Data

Appendix W. Age-Adjusted OSHA Illness and Injury Rates by Diagnostic Category*

Part 1. Men

\begin{tabular}{|c|c|c|c|c|c|}
\hline & & $\begin{array}{l}\text { Number of } \\
\text { Diagnoses }\end{array}$ & $\begin{array}{c}\text { Age-Adjusted } \\
\text { Rate per } 1,000 * *\end{array}$ & $\begin{array}{c}\text { Lower } 95 \% \\
\text { Confidence } \\
\text { Limit per } 1,000\end{array}$ & $\begin{array}{c}\text { Upper } 95 \% \\
\text { Confidence } \\
\text { Limit per 1,000 }\end{array}$ \\
\hline Diagnostic Category & ICD-9-CM Code & \multirow[b]{2}{*}{14} & \multirow[b]{2}{*}{3.6} & \multirow[b]{2}{*}{1.7} & \multirow[b]{2}{*}{7.2} \\
\hline NERVOUS SYSTEM (NS) \& SENSE ORGANS & 320-389 & & & & \\
\hline -Disorders of Peripheral NS & $350-359$ & 3 & 0.6 & 0.2 & 1.9 \\
\hline -Disorders of Eye & $360-379$ & 3 & 1.6 & 0.4 & 6.3 \\
\hline -Dis of Ear \& Mastoid & 380-389 & 8 & 1.3 & 0.6 & 2.8 \\
\hline RESPIRATORY SYSTEM & $460-519$ & 10 & 1.1 & 0.6 & 2.0 \\
\hline -Acute Respiratory Infections & $460-466$ & 2 & 0.2 & 0.1 & 0.9 \\
\hline -Other Dis Upper Respiratory Tract & $470-478$ & 5 & 0.5 & 0.2 & 1.3 \\
\hline -Chronic Obstructive Dis & $490-496$ & 1 & 0.1 & 0.0 & 0.8 \\
\hline -Lung Dis from External Agents & $500-508$ & 1 & 0.1 & 0.0 & 0.8 \\
\hline -Other Respiratory Dis & $510-519$ & 1 & 0.1 & 0.0 & 0.8 \\
\hline SKIN \& SUBCUTANEOUS TISSUE & 680-709 & 1 & 0.1 & 0.0 & 0.8 \\
\hline -Other Inflammatory Conditions & $690-698$ & 1 & 0.1 & 0.0 & 0.8 \\
\hline $\begin{array}{l}\text { MUSCULOSKELETAL \& CONNECTIVE } \\
\text { TISSUE }\end{array}$ & 710-739 & 29 & 7.0 & 4.5 & 10.9 \\
\hline -Arthropathies & $710-719$ & 18 & 4.6 & 2.6 & 8.2 \\
\hline -Dorsopathies & $720-724$ & 5 & 0.8 & 0.3 & 2.0 \\
\hline -Rheumatism, Excluding Back & $725-729$ & 6 & 1.6 & 0.7 & 4.0 \\
\hline $\begin{array}{l}\text { SYMPTOMS, SIGNS, \& ILL-DEFINED } \\
\text { CONDITIONS }\end{array}$ & $780-799$ & 15 & 2.3 & 1.3 & 4.0 \\
\hline -Symptoms & 780-789 & 15 & 2.3 & 1.3 & 4.0 \\
\hline INJURY \& POISONING & $800-999$ & 44 & 11.0 & 7.3 & 16.5 \\
\hline -Fracture - Upper Limb & 810-819 & 1 & 0.2 & 0.0 & 1.5 \\
\hline -Sprains \& Strains - Back & 846-847 & 6 & 1.3 & 0.6 & 3.0 \\
\hline -Sprains \& Strains - Other & $840-845,848$ & 10 & 1.4 & 0.7 & 2.7 \\
\hline -Open Wound - Head, Neck, Trunk & $870-879$ & 3 & 1.8 & 0.5 & 6.3 \\
\hline -Open Wound - Upper Limb & 880-887 & 3 & 1.8 & 0.5 & 6.3 \\
\hline -Open Wound - Lower Limb & $890-897$ & 1 & 0.3 & 0.0 & $\overline{1.8}$ \\
\hline -Superficial Injury & 910-919 & 1 & 0.5 & 0.1 & 3.9 \\
\hline -Contusion & $920-924$ & 8 & 1.2 & 0.6 & 2.6 \\
\hline -Foreign Body Entering Orifice & 930-939 & 3 & 1.6 & 0.4 & 6.3 \\
\hline -Burns & $940-949$ & 1 & 0.1 & 0.0 & 0.8 \\
\hline -Toxic Effects - Non-medicinal & $980-989$ & 4 & 0.4 & 0.2 & 1.1 \\
\hline -Complications of Surgical/Medical Care & 996-999 & 3 & 0.3 & 0.1 & 1.0 \\
\hline Total & & 113 & 25.1 & 19.6 & 32.1 \\
\hline
\end{tabular}

* Only those diagnostic categories with at least one occurrence appear in this table.

**Standardized to age distribution of 2000 U.S. population. 
Y-12 National Security Complex 2007

OSHA Data

Appendix W. Age-Adjusted OSHA Illness and Injury Rates by Diagnostic Category*

Part 2. Women

\begin{tabular}{|c|c|c|c|c|c|}
\hline & & $\begin{array}{l}\text { Number of } \\
\text { Diagnoses }\end{array}$ & $\begin{array}{c}\text { Age-Adjusted } \\
\text { Rate per } 1,000 * *\end{array}$ & $\begin{array}{c}\text { Lower } 95 \% \\
\text { Confidence } \\
\text { Limit per } 1,000\end{array}$ & $\begin{array}{c}\text { Upper } 95 \% \\
\text { Confidence } \\
\text { Limit per 1,000 }\end{array}$ \\
\hline Diagnostic Category & ICD-9-CM Code & \multirow[b]{2}{*}{5} & \multirow[b]{2}{*}{2.2} & \multirow[b]{2}{*}{0.9} & \multirow[b]{2}{*}{5.4} \\
\hline NERVOUS SYSTEM (NS) \& SENSE ORGANS & 320-389 & & & & \\
\hline -Disorders of Peripheral NS & $350-359$ & 5 & 2.2 & 0.9 & 5.4 \\
\hline RESPIRATORY SYSTEM & $460-519$ & 1 & 0.5 & 0.1 & 3.7 \\
\hline -Other Dis Upper Respiratory Tract & $470-478$ & 1 & 0.5 & 0.1 & 3.7 \\
\hline $\begin{array}{l}\text { MUSCULOSKELETAL \& CONNECTIVE } \\
\text { TISSUE }\end{array}$ & $710-739$ & 25 & 18.0 & 11.5 & 28.2 \\
\hline -Arthropathies & $710-719$ & 14 & 9.0 & 4.9 & 16.5 \\
\hline -Rheumatism, Excluding Back & 725-729 & 11 & 9.0 & 4.6 & 17.5 \\
\hline $\begin{array}{l}\text { SYMPTOMS, SIGNS, \& ILL-DEFINED } \\
\text { CONDITIONS }\end{array}$ & $780-799$ & 11 & 6.3 & 3.3 & 12.0 \\
\hline -Symptoms & 780-789 & 11 & 6.3 & 3.3 & 12.0 \\
\hline INJURY \& POISONING & 800-999 & 15 & 6.7 & 4.0 & 11.2 \\
\hline -Fracture - Upper Limb & 810-819 & 1 & 0.3 & 0.0 & 2.3 \\
\hline -Sprains \& Strains - Back & 846-847 & 1 & 0.5 & 0.1 & 3.7 \\
\hline -Sprains \& Strains - Other & $840-845,848$ & 3 & 1.4 & 0.4 & 4.4 \\
\hline -Open Wound - Head, Neck, Trunk & $870-879$ & 1 & 0.5 & 0.1 & 3.7 \\
\hline -Contusion & $920-924$ & 5 & 2.4 & 1.0 & 5.9 \\
\hline -Toxic Effects - Non-medicinal & 980-989 & 1 & 0.5 & 0.1 & 3.7 \\
\hline -Complications of Surgical/Medical Care & 996-999 & 3 & 1.0 & 0.3 & 3.1 \\
\hline Total & & 57 & 33.7 & 25.1 & 45.3 \\
\hline
\end{tabular}

* Only those diagnostic categories with at least one occurrence appear in this table.

**Standardized to age distribution of 2000 U.S. population. 
Y-12 National Security Complex 2007

OSHA Data

Appendix W. Age-Adjusted OSHA Illness and Injury Rates by Diagnostic Category*

Part 3. Men and Women

\begin{tabular}{|c|c|c|c|c|c|}
\hline & & $\begin{array}{l}\text { Number of } \\
\text { Diagnoses }\end{array}$ & $\begin{array}{c}\text { Age-Adjusted } \\
\text { Rate per 1,000** }\end{array}$ & \begin{tabular}{|c|} 
Lower $95 \%$ \\
Confidence \\
Limit per 1,000
\end{tabular} & $\begin{array}{c}\text { Upper } 95 \% \\
\text { Confidence } \\
\text { Limit per } \mathbf{1 , 0 0 0}\end{array}$ \\
\hline Diagnostic Category & ICD-9-CM Code & \multirow[b]{2}{*}{19} & \multirow[b]{2}{*}{3.4} & \multirow[b]{2}{*}{1.9} & \multirow[b]{2}{*}{6.0} \\
\hline NERVOUS SYSTEM (NS) \& SENSE ORGANS & $320-389$ & & & & \\
\hline -Disorders of Peripheral NS & $350-359$ & 8 & 1.1 & 0.5 & 2.3 \\
\hline -Disorders of Eye & $360-379$ & 3 & 1.2 & 0.3 & 4.6 \\
\hline -Dis of Ear \& Mastoid & $380-389$ & 8 & 1.1 & 0.5 & 2.2 \\
\hline RESPIRATORY SYSTEM & $460-519$ & 11 & 1.0 & 0.5 & 1.8 \\
\hline -Acute Respiratory Infections & $460-466$ & 2 & 0.2 & 0.0 & 0.7 \\
\hline -Other Dis Upper Respiratory Tract & $470-478$ & 6 & 0.6 & 0.2 & 1.4 \\
\hline -Chronic Obstructive Dis & $490-496$ & 1 & 0.1 & 0.0 & 0.6 \\
\hline -Lung Dis from External Agents & $500-508$ & 1 & 0.1 & 0.0 & 0.6 \\
\hline -Other Respiratory Dis & $510-519$ & 1 & 0.1 & 0.0 & 0.6 \\
\hline SKIN \& SUBCUTANEOUS TISSUE & 680-709 & 1 & 0.1 & 0.0 & 0.6 \\
\hline -Other Inflammatory Conditions & $690-698$ & 1 & 0.1 & 0.0 & 0.6 \\
\hline $\begin{array}{l}\text { MUSCULOSKELETAL \& CONNECTIVE } \\
\text { TISSUE }\end{array}$ & $710-739$ & 54 & 9.5 & 7.0 & 13.0 \\
\hline -Arthropathies & $710-719$ & 32 & 5.5 & 3.7 & 8.4 \\
\hline -Dorsopathies & $720-724$ & 5 & 0.6 & 0.2 & 1.6 \\
\hline -Rheumatism, Excluding Back & 725-729 & 17 & 3.4 & 2.0 & 5.8 \\
\hline $\begin{array}{l}\text { SYMPTOMS, SIGNS, \& ILL-DEFINED } \\
\text { CONDITIONS }\end{array}$ & $780-799$ & 26 & 3.3 & 2.2 & 5.0 \\
\hline -Symptoms & 780-789 & 26 & 3.3 & 2.2 & 5.0 \\
\hline INJURY \& POISONING & $800-999$ & 59 & 10.1 & 7.2 & 14.2 \\
\hline -Fracture - Upper Limb & $810-819$ & 2 & 0.3 & 0.1 & 1.2 \\
\hline -Sprains \& Strains - Back & 846-847 & 7 & 1.1 & 0.5 & 2.4 \\
\hline -Sprains \& Strains - Other & $840-845,848$ & 13 & 1.4 & 0.8 & 2.5 \\
\hline -Open Wound - Head, Neck, Trunk & 870-879 & 4 & 1.5 & 0.5 & 4.6 \\
\hline -Open Wound - Upper Limb & 880-887 & 3 & 1.3 & 0.4 & 4.6 \\
\hline -Open Wound - Lower Limb & $890-897$ & 1 & 0.2 & 0.0 & 1.2 \\
\hline -Superficial Injury & $910-919$ & 1 & 0.4 & 0.1 & 2.8 \\
\hline -Contusion & $920-924$ & 13 & 1.7 & 1.0 & 3.1 \\
\hline -Foreign Body Entering Orifice & 930-939 & 3 & 1.2 & 0.3 & 4.6 \\
\hline -Burns & $940-949$ & 1 & 0.1 & 0.0 & 0.6 \\
\hline -Toxic Effects - Non-medicinal & $980-989$ & 5 & 0.5 & 0.2 & 1.3 \\
\hline -Complications of Surgical/Medical Care & 996-999 & 6 & 0.5 & 0.2 & 1.1 \\
\hline Total & & 170 & 27.4 & 22.7 & 33.1 \\
\hline
\end{tabular}

* Only those diagnostic categories with at least one occurrence appear in this table.

**Standardized to age distribution of 2000 U.S. population. 